NBER WORKING PAPERS SERIES

TWENTY-TWO YEARS OF THE NBER-ASA QUARTERLY ECONOMIC OUTLOOK SURVEYS: ASPECTS AND COMPARISONS OF FORECASTING PERFORMANCE

Victor Zamowitz

Phillip Braun

Working Paper No. 3965

\author{
NATIONAL BUREAU OF ECONOMIC RESEARCH \\ 1050 Massachusetts Avenue \\ Cambridge, MA 02138 \\ January 1992
}

Prepared for the Conference on New Research on Business Cycles, Indicators and Forecasting. The authors thank Ray Fair, Chistopher Sims, Allen Sinai, James Stock, Mark Watson. and the participants in the discussion at the NBER meeting on May 4, 1991 for helpful comments: Christopher Culp for rescarch assistance: Cynthia Davis for typing; and the NBER for financial assistance. This paper is part of NBER's rescarch program in Economic Fluctuations. Any opinions expressed are those of the authors and not those of the National Bureau of Economic Research. 
NBER Working Paper $\$ 3965$

January 1992

\title{
TWENTY-TWO YEARS OF THE NBER-ASA QUARTERLY ECONOMIC OUTLOOK SURVEYS: ASPECTS AND COMPARISONS OF FORECASTING PERFORMANCE
}

\begin{abstract}
The National Bureau of Economic Research, in co-operation with the American Statistical Association, conducted a regular quarterly survey of professional macroeconomic forecasters for 22 years beginning in 1968. The survey produced a mass of information about characteristics and results of the forecasting process. Many studies have already used some of this material, but this is the first comprehensive examination of all of it.

This report addresses several subjects and produces findings on each, as follows:

(1) The distributions of error statistics across the forecasters: the dispersion among the individual predictions is often large and it typically increases with forecast horizon, as do the mean absolute (or squared) errors.
\end{abstract}

(2) The role of the time-scries properties of the target data: the more volatile the time scrics, the larger as a rule are the errors of the forecasts.

(3) The role of revisions in "actual" data: forecast errors tend to be larger the greater the extent of the revisions.

(4) Differences by subperiod: there is little evidence of an overall improvement or deterioration in forecasts between the 1970s and the 1980s.

(5) Combining the individual forecasts into group mean or "consensus" forecasts: this gencrally results in large gains in accuracy.

(6) Comparisons with a well-known macroeconometric model: the group forecasts are more accurate for most but not all variables and spans.

(7) Comparisons with state-of-the-art time series models: the group forecasts and at least half of the individual forecasts tend to outperform Bayesian vector autoregressive models in most (but not all) cases. The univariate ARIMA forecasts are generally the weakest.

Victor Zamowitz Graduate School of Business University of Chicago 1101 East 58th Street Chicago, IL 60637 and NBER
Phillip Braun Kellogg School of Management Northwestern University

Leverone Hall Evanston, IL 60208 
1. Introduction

Human action has always been to a large extent oriented to the future. Since ancient times, man hoped to outwit fate and survive by magic divination; he also hoped to outwit nature and others by shrewd calculation. Attempts to predict the future, therefore, are as old as nragic, but they are also as old as commerce, saving and investment. Their motivation must have always been largely economic, despite the inevitable frustrations of econonic forecasting.

Great foresight in business matters is presumably highly profitable and rare. Its possessor will do well to exploit it directly for personal enrichment, hence should not be inclined to offer its products to the public in the open market. An economist who perceives competitive markets as working with reasonable efficiency should not expect any forecasts of stock prices or interest rates to be both freely traded and consistently much better than average. Forecasting macroeconomic aggregates such as real GNP and its major expenditure components is likely to have less potential for direct profitability than forecasting financial variables. Hence, it is presumably less vulnerable to that old American adage rebuking expert advisers: "If you're so smart, why ain't you rich?" (cf. McCloskey 1988).

For reasons explained in part 2 below, macroforecast assessments, to be interesting and robust, should cover a broad range of forecasters, variables, and economic conditions. The forecasts must be explicit, verifiable, and sufficient to allow a responsible appraisal. 
Unfortunately, most of the available time series of forecasts are short and none are free of some gaps, discontinuities and inconsistencies. Relying on a small sample of specific forecasts from an individual source risks overexposure to isolated hits or misses due to chance. It is therefore necessary to concentrate on a set of forecasts from numerous and various sources. This is likely to improve the coverage by types of information and methods used as well.

The way to collect the required data is to conduct regularly, for a sufficiently long time and with appropriate frequency, a survey that would be reasonably representative of the professional activities of macroeconomic forecasters. A joint project of the National Bureau of Economic Research (NBER) and the Business and Economic Statistics Section of the American Statistical Association (ASA) had the purpose of accomplishing just that. The NBER-ASA survey assembled a large amount of information on the record of forecasting annual and quarterly changes in the U.S. economy during the period 1968:41990:1 (86 consecutive quarters). It reached a broadly based and diversified group of persons regularly engaged in the analysis of current and prospective business conditions. Most of the responding economists came from corporate business and finance, but academic institutions, government, consulting firms, trade associations, and labor unions were also represented. The forecasts covered a broad range of principal aggregative time series relating to income, production, consumption, investment, profits, government purchases, unemployment, the price level, and interest rates. The surveys also collected 
data on the methods and assumptions used by the participants and on the probabilities they attached to alternative prospects concerning changes in nominal or real GNP and the implicit price deflator.

The NBER-ASA data have their shortcomings, the main of these being probably the high turnover of participants and large frequency of gaps in their responses. The collected data represent a mixture of public and private predictions. The survey members, generally professional forecasters, were identified by code only. Their anonymity helped to raise the survey response rates but may have had otherwise ambiguous consequences (encouraging the independence of judgment? reducing the sense of individual responsibility?).

The initiative to develop and maintain the quarterly NBER-ASA survey was strongly motivated by the desire to make it "the vehicle for a scientific record of economic forecasts" (Moore 1969, p. 425). The expectation that such a survey would be of considerable service to both the profession and the public was shared by Moore with others who helped to implement his proposal (including one of the authors of this paper who had the responsibility for reporting on the NBER-ASA survey during the entire period of its existence). In retrospect, it seems fair to say that the assembled data do indeed provide us with rich and in part unique information, which can help support much needed research on the potential and limitations of forecasting economic change.

Twenty-two years of a survey that attracted numerous responses from a variety of sources each quarter add up to a mass of information about the processes and results of 
macroeconomic forecasting. Although many studies have already used some of this material, much of it was, and still is, to be explored. This report is the first to examine all the variables included in the NBER-ASA forecasts, for all horizons and over the entire period covered. It concentrates on the properties of the distributions of summary measures of error, by variable and span of forecast, viewed against the background of descriptive statistics for the predicted time series. Other subjects of interest include the role of characteristics and revisions of "actual" data in the evaluation of the forecasts; differences by subperiod, roughly the 1970 s vs. the 1980 s; the relationship between the individual and group mean or "consensus" forecasts from the surveys; the comparative accuracy of the survey results and predictions with a well-known macroeconometric model; and comparisons with forecasts from state-of-the-art multivariate and univariate time series models.

Part 2 of this paper examines some general problems and history of forecast evaluations and surveys. Part 3 presents the NBER-ASA data and the methods used. Parts 4 through 7 discuss the results of the analysis and form the core of the paper. Part 8 draws the conclusions.

2. The Diversity of Forecasts and Their Evaluation

\subsection{Some Reflections on Predictability and Uncertainty}

It is readily observed that, at any time, predictions of a given variable or event can and in general do differ significantly across forecasters. Indeed, modern macroeconomic 
forecasts display a great diversity, which must be taken into account in thinking about how to assemble and evaluate the related data.

Although changes in the economy are predicted primarily to meet the demand for forecasts by public and private decision makers, they are also predicted to test theories and analytical methods and to argue for or against points of policy. Some conditions and aspects of the economy are much more amenable to prediction than others. Furthermore, individual forecasters differ with respect to skills, training, experience, and the espoused theories and ideologies. They compete by trying to improve and differentiate their models, methods, and products. They respond to new developments in the economy and new ways to observe and analyze them. In sum, there are both general and specific reasons for the observed diversity of forecasts.

Comparisons among forecasts that are differentiated in several respects are difficult yet unavoidable. The quality of a forecast is inherently a relative concept. Common standards of predictive performance must therefore be applied to properly classified forecasts along each of the relevant dimension.

Surely, the main value of a forecast lies in its ability to reduce the uncertainty about the future faced by the user. In general, a forecast will perform better in this regard the smaller and closer to randomness its errors are. However, the value of a forecast depends not only on its accuracy and unbiasedness but also on the predictability of the variable or event concerned. Some events and configurations of values are common, others are rare. 
Where the probability of occurrence for the forecasting target is high, uncertainty is low and prediction is easy but not very informative; where that probability is low, uncertainty is high and prediction is difficult but potentially very valuable (cf. Theil 1967).

For example, total stocks of the nation's wealth and productive capital normally change little from one month or quarter to the next, barring a catastrophic war or a natural disaster, and so can be predicted with small relative errors. Much the same applies to other typically "slow" stock variables such as total inventories of goods or monetary aggregates and the overall price level (but not in periods of rapid inflation!). In contrast, income and expenditure aggregates represent "fast" flow variables, some of which, e.g., corporate profits, investment in plant and equipment, housing starts, and change in business inventories are highly volatile over the short horizons and apt to be very difficult to forecast accurately. Rates of change in indexes of price levels fall in the same category.

There are also situations that are unique or nearly so where no objective or subjective probabilities based on past history or experience are believed to apply and "true" (nonergodic) uncertainty rules (as in Knight 1921, p. 233). According to Keynes (1936, p. 149), "Our knowledge of the factors which will govern the yield of an investment some years hence is usually very slight and often negligibie," yet businessmen must make decisions to make or buy plant and equipment despite this recognized state of ignorance. In economics, as in history, statistical-stochastic methods have limited applicability (cf. Hicks 1979; Solow 1985). Forecasters cannot afford to be deterred by such considerations and assume some 
predictability throughout, never full uncertainty. Across many variables, uncertainty depends on the "state of nature" (more explicitly, on the state of the economy or the phase of the business cycle). Thus, it is much easier to predict continued moderate growth once it is clear that the economy entered a period of sustained expansion than it is to predict the occurrence and timing of a general downturn after the expansion has lasted for some time and may be slowing down.

Influential public macroforecasts could in principle be either self-invalidating or selfvalidating. Thus, if the government believed a forecast of a recession next year, it might succeed in stimulating the economy so as to make the expansion continue. On the other hand, if consumers generally came to expect a recession because of such a forecast, they may each try to protect themselves by spending less now and dissaving later when the bad times arrive. Businessmen, acting on similar expectations, may reduce investment expenditures and financing, production, and inventory costs. But such actions, although individually rational, would collectively help bring about the recession no one wants.

Indeed, an early theoretical monograph on forecasts of general business conditions concluded, on these grounds, that they cannot be accurate, particularly if they are made public (Morgenstern 1928). However, it is not necessarily true that a known forecast must be falsified by agents' reaction to it, even if that reaction does affect the course of events. Conceptually, the reaction can be known and taken into account for bounded variables related by continuous functions (Grunberg and Modigliani 1954).' But the public prediction 
can be correct only if the corresponding private prediction is correct, which of course is often not the case. Forecasting remains difficult whether or not its results are published. The premise of a generally shared belief and confidence in a commonly held forecast is so unrealistic as to deprive the theoretical exercises based on it of much practical interest.

\subsection{A Brief History of Forecast Appraisals and Surveys}

Qualitative judgments about contemporary levels of, and changes in, general business activity are among the oldest economic data. A compilation of such records provided partial evidence for the NBER work on identifying and dating the business cycles of history (Thorp 1926; Burns and Mitchell 1946). A look at these "business annals" that go back to the 1830 s reminds one of the importance of public perceptions and expectations concerning aspects of the general economic and financial activity: employment, production, prices, interest rates.

This expectational element in the dynamics of economic life has probably long attracted great attention of students of current events and men of affairs.

It has not much concerned those early theorists who have been preoccupied with problems of long-run static equilibrium. But some prominent economists in the classical tradition stressed the role in business cycles of variations in expectations and "confidence" (Marshall), or hypothesized the occurrence of sequences of overoptimism and overpessimism (Pigou), or attributed to bankers and entrepreneurs predictive errors resulting in malinvestments 
(Hayek). Keynes and some of his later followers elaborated on the destabilizing role of uncertainty. Along with the formal models of interacting economic processes came the theories of expectation formation, first that of adaptive and later that of rational expectations. In the last twenty years or so, incomplete information and expectational errors acquired prime importance in models of economists of various persuasions (monetarist, new-classical, new-Keynesian). The corresponding literature grew rapidly.

Lack of quantitative data has long hampered the progress of economics, causing empirical work and tests to lag well behind the formulation of theories and hypotheses. Numerical data on forecasts and expectations are particularly scarce, except for the very recent period of great expansion in economic and financial prediction and consulting activities. Hence, the literature on macroeconomic forecasting has a brief history, although it too grew rapidly of late. ${ }^{2}$

The first forecasting services in the United States to gain considerable success date back to the years immediately preceding World War I and the 1920s. They used lead-lag relationships to predict business cycle turning points, relying mainly on the tendency of stock prices to lead and short-term interest rates to lag business activity. The sequence, best-known as the Harvard "ABC" curves, had a basis in theory and fact but it was a crudely oversimplified predecessor of the indicator system subsequently developed at the NBER. It performed rather well in the period 1903-14 and in the depression of 1920-21, and it would have applied generally in recent times as well (cf. Moore 1969), but the 
Harvard service failed to foresee the onset and extent of the Great Depression, which doomed this and the related forecasting efforts. A 1988 post-mortem study, using the Harvard data and modern vector autoregressive (VAR) model techniques, concludes that the large declines in output that followed the 1929 stock market crash were not forecastable (Dominguez, Fair, and Shapiro 1988). ${ }^{3}$ This, however, is disputed by a very recent paper that applies the Neftci sequential-analysis method to the Harvard index (Niemira and Klein 1991).

Monthly forecasts from six sources, 1918-28, were scored for accuracy in Cox 1929, to our knowledge the first methodical appraisal of ex ante predictions of U.S. business activity. Cox found evidence of a moderate forecasting success despite the poor showing at the $1923-24$ recession.

The earliest compilation of quantitative macro-forecasts, so far as we can tell, was the informal survey conducted since 1947 by Joseph Livingston, the late syndicated financial columnist based in Philadelphia. Twice a year he collected predictions of such variables as industrial production and the consumer price index and summarized the results in a business outlook column published in June and December. The forecasters were mostly business and financial economists but also some academics. The Livingston data represent a unique source of valuable information on forecasts for the early post-World War II period, and in the 1970 s they began to be widely used in research, primarily on price expectations. But Livingston adjusted his published "consensus forecasts" (means of the 
collected individual predictions) in an attempt to take into account any large revisions in the actual data that may have occurred between the mailing of his questionnaire and the submission of his column to the press. Carlson 1977 recalculated the semiannual Livingston forecasts of CPI and WPI inflation rates for $1947-75$ from the original data so as to reflect properly the timing of the predictions and the information incorporated in them.

As quantitative macroeconomic data and forecasts began to accumulate in the $1950 \mathrm{~s}$ and 1960 s, valid examinations of the accuracy and properties of the latter became increasingly possible (Okun 1959; Theil 1961, 1966; Suits 1962, Stekler 1968). A comprehensive NBER study initiated in 1963 resulted in a systematic collection and appraisal of annual and quarterly, public and private, judgmental and econometric forecasts of important economic aggregates and indexes as well as such events as business cycle peaks and troughs (Zarnowitz 1967, 1972; Fels and Hinshaw 1968; Mincer 1969; Moore 1969; Cole 1969; Evans, Haitovsky, and Treyz 1972; Haitovsky, Treyz, and Su 1974).

In 1968, a regular quarterly survey of general economic forecasts was established at the initiative of Geoffrey Moore, then president of ASA, to be conducted co-operatively by the NBER and the Business and Economic Statistics Section of the ASA. ${ }^{5}$ This was the first major organized effort to build up reliable information about the potential and limitations of short-term aggregative economic forecasts, which would provide a broad base for research and improvements in this field. The ASA has "agreed to carry out the surveys for a period long enough to assure accumulation of useful experience and evidence," while 
the National Bureau "has assumed responsibility for the tabulation of forecasts, computation of error statistics and other measures, and research in evaluating the results and their analytical implications" (Zarnowitz 1968, pp. 1-2). The co-operation was to last 22 years. One measure of its success is that in 1990 the Federal Reserve Bank of Philadelphia undertook to continue the survey essentially in the same way as it was conducted by the NBER and the ASA.

\section{The NBER-ASA Survey: Characteristics, Measures, and Data}

\subsection{Coverage}

Table 1 identifies each of the variables covered by title, source, symbol, the Commerce series number, and the form in which we use the data. In the period 1968:41981:2 (column 5), direct forecasts were made for seven nominal indicators and three real indicators; also, predictions for GNP in constant dollars were derived from those for GNP in current dollars and the implicit price deflator. In the period 1981:3-1990:1 (column 6), direct forecasts were made for six nominal and eleven real variables. Seven major expenditure components of real GNP, the consumer price index, Treasury bill rate, and corporate bond yield were added to the list; four nominal series (expenditures for consumer durables, plant and equipment, and national defense, and change in business inventories) were dropped. 
The change in 1981 resulted from new initiatives taken by the NBER in the preceding year. A special questionnaire mailed to a long list of professional forecasters (both the past and present survey participants and others) collected much useful information about the reactions to the design and uses of the NBER-ASA survey, the improvements suggested, and the assumptions and procedures favored. There was strong sentiment for expanding the survey by including several additional variables. The problem was how to comply with these wishes without either losing the essential continuity or overloading the survey and risking discouragement of future participations. An advisory committee helped make the desirable changes. ${ }^{6}$

A large number of individuals participated in the earliest surveys but many were not prepared to fill out a detailed questionnaire each quarter and soon dropped out. Of the more than 150 persons who responded to the survey at one time or another, many had sporadic records and some submitted incomplete questionnaires. To exclude such occasional forecasters, we decided to use only

the responses of those who answered at least 10 surveys, providing information for most variables and horizons. Note that the surveys need not be consecutive; had we required long records of uninterrupted participation, few respondents would have qualified.

Table 2 shows how this selection was accomplished and with what results. Using the forecasts of spending on consumer durables for 1968-81, the number of respondents fell from a total of 156 to 86 in the sample, but the average number of surveys covered per 
respondent was greatly increased (e.g., doubled from 11 to 22 according to the medians). The average number of respondents per survey was reduced but slightly, remaining above 40. The variability of coverage over time was lowered considerably throughout (cf. columns 1 and 2).

The participation rates in the surveys were much smaller in 1981-90 than in 1968-81. In terms of the forecasts of real nonresidential investment, the number of respondents fell from a total of 74 to 29 in the sample. Again, however, the selection process achieved relatively good results. The retained forecasters averaged about 20 surveys, more than double the number for all survey participants. The median number of surveys covered per respondent declined just from 21 to 18 . Here too the relevant dispersion measures were all substantially reduced (cf. columns 3 and 4 ).

Finally, the sample for the total period 1968-90, based on forecasts of the unemployment rate, consists of 111 out of a total of 159 persons. The coverage of surveys per respondent ranges from 10 to 70 , with a mean of about 28 ; the corresponding figures for respondents per survey are $12-67$ and 37 . Here the dispersion statistics show relatively small declines in the transition from "all" to "sample" (cf. columns 5 and 6). All in all, the turnover among the survey participants was considerable, which should be remembered when looking at the results of our study. 


\subsection{Forecasters' Affiliations and Methods}

In 1968-80 the questionnaire asked the participating forecasters about their primary affiliation but later the question was dropped. As illustrated in table 3, academic economists represented on average about 7 percent and government economists about 8 percent of the membership (lines 5 and 6). All other respondents, except for a few from labor unions and trade associations, came from the business world. Manufacturing accounted most of the time for at least one third and up to $40 \%$ of the participants; commercial banking and other financial institutions for one fifth or more; consulting and research firms also for $20 \%$ or more in $1975-80$, less in earlier years (lines 1-4).

These distributions resemble those for the universe of business forecasters as represented by the respondents to the annual economic outiook surveys of the National Association of Business Economists in 1975-89. Here from one third to more than $40 \%$ of respondents were in the industrial economy (manufacturing, energy, utilities), $25-30 \%$ in finance, $12 \%$ or more in consulting and research, $4 \%$ in other private services, and $6-12 \%$ in government and academia. The assessments of some of the NABE surveys looked for but found no systematic differences in forecasting performance between these industry groups.

Another question asked regularly through 1981 concerned the relative importance the survey participants assigned to each of several items on a short list of forecasting methods or tools. Business economists use a variety of procedures to predict the major 
expenditure components of GNP, combine these predictions in nominal and real terms, and check and adjust the resulting forecasts for consistency with logic, theory, and the currently available information. This "informal GNP model" is an eclectic and flexible approach with large elements of judgment (Butler and Kavesh 1974). Over 70\% of the NBER-ASA survey respondents reported using it and over $50 \%$ on average ranked it first (table 4 , column 1). About one-fifth of the group favored econometric models, whether own or outside, and one-fourth had their own econometric models (not necessarily comprehensive and first-ranked). Users of outside models accounted for more than $40 \%$ of the early members and more than half of those in the late 1970s and early 1980s (columns 2 and 3).

Leading indicators were employed by about $70 \%$ of the survey membership in 196870 but later that share declined closer to $50 \%$. They were ranked second by most respondents. Similar majorities referred to anticipations surveys, which generally were given lower ranks. Other methods, such as time-series models, were specified by fewer than $20 \%$ of the participants and preferred by about half of them (columns 4-6).

These findings leave no doubt about one point, namely that the listed methods were predominantly used in various combinations. Very few individuals preferred any one of them so as to exclude the others. Presumably there is a good reason for this in that the different methods tend to complement each other. For example, new reading on monthly cyclical indicators and the latest results from an investment or consumer anticipations survey may be used to modify forecasts from econometric models or the informal approach. 
There seems to be little or no systematic relation between the forecasters' rankings of the methods and the accuracy of their predictions, allowing for the difference between the targeted variables, spans, etc. This is suggested by cross-sectional (survey by survey) regressions of individual forecast errors on dummy variables representing the first-ranked methods as well as by comparisons of properly standardized average errors over time (Zarnowitz 1971; Su and Su 1975). The lower panel in table 4 (lines 5-8) presents average root mean square errors (RMSEs) for groups classified by their self-declared methodological preferences. These measures are based on a large number of individual forecasts of rates of change in nominal and real GNP, IPD inflation, and the levels of the unemployment rate; they omit occasional forecasters and aggregate across predictions for the current quarter and three quarters ahead. The differences between the RMSEs are generally small and of uncertain significance.

\subsection{Basic Measures of Error in Forecasts of Changes and Levels}

For series with upward trènds, e.g., GNP in current and constant dollars and the implicit price deflator, the most relevant forecasts are those of percentage change. Let the current survey quarter and the four quarters that follow be denoted by $t=1, \ldots, 5$, respectively. The most recent quarter for which data are available precedes the date of the survey $(t=0)$. Then the predicted average changes refer to $0-1,0-2, \ldots 0-5$, and the implied marginal (or intraforecast) changes refer to $0-1,1-2, \ldots 4-5$. 
For approximately stationary series such as the unemployment rate, real inventory investment, and real net exports, the most relevant forecasts are those of levels in the original units. They refer to quarters $1, \ldots, 5$.

Our data consist of more than 17,000 individual time series of forecasts defined by source, variable, and horizon. For example, for 1968-90, there are 111 respondents in our sample, reporting on seven variables over five spans each, which yields 3,885 series $(=111$ $\times 7 \times 5$; but consideration of four marginal changes for five of these variables adds another subset of 2,220 series). The tables below record the distributions of the summary measures of error across these individual series for each variable, period, and horizon covered. We distinguish three measures - the mean error (ME), the mean absolute error (MAE), and the root mean square error (RMSE)-- and compute for each several location and dispersion statistics. These include means, standard deviations, medians, interquartile ranges, skewness, and kurtosis (denoted by $M, S D, M D, I Q R, S K$, and $K U$, respectively). Not all the detail of this compilation can be presented here, of course, but it is available for purposes of verification and further research.

\subsection{Data Revisions and Forecast Accuracy}

Some of the variables covered by the surveys, such as the consumer price index and the interest rates, are subject to few or no revisions. Others, notably the aggregates and indexes taken from the national income and product (NIPA) accounts, are revised 
frequently and some of the revisions are large. An old but still controversial issue is which revision or vintage of such data should be used in evaluating the accuracy of forecasts. The preliminary figures are most closely related to the latest figures that were available to the forecasters, but they may theniselves be partly predictions or "guesstiniates" and may seriously deviate from "the truth" as represented by the last revision of the data. On the other hand, the final data may be issued years after the forecast was made and may incorporate major benchmark revisions. That the forecasters should be responsible for predicting all measurement errors to be corrected by such revisions, is surely questionable.

Appraisals of forecasts differ: some are based on early data (e.g., Zarnowitz 1967), others on late data, generally pre-benchmark revisions (e.g., McNees 1979; Zarnowitz 1985). Judgmental forecasts that rely heavily on recent preliminary figures may look best when compared with early data; econometric model forecasts that incorporate long series of revised data may be more favored by evaluations using later vintages.

Table 5 shows, for the NBER-ASA percentage change forecasts of GNP, RGNP, and IPD, the MAEs and RMSEs obtained by comparisons with 15-day, 45-day, early July, and late July data. In general, the errors tend to increase monotonically the more revised the data are, but there are exceptions. However, the differences between the successive error measures in each segment and column of the table are relatively small, typically less than $1 / 10$ of one percent. This is fortunate because it suggests that the choice of which vintage of the data to use may not be so critical. But larger differences may occur in particular 
subperiods and offset each other over the total period covered. Our results certainly do not detract from the importance of measurement errors in the forecasting context, which has been demonstrated to be large (Cole 1969).

To save space and avoid relying on the extremes of either very preliminary or repeatedly revised data, we shall henceforth use the 45-day estimate in most of our text references and all of our tabular presentation. But no single data vintage is an optimal standard here; the choice of any is inevitably more or less arbitrary and too restrictive.

4. Forecasts of Nominal and Real GNP Growth and Inflation

\subsection{Graphical Comparisons of Predictions}

A convenient way to relate visually the distributions of survey forecasts and the actual data is to plot the former in form of box diagrams and the latter as a continuous series, quarter by quarter, to common scales. Charts 1-3 apply this device to predictions of nominal and real GNP growth and IPD inflation rates. There is one graph for each variable and horizon. The midpoint of each box marks the location of the group's mean forecast, the top and bottom mark the mean \pm one standard deviation. A longer vertical line bisects each box and connects the highest and the lowest forecasts recorded on the same occasion. A heavy curve superimposed upon the array of the boxes and vertical lines represents the actual outcomes (45-day estimates). 
The graphs make it clear that the curves cross most of the boxes. This means that the realizations fall within 1 SD of the mean or "consensus" predictions most of the time. However, some large declines in actual values are widely missed or underestimated, which shows up as boxes lying conspicuously above the troughs or valleys in the curves. Similarly, widespread underpredictions of some large actual rises show up as boxes situated below the local peaks for concentrations of high values. Occasionally, the actual would even be missed by all respondents to the survey, as seen in instances where the entire vertical line of forecasts lies above or below the curve.

These errors are clearly associated with business cycles. Chart 1 shows clusters of large overestimates of real GNP growth in all major slowdowns and recessions covered: 1969-70, 1973-74, 1981-82, and 1985-86. It also shows clusters of large underestimation errors in all recoveries and booms: 1972, 1975, late 1980, 1983-84, and 1987. So overprediction of growth occurs mainly when the economy weakens and declines, underprediction when it strongly rises. Both types of error can be seen as particularly pronounced and persistent in forecasts with longer spans. Overall, the errors of overprediction in bad times tended to be larger than those of underprediction in good times.

Chart 2 shows that inflation was at times widely underpredicted in 1969-71, even though it was then fairly stable. In 1973-74, a period of supply shocks and deepening recession, inflation rose sharply and was greatly underestimated by most survey participants. 
Here the curves can be seen to rise above most of the boxes and even to peak above the highest forecasts for the longer horizons. The same tendency to underpredict also prevailed in 1976-80, though in somewhat weaker form. In this period inflation rose more gradually, while the economy first expanded vigorously and then, in 1979-80 experienced another oil shock, a slowdown, and a short recession. In between, during the recovery of 1975-76, inflation decreased markedly and was mostly overestimated. Another, much longer disinflation occurred in $1981-85$, a phase which followed the shifts to a tight monetary policy in late 1979 and included the severe 1981-82 recession and then a strong recovery. Here again most forecasters are observed to overpredict inflation. Finally, in 1986-89 inflation, which began to drift upward, was generally well predicted most of the time (except in the mid-quarter of 1987 when it dipped suddenly and was overestimated).

In sum, there is also a cyclical pattern to the errors of inflation forecasts. Accelerated inflation was associated predominantly with under-prediction, disinflation will overprediction errors.

Chart 3, which compares the forecast distributions and actual values for nominal GNP growth rates, shows a broad family resemblance to the corresponding graphs for real GNP growth in Chart 1. For example, both nominal and real growth tended to be underpredicted in such boom years as 1972 and 1983 and overpredicted in such recession years as 1974 and 1981-82. But inflation expectations and their relation to real growth forecasts are also important here. Predictions of nominal GNP are often helped by inverse 
correlations between the changes in IPD and RGNP, and the associated offsets between the forecast errors for the two variables. (This has been noted before, see Zarnowitz 1979, p. 15.) Thus, in the inflationary recession of 1973-74 associated with the first occurrence of major supply and oil shocks, real growth was overpredicted and inflation underpredicted. The reverse combination of too low RGNP and too high IPD forecasts can be observed in the recoveries of 1974 and 1983-84. However, there are also episodes of positive correlation, e.g., in 1981-82 both real growth and inflation were overpredicted, which resulted in nominal growth forecasts that turned out much too high.

\subsection{Distributions of Summary Measures of Error}

Table 6 presents the statistics on the distributions of the mean errors in the sampled NBER-ASA survey forecasts of GNP, RGNP, and IPD. For the forecasts of average changes in GNP, the means are all negative, but the corresponding medians have mixed signs. The averages for the marginal change errors are predominantly positive. The dispersion measures (SD and $I Q R$ ) are very large relative to the averages. Thus, these statistics (line 1-4) fail to show clearly any dominant under- or overprediction bias. Similar observations can be made about the real GNP forecasts (lines 7-10). However, underestimation errors definitely prevail in the inflation (IPD) forecasts. Here all the averages, $M$ and $M D$, are negative, and the relative size of the corresponding SD and IQR figures is less. 
The $M$ and MD statistics tend to increase monotonically in absolute value with the length of the span, strongly for the forecasts of average change, less so for those of the marginal change. The SD and IQR statistics tend to be much larger the longer the span and the more remote the forecast target, for each of the three variables. (Cf. lines 1-4, 7 10, and 13-16.)

There is evidence that the distributions for GNP and RGNP are skewed to the left (i.e., SK $<0$ ), with medians larger than the means. For IPD, SK is very small throughout and $M$ and $M D$ are very close. (Cf. lines, 5,11 , and 17.)

The distributions for GNP and RGNP show large values for kurtosis, indicating the presence of long thick tails (for the normal distribution, $\mathrm{KU}=3$ ). Again, the situation is very different for IPD where the KU statistics are very low. (Cf. lines 6, 12, and 18).

Tables 7 and 8 , each of which has the same format as table 6 , show the distribution statistics for the mean absolute errors and the root mean square errors, respectively. The RMSQs are, of course, larger than the corresponding MAEs, and the statistics in table 8 are generally larger than their counterparts

in table 7 (e.g., they average about 30-60\% higher for the GNP measures). Otherwise, the two sets have very similar characteristics, which can be summed up as follows.

For both the MAEs and the RMSQs of the individual forecasts, the means and medians increase with the span regularly, strongly for the average changes, less so for the marginal changes. The main reason is that errors cumulate over time, 
but it is also true that the more distant target quarters are predicted somewhat less accurately than the near ones. The dispersion statistics SD and IQR also increase as the forecast horizon lengthens, except for the marginal IPD errors.

SK $>0$ everywhere here and the SK statistics are generally large for GNP and RGNP but small for IPD. Consistently, the MDs tend to be smaller than the MEs. The distributions tend to be skewed to the right.

Several of the KU statistics for GNP and RGNP are quite large. Little kurtosis is observed in the IPD forecasts, except for the shortest ones.

We conclude that the survey respondents tended to underestimate inflation but not (or in any event much less) the nominal and real GNP growth rates. The IPD forecast distributions were more nearly symmetrical and had fewer outliers than the distributions for GNP and RGNP.

\subsection{Individual vs. Group Mean Forecasts}

Combining corresponding forecasts that come from different sources or use different techniques tends to produce significant gains in accuracy. This is by now well known from many studies, including some based on the NBER-ASA surveys. ${ }^{10}$ In what follows we extend and update the evidence on this point.

Averaging all predictions in each survey for a given variable and horizon results in a time series of group mean (or median) forecasts. These are often called "consensus" forecasts, whether or not there is much actual consensus among the respondents. The group mean predictions based on our GNP, RGNP, and IPD sample forecasts have 
considerably smaller errors than the average individual respondent, as shown by comparisons of the ME, MEA, and RMSE entries in Table 9 (cf. columns 1 and 4, 2 and 5 , and 3 and 6). The absolute or squared errors tend to increase with the span of forecast for both individuals and group means, but less so for the latter.

For each individual time series of forecasts, a series of group mean forecasts has been computed with a strictly matching coverage in terms of the survey dates and target characteristics. Table 10 shows the locational statistics for the distributions of the ratios of the individual RMSEs to the corresponding group RMSEs. These measures indicate that the group mean forecasts were more accurate than about $75 \%$ of the sampled respondents' forecasts. Thus, most of the first or lower quartile $\left(Q_{1}\right)$ ratios are close to one (but some for RGNP are lower); most of the median $\left(Q_{2}\right)$ ratios are 1.1-1.2; and most of the third or upper quartile $\left(\mathrm{Q}_{3}\right)$ ratios are 1.3-1.5 (cf. lines 2-4, 7-9, and 12-14). These distributions are bounded from below (any ratio $>0$ ) and are heavily skewed to the right (e.g., the entries for the best forecasts in Table 10 are $0.5-0.9$, those for the worst forecasts are 3-7).

The ratios of the individual to the group RMSEs, unlike their numerators and denominators, do not depend systematically on the length of the forecast or distance to the target quarter. Also, the diversity of the individual forecasts by source, variable, and horizon is greatly reduced by the normalization with the group means. Thus, the ratios for the same quartiles are not very different for GNP, RGNP, and IPD. 


\subsection{Some Overall Accuracy and Variability Measures}

The preceding tables offer some insight into the structure of errors calculated from the survey forecasts but not into their relative levels. The latter will be assessed by comparisons with benchmark predictions from time-series models selected to fit the characteristics of the variables concerned and with forecasts from other sources. But first we take a quick look at the average values of the outcomes for the target series so as to gain some idea about the orders of magnitudes involved.

Columns $7-9$ in table 9 show, successively, the means, standard deviations, and root mean squares of the actual percent changes in the targeted variables. The absolute values of the average errors in the individual forecasts and, a fortiori, in the group mean forecasts are generally very small compared with the average actual changes, particularly for GNP and IPD (cf. columns 1 and 7). The average RMSEs of the individual forecasts are about $30-37 \%$ of the RMSVs for the nominal GNP growth and inflation and $68-72 \%$ of the RMSVs for the real GNP growth rates (cf. columns 3 and 9). The RMSEs of the group mean forecasts are about 23-29\% of the RMSVs for the nominal GNP growth and inflation and 51-53\% of the RMSVs for real GNP growth (cf. columns 6 and 9).

\subsection{Have Any Forecasters Exceled Consistently?}

Each forecaster in our sample of 111 was ranked by accuracy of his or her predictions, separately for each forecast target as defined by the date of the survey ( $t$ ), 
variable, and span (e.g. for the GNP 0-1 predictions made in 1970:1). Let $r_{\text {it }}$ be the rank of the $i$-th respondent in the time $t$ survey, which increases from the smallest to the largest squared error. The number of surveys covered per respondent $\left(m_{i}\right)$ varied widely across the individuals, and the number of respondents per survey $\left(n_{4}\right)$ varied widely across time (see table 2 , column 6). In view of this variability, it was necessary to normalize the ranks by the number of participants in the particular survey. This is done by calculating $R_{t}=100 r_{i t} / n_{t}$. The best forecast in each set would have $r_{i t}=1$ and hence $R_{i t}=100 / n_{i}$; the worst forecast would have $r_{i t}=n_{i}$ and hence $R_{i t}=100$. This setup permits us to consider the question: How stable were the accuracy rankings of the forecasters over time?

When the ranks are aggregated across the corresponding sets for each individual, measures of central tendency and dispersion are obtained that characterize the distributions over time of the ranks. Thus, for a given variable and span, the overall rank of the $\mathrm{i}$-th forecaster is $R_{i}=1 / m R_{i t}$, and the corresponding standard deviation equals $\left[1 / \mathrm{m} \sum_{\mathrm{t}}^{\mathrm{m}} \mathrm{R}_{\mathrm{it}}-\mathrm{R}_{\mathrm{i}}^{2}\right]^{1 / 2}$. We compute such means, SDs, medians, quartiles, and ranges for each of the 111 individuals covered. Table 11 presents simple averages of some of these measures in columns 1-4. For example, the grand mean (M) in column 1 represent $\vec{R}=1 / 111 \sum_{i} R_{i}$

In addition, columns 5-10 in Table 11 summarize the distributions across 
individuals of the mean normalized ranks $R_{i}$. The selected statistics include $S D$, quartiles, and extremes. For example, here $S D=\left[1 / 111 \sum_{i}\left(R_{i}-\dot{R}\right)^{2}\right]^{1 / 2}$ (column 5).

The entries in column 1 are all very close: $53-55$ for GNP, 52 for RGNP, 54-59 for IPD. The corresponding medians (not shown) are similarly clustered but 1-2 points larger. In fact, there is very little variation between the entries in any column of table 11 . That is, the distributions of the normalized ranks are very similar for any of three variables covered, and for any of the five spans.

Typically, any forecaster would rank high at some times and low at others. Indeed, the average range of $85-90$ (column 4 ) is close to the maximum range possible for the $\mathbf{R}_{\mathrm{it}}$ ranks (which cannot exceed 99 and would not be much larger than 90 for relatively small values of $n_{\mathfrak{l}}$ ). The forecaster's rank would fall in the center half of the distribution (i.e., in the interquartile range $I Q R$ ) nearly $50 \%$ of the time, and within $\pm S D$ of the mean perhaps up to $66 \%$ of the time (columns 2 and 3). There is no evidence of a high skewness or a high kurtosis in these distributions. To sum up, the forecasting performance of any individual relative to others is likely to be highly variable over time.

On the other hand, the dispersion of the corresponding forecasts and their errors across the individuals will tend to be limited by the commonality of the targets of the forecasters, and of the information and methods available to them. The correlations between the forecasters' errors are expected to be positive and may be high. Our measures presumably reflect all these regularities. Interestingly, the standard deviations in column 2 , are $26-28$, those in column 5 are only $9-12$ (note that the definition of the former 
includes time $t$ explicitly, while the definition of the latter does not). Similarly, the IQRs in column 3 are 45-50, those implied by columns 7 and 9 are 9-15; and the corresponding total ranges are 85-90 and 30-59 (cf. columns 4 and 6-10). These numbers seem consistent with the results obtained in some previous studies indicating that fluctuations over time contribute more than differences across forecasters to the overall variation in forecast errors (see Zarnowitz 1974, pp. 578-79).

For each of the forecast targets identified in lines 1-15 of table 11, the ranks according to $R_{i}$ form a relatively tight cluster between the values of $Q_{1}$ and $Q_{3}$ that average 47 and 59, respectively (columns 7-9). A quarter of the group performed poorly relatively to the others, with $R_{i}$ values ranging from well above 60 to 100 (columns 9-10). However, our attention centers on the top-ranking quarter, with $R_{i}$ values averaging in the 30 s and 40 s (columns 6-7). The latter can be said to have exceled with respect to the given category of forecast targets.

All these subsets, of course, consist of individuals who are coded and identifiable. It is important to ask next what the correlations of the ranks are between the different variables and spans. For example, do those who predicted best the growth of real GNP also tend to excel in predicting inflation? Do those who rank high in forecasting over the shortest horizons also rank high in forecasting over the longer horizons?

Table 12 indicates that the answers to these questions are on the whole positive. The correlations among our normalized ranks, both across the variables for each span (lines 
1-3) and across the spans for each variable (lines 4-13), are all positive and sufficiently high not to be due to chance. Forecasters who predict relatively well (poorly) any one of these targets are also likely to predict well (poorly) any of the other targets. Not surprisingly, the correlations are higher the more closely related are the forecast targets. Thus, they are higher for GNP and RGNP than for RGNP and IPD, and higher for successive spans, e.g., 0-1 and 0-2, than for more distant spans, e.g., 0-1 and 0-5. Similar results have been found for other variables and periods, and for marginal as well as average change forecasts (cf. Zarnowitz 1984, pp. 17-19).

\subsection{Comparisons with Bayesian Vector Autoregressive (BVAR) Forecasts}

We use a BVAR model with five variables: RGNP, IPD, M2 (broad money supply), LI (the composite index of leading indicators), and TBR (the three-month Treasury bill rate). TBR is a level series, the others are series of growth rates. The model is estimated on quarterly series, each taken with six lags. The data are the presently available ones, i.e., they incorporate all revisions, and in this sense the forecasts based on them are expost. But the forecasts are generated sequentially, using only the information preceding the date of the forecast.

Unlike the forecasters who can take advantage of the early information provided by the monthly and weekly time series released during the survey quarter, the BVAR model does not draw on any such data. On the other hand, unlike the BVAR model, which is 
based on the present, revised series, the forecasters work under the disadvantage of having access only to the latest preliminary data, that is, data that contain measurement errors which are yet to be eliminated by revisions.

Because the quarterly data for the survey quarter (1) are not known to the forecasters, our first approach was to impute the same lack of knowledge to our BVAR model. Here, then, the shortest prediction is for $0-1$, the longest prediction is for $0-5$. But, as pointed out by Christopher Sims during the conference, this approach (now called "variant $A$ ") ignores any effects on the survey forecasts of the most recent economic news. Since the knowledge of the news on balance presumably helps the forecasters, variant $A$ in this respect handicaps our BVAR, as it would more generally any model based strictly on quarterly time series only.

For this reason, we also present the results of alternative calculations ("variant B"), which assume full knowledge of the actual values in quarter 1 , or effectively perfect foresight. Here for $0-1$ the error of the BVAR model is identically zero, and no comparisons with the survey forecasts are available; the shortest prediction is for 1-2. Thus, the two variants represent contrasting extremes: in A there is no knowledge, in B there is full knowledge of period 1 values. Variant $B$ handicaps the real-life forecaster who has only partial and indirect knowledge of the target variables in the current (survey) quarter.

It follows that the truth about the relative accuracy of the individual forecasts from the surveys and the BVAR forecasts falls somewhere between variants A and B. Table 13 
provides the evidence, showing in columns 1-3 that the measures of error of BVAR-A for spans $0-1,0-2, \ldots$ etc. are approximately equal to the corresponding measures of error of BVAR-B for spans $0-2,0-3, \ldots$, etc., respectively (compare lines 1 and 7,2 and 8 , and so on). As would be expected, the RMSE ratios in columns 4-8 are throughout lower for variant $A$ than variant $B$, when comparing entries for the corresponding spans (lines 2 and 7, 3 and 8 , and so on). That is, variant B calculations show the BVAR model forecasts in a relatively more favorable light then variant $\mathrm{A}$ calculations do.

We present the results for both variants of the retroactively used time-series models for comparisons relating to GNP, RGNP, and IPD (this covers both our own and outside, multivariate and univariate models). For the other variables, only variant $A$ is used. The "true" outcomes are probably more often than not closer to the variant $A$ than to the variant B comparisons because (1) the forecasters' information about the recent and current developments is in fact quite limited and deficient, and (2) the forecasters use preliminary data and the time-series models use revised data. When all is considered, it can be argued that variant $B$ handicaps the forecasters more than variant $A$ handicaps the models.

The RMSE ratios in table 13 , columns $4-8$, indicate that at least $75 \%$ of the individual forecasts of GNP, $50 \%$ of those of IPD, and $25 \%$ of RGNP were more accurate than the variant $A$ BVAR forecasts. Thus, the $Q_{3}$ ratios are less than 1.0 for nominal growth and close to 1.0 for inflation. For real growth, the MD ratios approach unity at spans of 2-3 quarters and exceed it at longer spans. The ratios based on the BVAR 
forecasts variant B still show most of the survey forecasts to be superior for GNP, but not for IPD or RGNP. Here the ratios rise above 1.00 for all horizons at $\mathrm{Q}_{3}$ for GNP, at MD for IPD, and even at $Q_{1}$ for RGNP.

The BVAR mean errors are all positive, unlike the MEs for the NBER-ASA survey forecasts which are mostly negative for GNP and IPD, and mostly positive but somewhat mixed for RGNP. (For this and the rest of the paragraph, see table 13, columns 1-3, and table 9, columns 1-6.) Comparisons of the MAEs and RMSEs of BVAR with the corresponding measures for the average individual survey forecast produce a mixed picture, depending on the series and criteria used. However, the comparisons with the group means are generally adverse for BVAR of either variant.

Such variables as the leading index and the short-term interest rate act as strong codeterminants of growth in total output, as suggested by regression estimates and out-ofsample predictions with VAR models (Zarnowitz and Braun 1990; Zarnowitz 1991, chapter 11). Our findings here are consistent with these results. The BVAR forecasts of RGNP perform relatively well, which holds a potentially useful lesson for the forecasters to take proper account of these relationships. But the BVAR forecasts of GNP and IPD are apparently much weaker.

\subsection{Comparing Forecasts for the First and Second Halves of 1968-90}

The period 1968:4-1979:3 was one of upward drifts and large instability in 
both inflation and unemployment; of business contractions in 1969-70 and 1973-75; of the Vietnam war and price control disturbances in the early years, and severe supply (mainly oil-price) shocks in the middle and late years. The period 1979:4-1990:1 was one of more successful attempts to slow inflation by restrictive monetary policy; of sharp rises in prices and interest rates followed by downward trends in the wake of two back-to-back recessions in 1980 and 1981-82; of a long expansion that followed, interrupted by slowdowns in 1984 . 86 and 1989; of new trade and financial problems. It is of interest to ask how the macroforecasts fared in these two so different periods of approximately equal length.

The errors of the individual forecasts from the NBER-ASA surveys were on average larger in 1979-90 than in 1968-79 for GNP but smaller for IPD, judging from the comparisons of the RMSEs in table 14, columns 1 and 5. For RGNP, the differences between the two subperiods are small and mixed, depending on the horizon of the forecasts.

The average individual to group-mean RMSE ratios differ little between 1968-79 $(1.04 \leq \mathrm{i} / \mathrm{g} \geq 1.34)$ and $1979-90(1.15 \leq 1 / \mathrm{g} \geq 1.31)$. They decreased somewhat in the latter period for short GNP and RGNP forecasts, increased more for longer IPD forecasts, but remained approximately unchanged in most cases (cf. columns 2 and 6).

The individual-to-BVAR RMSE ratios for GNP rose from .6 or less in 1968-79 to around .8 in 1979-90; those for RGNP rose as well, from an approximate range of $.6-1.0$ to .9-1.2; and those for IPD declined from .9-1.0 to .6-.9 (columns 3 and 7). These i/bv 
ratios, then, show that on average the NBER-ASA survey forecasts outperformed our BVAR forecasts, except for RGNP in 1979-90. The group mean predictions from the surveys were throughout more accurate than BVAR, i.e., the ratios $\mathrm{g} / \mathrm{bv}<1$ in all cases (columns 4 and 8 ). As might be expected, the changes in $\mathrm{i} / \mathrm{bv}$ and $\mathrm{g} / \mathrm{bv}$ between the two subperiods paralleled each other directionally.

There is no evidence here that the forecasts on the whole either improved or deteriorated in the 1980s as compared with the 1970s. The BVAR benchmark proved a little more effective in 1979-90 than in 1968-79 for nominal and real GNP growth and somewhat less effective for inflation.

\section{Other Forecasts for $1968-90$}

\subsection{Percent Change Forecasts: Industrial Production and Corporate Profits}

Table 15 shows that the average errors of the forecasts of IP and CP tended to be positive but widely dispersed and strongly increasing with the span (columns 1-3). The RMSEs increased similarly (columns 4-6). Comparisons with the average size and variability of the actual changes (columns 9-11) indicate a moderate level of accuracy for the IP forecasts but poor overall performance for the CP forecasts (where the mean and median RMSEs exceed the actual SD and RMSV values). The large positive values of SK and $\mathrm{KU}$ for the IP predictions up to three quarters ahead suggest skewness to the right and fat tails; the latter may also characterize the longer CP predictions (columns 7-8). 
Combining the individual forecasts by simple averaging reduces the errors substantially for IP (except for the longest span) but not for $\mathrm{CP}$, where the gains from using the group mean or consensus forecast are small (cf. table 15 , columns 4 and 6, with table 16, column 1). Accordingly, the RMSE ratios $\mathrm{i} / \mathrm{g}$ are smaller for CP than for IP; but it is still true for both variables that only about the best $25 \%$ of the sample are more accurate than the group mean forecasts (see table 16, columns 2-4).

The BVAR model forecasts (variant A only) outperform the group mean forecasts for profits. The comparisons for the production index yield closer and mixed results, which favor the survey group's predictions for the shorter and the BVAR predictions for the longer horizons. (Cf. the corresponding entries in columns 1-4 and 5-8 of table 16.)

Both IP and CP forecasts had larger RMSEs in 1979-90 than in 1968-79 in almost all cases (table 17, columns 1 and 5). Compared with BVAR, variant A, the survey forecasts look better in the earlier than in the later subperiod, particularly for IP (cf. columns 3 and 4 with columns 7 and 8 , respectively).

\subsection{Level Forecasts: Unemployment Rate and Housing Starts}

For UR (table 18, lines $1-5$ ), the mean errors are predominantly negative, suggesting some underprediction, but they also show considerable dispersion. Level errors, unlike average change errors, do not cumulate, but the RMSEs still increase substantially with the distance to the target quarter. The summary error measures are quite small relative to the 
statistics for the actual values of UR. For short forecasts, the distributions of the RMSEs are skewed to the right and have fat tails, judging from the large SK and KU values.

For HS (lines 6-10), the mean errors are close to zero and have mixed signs. They do not depend on the distance to the target (unlike the mean errors for UR, which increase with the distance). The RMSE and SD values, as usual, increase for the longer forecasts, but they remain fairly small compared with the measures for the actual values of HS. The SK and KU figures are small.

Combining the individual forecasts results in substantial gains in accuracy for both variables but particularly UR (cf. table 19 , column 1 , and table 18 , columns 4 and 6 ). The RMSE ratios $\mathrm{i} / \mathrm{g}$ are generally higher for $U R$ than for $H S$, but once again the $Q_{1}$ ratios are close to one throughout, i.e., about $75 \%$ of the individual forecasts are less accurate than the group means in either case (table 19, columns 2-4). The BVAR forecasts, variant A, are about as accurate as the group mean forecasts for target quarters 3-5 of both UR and HS; for closer targets, the comparisons favor the surveys for UR and the BVAR for HS (cf. the corresponding entries in columns 1-4 and 5-8).

Table 20 shows that the NBER-ASA forecasters on the whole predicted UR somewhat better, and HS somewhat worse, in 1968-79 than in 1979-90 (cf. columns 1 and 5). The relative performance of the group mean vs. individual forecasts was very similar in the two periods (columns 2 and 6); that of the BVAR variant A model improved in most cases for UR but showed no systematic change for HS (columns 3-7 and 4-8). 
6. Comparisons with Selected Econometric and Time-Series Model Forecasts

\subsection{The Michigan University Research Seminar in Quantitative Economics}

The Michigan RSQE has the longest record of the several well-known service bureaus working with macroeconometric forecasting models. RSQE kindly provided us with the record of their forecasts, and we were able to compare them with the NBER-ASA survey forecasts for ten variables. It is important to note that the quarterly Michigan forecasts begin in 1970:4 and were not made in the first quarter in years 1975 and 1976, and in the second quarter in years 1971-75 and 1977-79. ${ }^{11}$ We matched the Michigan and the NBER-ASA forecasts period by period. Further, the Michigan predictions were made typically in March, June (occasionally May), August (rarely September), and November (in 1974-75, December). The NBER-ASA survey questionnaire was usually mailed in the first half of each quarter but it was only in the last month of the quarter that all responses were collected. Thus, at least some of the survey forecasts had the advantage of later timing (which means more potentially useful up-to-date information) vis-a'-vis the Michigan forecasts.

Comparing the ME, MAE, and RMSE statistics for the Michigan and the NBERASA group mean forecasts shows the latter to have been more accurate for GNP, RGNP, and IPD (cf. columns 1-3 and 4-6 in table 21). Consistent evidence comes from the RMSE ratios that have ranges of approximately $0.7-0.9,0.9-1.1$, and $1.0-1.3$ for $Q_{1}, M D$, and $Q_{3}$, respectively (columns 7-9). Thus, generally about half or more of the individual forecasts from the surveys were at least somewhat more accurate than the Michigan forecasts. 
The results for the other variables are mixed. As shown in table 22, the Michigan predictions of real consumption show on the whole larger errors than the NBER-ASA "consensus," but not by much and not for the longest horizon (lines 1-5). They are better than $50 \%$ of the individual survey forecasts for the two shortest spans, and better than $75 \%$ for the three longest spans. The comparisons for real nonresidential investment favor the group averages by modest margins, except again for the longest span covered. For real residential investment, the Michigan forecasts are definitely better than all but the shortest group mean forecasts. National defense expenditures are predicted better by the surveys through span 0-3 and better by Michigan for the two longer spans. More than half of the RMSE ratios $\mathrm{i} / \mathrm{M}$ for NFI, RFI, and DEF are less than one (lines 6-20).

The pattern that the NBER-ASA group mean forecasts have an edge for the two shortest spans and the Michigan forecasts for the two longest spans holds for the unemployment rate and the Treasury bill rate in table 23 (lines 1-5 and 6-10). The middle span shows about equal RMSEs for the two sets. The corporate bond yield predictions from Michigan outperform those from the surveys for all but the shortest span (lines 11-15).

\subsection{Sims' Probabilistic Forecasts}

In addition to outside econometric model forecasts, we wished to compare the results of the NBER-ASA surveys to outside time-series forecasts. We are indebted to Chris Sims for data on predictions from both a sophisticated BVAR and univariate ARIMA models. 
Recall that our own BVAR model used earlier in this paper includes RGNP, IPD, TBR, M2, and LI, plus the variable predicted (if not one of the above). The Sims model includes the first three variables in our set, plus six others: M1, UR, NFI, S\&P 500 stock price index, a commodity price index, and the trade-weighted value of the dollar. ${ }^{12}$ It is a nine-variable, five-lag model, whereas ours is a five-or-six variable, six-lag model.

Sims model is an extension of the model constructed in 1980 and used in quarterly forecasting during $1980-86$ by Litterman (1986). It is three variables larger than the original Litterman model and it allows time-variation in coefficients, predictable time variation in forecast error variance, and non-normality in disturbances (Sims 1989). The modifications give rise to non-normal, nonlinear models and hence to considerable complications in estimation and analysis (Sims and Todd 1991). The Sims model (like our own BVAR) forecasts are simulations of real-time forecasts in that they use only data from time periods before the periods to be predicted. But for several reasons, including the use of current versions of the data, they are far from being true ex ante forecasts (again, the same applies to our BVAR as well).

In evaluating the BVAR forecasts (both Sims' and our own), we used the current data, which is consistent with their construction and believed to be fair. Use of preliminary figures would have resulted in finding larger errors.

Again, like for our own BVAR (see table 13 and text above), the comparisons of Sims model forecast with the NBER-ASA survey forecasts for GNP, RGNP, and IPD are 
presented in two variants $A$ and $B$ (table 24). For reasons already explained, variant A favors the real-time predictions that incorporate contemporary news evaluations, while variant $B$ favors the predictions based on the ex post constructed time-series models.

Using variant A, Sims' forecasts (S) are found to have on the whole larger errors than the group mean forecasts from the NBER-ASA surveys for both GNP and RGNP (table 24, lines 1-5 and 11-15, cf. columns 1-3 and 4-6). The corresponding ratios RMSE $/ R^{2} M S E_{S}$ are relatively low, approaching 1.00 only for $Q_{3}$ (columns 7-9), which means that most individual forecasts from the surveys are more accurate than the $S$ forecasts. In contrast, the $\mathrm{S}$ forecasts are considerably more accurate than the group mean forecasts for IPD inflation, and here the RMSE ratios i/S mostly exceed 1.00, even for $Q_{1}$ (lines 21-25).

Using variant B as a criterion (lines 6-10, 16-20, and 26-30), we still see the group mean forecasts as retaining on balance an advantage over the $\mathrm{S}$ forecasts for GNP, but it is a much reduced advantage and one essentially limited to the longer spans. For RGNP, the NBER-ASA consensus predictions are somewhat more accurate than the $\mathrm{S}$ model predictions for the spans $0-4$ and $0-5$, whereas the opposite is true for the shorter spans. For IPD, the $S$ forecasts have smaller errors throughout. (Cf. columns 1-3 for variant $B$ with the corresponding entries in columns 4-6.) Looking at the RMSE ratios, i/S (columns 7-9), we find them to exceed 1.00 , that is, to favor the S model, for GNP at $Q_{3}$ only, for RGNP at $M D$ and $Q_{3}$, and for IPD at $Q_{1}, M D$, and $Q_{3}$. 
Interestingly, the original Litterman BVAR performed relatively well for real GNP and unemployment but worse for IPD, which motivated both Litterman and Sims to make changes designed to improve their inflation forecasts. But simulations disclosed "a tendency for improvements in the retrospective forecast performance of the BVAR model for inflation to be accompanied by deterioration in its performance for real variables" (Sims 1989, p. 1). A similar tradeoff was observed in the work with our own BVAR.

According to the measures in table 25 (based on the variant A only), most of the NBER-ASA survey forecasts for the unemployment rate (1968-90), the Treasury bill rate (1981-90), and the rate of growth in real nonresidential fixed investment (1981-90) exceeded the corresponding Sims model forecasts considerably in overall accuracy. This can be concluded from both the comparisons with group mean predictions from the surveys (cf. columns 1-3 and 4-6) and the low is ratios (columns 7-9).

The Sims model and our own BVAR forecasts have errors of generally similar order of magnitude. The Sims predictions are more accurate for GNP and IPD, less accurate for RGNP and UR. The results for NFI and TBR are mixed (favoring Sims at the two longest horizons only). ${ }^{13}$

\subsection{Univariate Time-Series Models}

Predictions from ARIMA models make popular benchmarks for evaluating forecasters' performance. We use ARIMAS as specified in Sims and Todd 1991, where 
they are reported to have worked well relative to the Simsian BVAR for financial variables and business fixed investment in 1980-90 (pp. 9-10). However, our measures show that the BVAR forecasts by Sims had throughout smaller overall errors than the corresponding ARIMA forecasts, whether the comparisons cover the variants A or the variants $B$ (cf. Table 24 and 25, columns 1-3, with Tables 26 and 27, columns 2-4).

The results of comparing the NBER-ASA survey forecasts with their counterparts of the Sims-Todd ARIMA type are less clear-cut. Most of the forecasters did better than the time-series models according to the variant $\mathrm{A}$ calculations, as is evident from the individual-to-ARIMA (i/A) ratios in columns 5-7 of Tables 26 and 27. But when variant $B$ is used, the forecasters are no longer clearly ahead for RGNP and fall somewhat behind for IPD (Table 26, lines $16-20$ and 26-30).

Beginning in 1976:2, Charles Nelson has produced ARIMA forecasts of rates of change in nominal and real GNP and the implicit price deflator synchronously with other real-time forecasts, updating them each quarter upon the announcement of the first preliminary numbers for the preceding quarter. Comparisons with five econometric models for the period 1976:2-1982:4 have shown these ex ante "benchmark" forecasts to be of competitive accuracy (Nelson 1984). Since 1988, Frederick Joutz has been preparing the ARIMA forecasts on a current basis (the same way as Nelson had before), and he kindly let us have the results for the purposes of a comparative analysis. 
Table 28 shows that the NBER-ASA group mean forecasts $(g)$ were on average consistently more accurate than the Joutz ARIMA (J) forecasts (cf. colunins 2-5 and 3-6). The RMSE ratios $\mathrm{g} / \mathrm{J}$ rose with the span from .73 to .88 for GNP and from .76 to .83 for RGNP; they varied irregularly between .78 and .81 for IPD. The RMSE ratios $\mathrm{i} / \mathrm{J}$ (columns 7-9) average .8-.9 for $Q_{1}, 1.0-1.1$ for $M D$, and 1.3-1.5 for $Q_{3}$. Our analysis confirms the findings that these ARIMA forecasts are indeed competitive, and that their relative accuracy tends to improve with their horizon for GNP and RGNP (but not for IPD, where they are weakest).

\section{A General Evaluation and Conclusions}

In presenting and discussing more than $\mathbf{3 0}$ tables on multiperiod quarterly forecasts for a score of variables by a total of more than 100 individuals, we had to make some hard choices about which problems to confront and which measures to use. Forecasts for twothirds of the time series covered were treated less comprehensively and relegated to an appendix, to make the paper easier to read. Even so, the inevitable abundance of detail risks obscuring the overall picture. Therefore, lest we miss the forest for the trees, a statement of general findings, conclusions, and qualifications is very necessary at this point.

1. The distributions of the error statistics show that there is much dispersion across the forecasts, which typically increases with the length of the predictive horizon. Forecasters differ in many respects and so do their products. The idea that a close 
"consensus" persists, i.e., that current matched forecasts are generally all alike, is a popular fiction. The differentiation of the forecasts usually involves much more than the existence of just a few outliers. However, it is also true that forecasters depend on common information, interact, and influence each other. This naturally induces some common trends. The more independent information the individuals possess, the more their predictions can differ. Thus, a clustering of forecasts could be due either to genuine agreement or common ignorance, while dissent may reflect uncertainty. ${ }^{14}$

2. Errors of the average change forecasts cumulate over the spans $0-1, \ldots, 0-5$ with great regularity for a variety of time series. To a large extent, this occurs because of the progression to larger changes in the corresponding actual values. But the errors of marginal change and level forecasts, too, often increase with the distance to the target quarter, although by much smaller margins and with much less regularity. As might be expected, the further out in the future the target, the less can be inferred about it from the past and the worse it is usually forecast. The less random and more predictable the series, the better this rule holds, in the sense that the forecasts will be more forward-looking and more appropriately differentiated with the distance to the target period. ${ }^{15}$

3. Macroeconomic variables differ greatly in forecastability. The more persistent (autocorrelated) series are, of course, more accurately predicted than series with high random variability. Thus, real GNP and consumption are far easier to forecast than residential investment and, especially, change in business inventories. Inflation was 
underestimated and poorly predicted by most forecasters most of the time. Negative correlations between RGNP and IPD forecast errors have long been observed (see Zarnowitz 1979, table 4 and text), and offsetting performance for inflation and real variables appears to be frequently encountered in studies of forecasting methods and results.

4. A comparison of the summary measures of error for 1968:4-1979:3 and 1979:41990:1 reveals no large and systematic differences that would indicate either deterioration or improvement in the overall performance of the respondents to the NBER-ASA surveys. The accuracy of GNP forecasts may have decreased somewhat but that of inflation forecasts increased. The 1970 s and the 1980 s differed significantly in a number of economically important dimensions, but it is difficult to say that either subperiod presented the forecasts with definitely greater problems than the other. Each experienced two business recessions, which is noted because previous research has shown that turning-point errors played a major role in downgrading the forecasting records (for a recent summary, see Zarnowitz 1991).

5. Group mean forecasts are generally much more accurate than the majority of individual forecasts. These consensus predictions are computed by simple averaging across the corresponding responses to each successive survey; we made no effort to use other than equal weighting. This paper, then, provides many examples of the rule that combining forecasts often results in substantial improvements. The method is very accessible and 
inexpensive. The gains are enhanced by the diversification of the forecasts that are combined, e.g., our group mean forecasts should be better, the more different and complementary the information embodied in their components. For some variables and periods the combinations work much better than for others. In principle, one would prefer to combine the information in a single model rather than combine the forecasts. In practice, the latter will typically be much easier.

6. Consider first comparisons with time-series models constructed on the assumption that the last-known values of the variables concerned refer to the prior quarter $t-1$ (variant A). The assumption is certainly valid for the quarterly variables in the real-time forecasts, but it results in some bias against the time-series forecasts. Table 29 sums up the evidence in form of the RMSEs averaged across spans. For the subset consisting of the median individual and the consensus forecasts from the NBER-ASA surveys, the Michigan econometric model, our BVAR (A) model, the Sims (A) probabilistic model, and the SimsTodd ARIMA (A) model (lines 1-4, 6, and 8), the consensus (group mean) survey forecasts rank first for GNP and RGNP, and second for IPD (following the Sims (A) model).

7. The alternative assumption, that the last-known values of the variables refer to the current quarter $t$ (variant $B$ ) is rather strongly biased in favor of the ex post forecasts with time-series models. The ARMSEs are all much lower for the variant B predictions than for their variant A counterparts (cf. lines 4, 6, and 8 wiht lines 5,7, and 9). When all nine sets of forecasts listed in table 28 are considered, Sims (B) model ranks 2,2 , and 1 for 
GNP, RGNP, and IPD, respectively. The corresponding ranks of BVAR (B) are also high: 3, 1, and 3. The NBER-ASA consensus forecasts are now almost tied for the first rank with Sims (B) and rank only 3 for RGNP and 5 for IPD (cf. lines 2, 5, and 7).

8. Table 30 sums up the evidence on the comparative accuracy of the several sets of forecasts included in this study, using the longest series of predictions available for each variable. Here again, root mean square errors averaged across the spans serve as the basis for ranking the forecasts, but only the variant (A) time-series predictions are used. By this criterion, the group forecasts from the NBER-ASA surveys earned 10 first and 10 second ranks for the 21 variables covered. The median individual forecasts ranked first or second 6 times, third 11 times, and lower four times. Our BVAR model had equal numbers of the first, second, and third ranks (5 each), plus six lower ranks. The Michigan (RSQE) forecasts, available for 10 variables, ranked first and second four times and once, third and fourth three times and twice, respectively. Sims probabilistic model forecasts, available for six variables, were mostly less accurate, and the ARIMA model forecasts were throughout least accurate.

9. Finally, Table 31, using sums of the ranks across variables, shows that the group (consensus) forecasts from the survey performed best overall in each of the periods covered; the Michigan forecasts were second best; the median individual forecasts, BVAR model forecasts, and the Sims forecasts share mostly the ranks 3 or 4 (there are ties); and the ARIMAs rank last. Note that major deviations from this ordering appear for some 
variables, notably Michigan is best for UR, Sims for IP. Also, these results conceal the differences between the forecast horizons, which are sometimes important (e.g., the Michigan forecasts would rate higher for the longer, lower for the short, spans).

10. It is important to emphasize that these comparisons concentrate on only one aspect of the forecasts and need not imply an overall superiority of any of them. For example, the econometric and time-series models are clearly much better defined, more explainable, replicable, and internally consistent than the survey forecasts. But the survey data collectively embody a great deal of apparently useful knowledge and information available to professional forecasters. An interesting project, which must be left for future research, would be to identify the best of the individual forecasts from the surveys, and to combine them with each other and with very different model forecasts. Regressions of actual values on predictions from different sources and models would serve as one method for implementing this objective. Given rich data from active forecasters and interesting models, studies of this type should yield useful lessons. 
Footnotes

1. Interestingly, the Morgenstern and Grunberg-Modigliani papers are in a sense precursors of the contemporary rational expectations models in which behavior follows forecasts that are consistent with the assumptions of the models and free of any systematic errors.

2. The same applies to the literature on microeconomic prediction, which is additionally restricted by the fact that much of the material on microforecasts is confidential.

3. Forecasts of a Yale service developed by Irving Fisher were not better in 1929 than those of the Harvard service developed by Warren Persons (see Dominguez et al. 1988).

4. Later studies of the Livingston forecasts generally used them as amended by Carison, but many earlier studies suffer from measurement errors in the published group averages.

5. The B\&E Section had long been engaged in producing annual surveys of forecasts by its members.

6. The committee was established with the support of the B\&E section of the ASA and its 1980 and 1981 chairmen, Arnold Zellner and George Tiao. The members included Rosanne Cole, Ray C. Fair, Edgar R. Fiedler, Albert A. 
Hirsch, F. Thomas Juster, Geoffrey H. Moore, George L. Perry, W. Allen Spivey, and Victor Zarnowitz. For more detail on these initiatives, see Zarnowitz 1982, pp. 11-13.

7. Missing observations (gaps in response) limit our ability to use these data to study such problems as the dependencies over time in the forecast errors (but see Zarnowitz 1985, section 3).

8. We are indebted to David L. Williams, Secretary-Treasurer of the NABE, for help in collecting the data used in the text paragraph above.

9. Most of these differences actually disappear when rounded off to one decimal point. Providing detail by span of forecast and for some other variables would not alter the picture significantly (see Zarnowitz 1983, pp. 84-85). However, it is probably worth noting that the group ranking first the outside econometric models had the smallest average RMSEs for most variables (column 3). This group included large companies using well-known econometric service bureaus as well as their own staffs of professional economists.

10. See Zarnowitz 1984, which uses the data for 1968-79. An early demonstration that simple averaging can reduce forecast errors is in Zarnowitz 1967, pp. 123126. For a survey of the literature, see Clemen 1989.

11. RSQE predicts normally eight times in each year. 
12. The data are generally expressed in log level form, except for TBR which was not logged.

13. For the RMSEs of the BVAR forecasts, see Table 13, column 3 (GNP, RGNP, IPD), and Tables 19, A.6, and A.8, column 5 (UR, NFI, and TBR, respectively).

14. Cf. Zarnowitz and Lambros 1987, a study which compares the point and probabilistic forecasts from the NBER-ASA surveys. Time and space restrictions prevented us from including in this paper the survey responses to questions on the probabilities of alternative GNP and IPD outcomes and turning points. See also Braun and Yaniv 1991.

15. It should be noted that annual forecasts are generally more accurate than all but the very short quarterly forecasts, owing to cancellation of errors for the quarters within the year (Zarnowitz 1979). In this paper, annual forecasts are not considered.

16. A few deviations from the rule appear in the longest forecasts, apparently due to outliers and small-sample problems. 
Chare 1

Forecast Distribuctons and Accual Values of Percent Changes in Real GNP. Three Hor120ns, 1968:4-1990:1

$0-1$

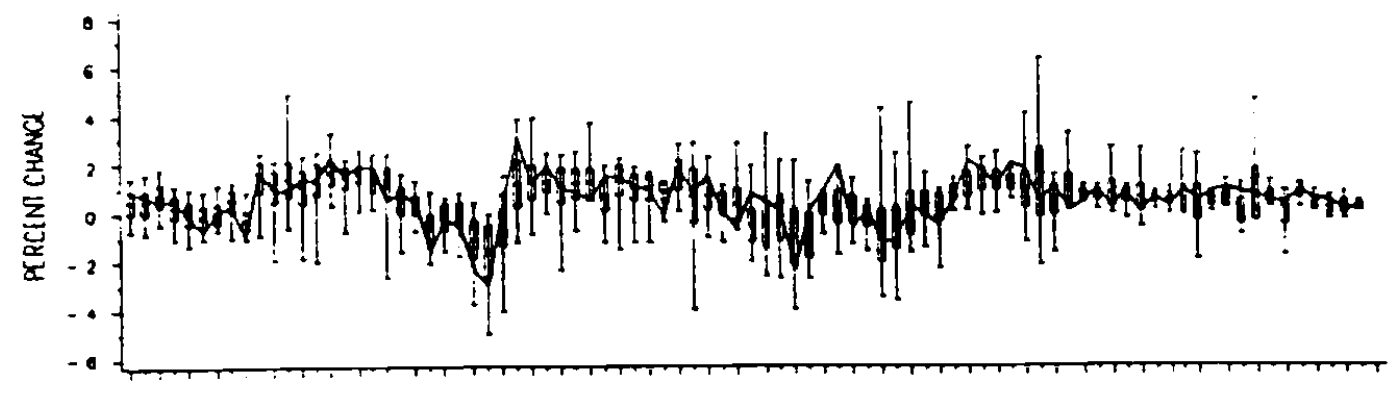

$0-3$

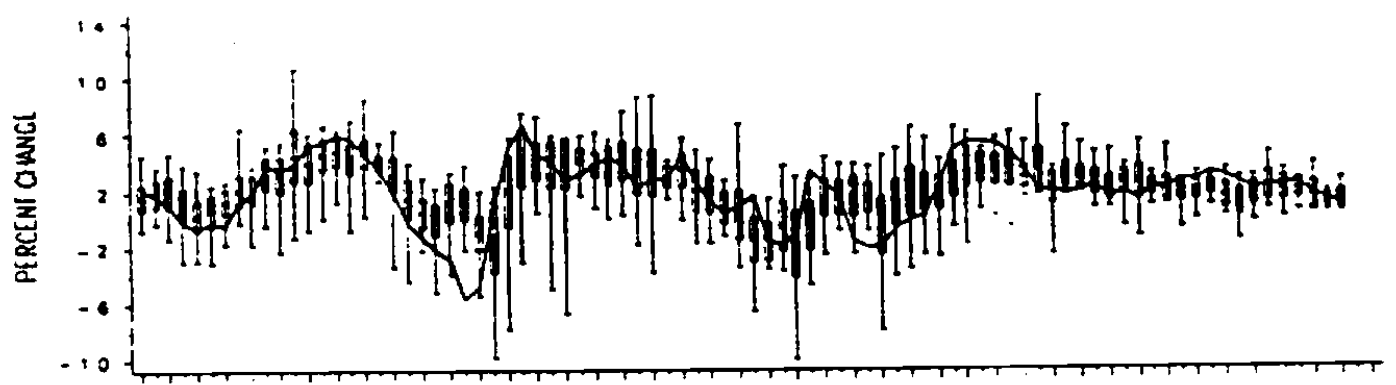

$0-5$

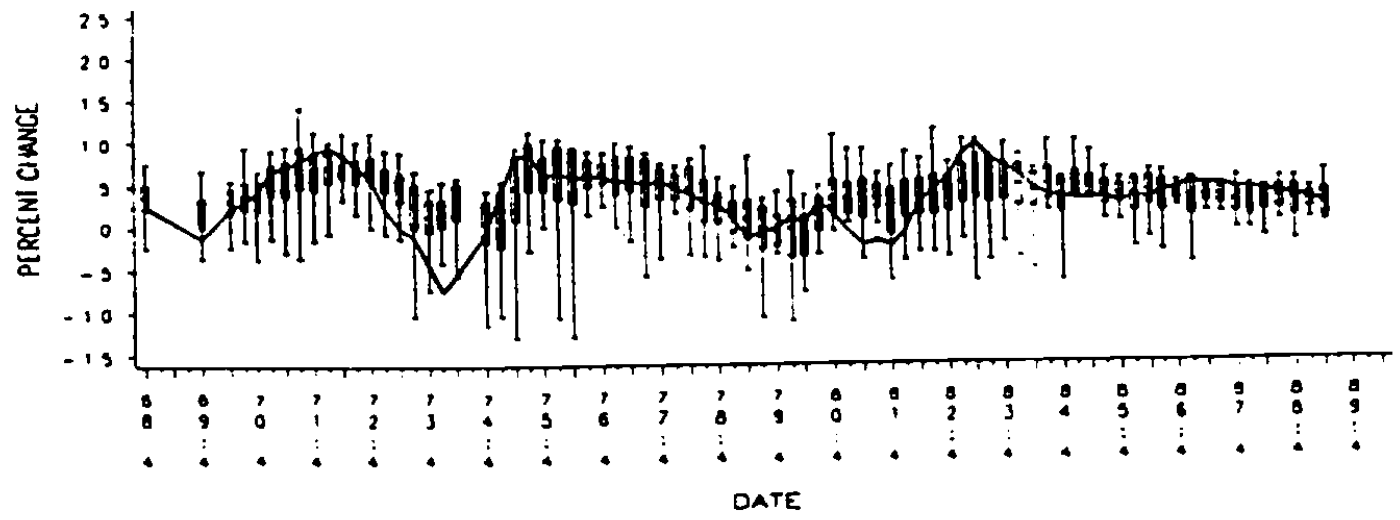

$\oiiint_{M}^{M} \begin{aligned} & M+S D \\ & M-S D \\ & L\end{aligned}$ 
Chart 2

Forecast Distributions and Actual Values of Percent Changes In IPD, Three Horizons, 1968:4-1990:1

$$
0-1
$$
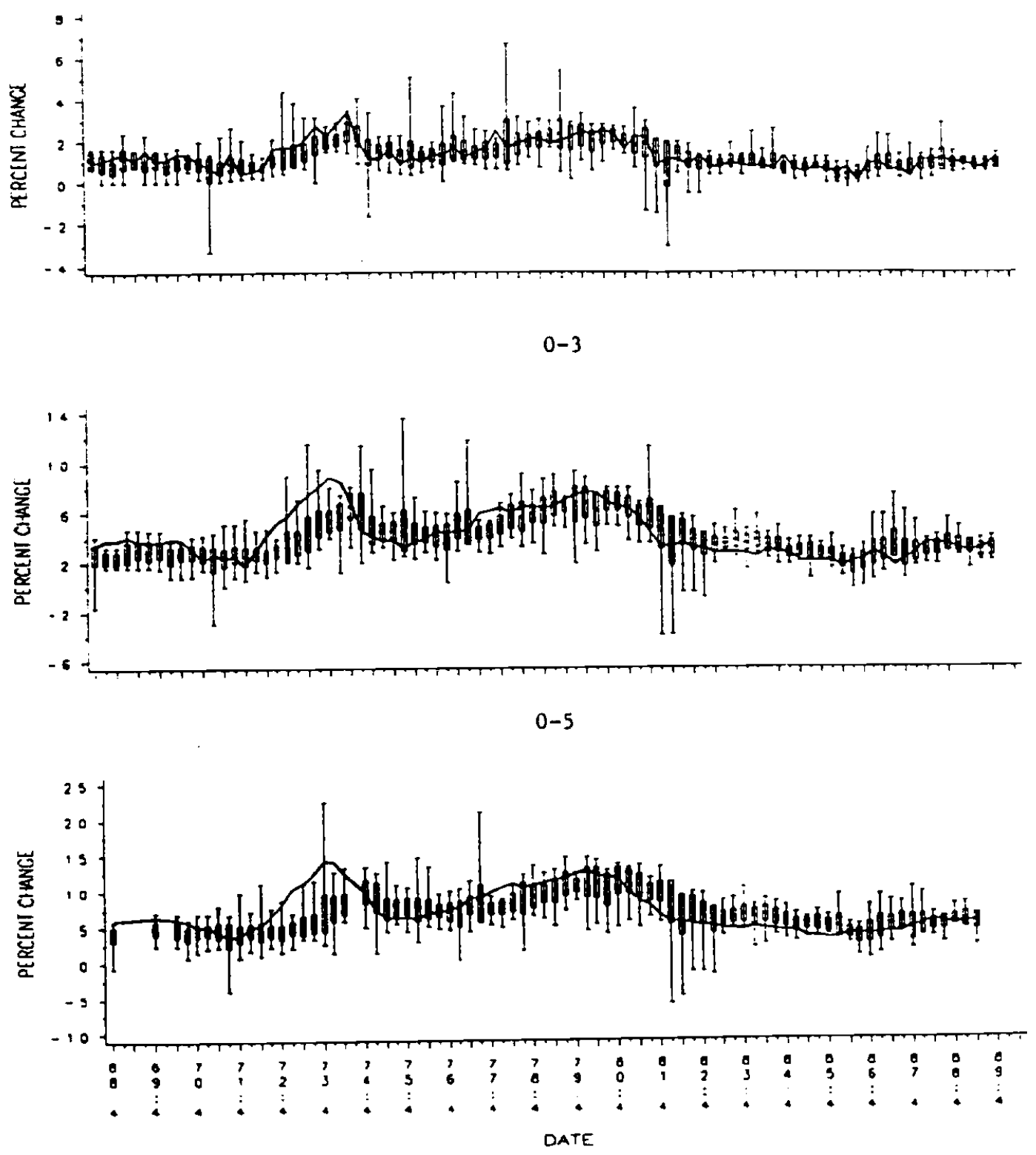
Chart 3

Forecast Distributions and Actual Values of Percent Changes in Nominal GNP. Three Horizons, 1968:4-1990:1

0-1

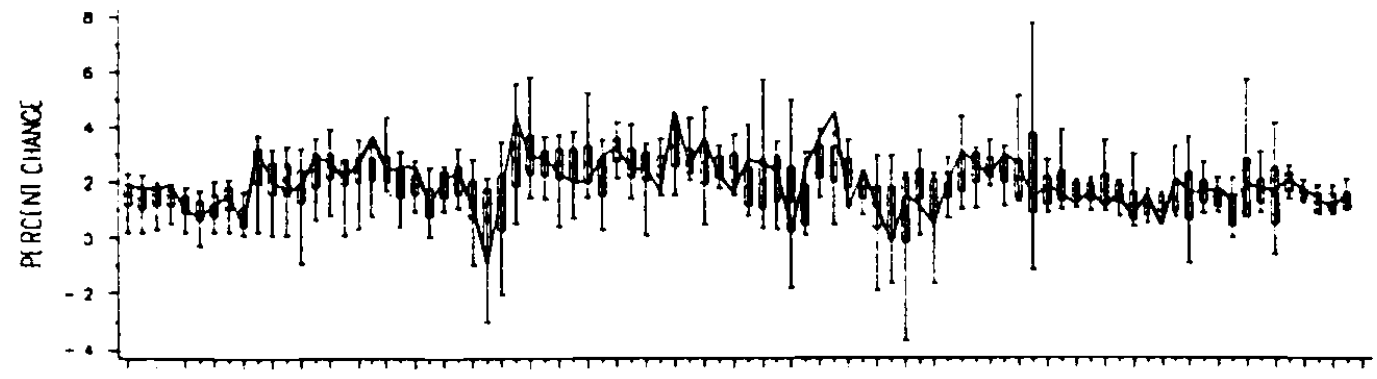

$0-3$

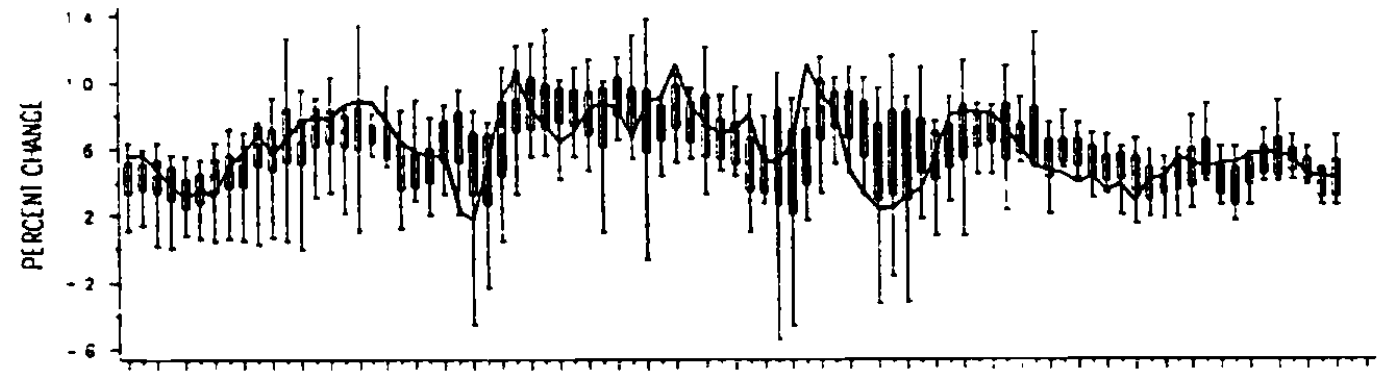

$0-5$

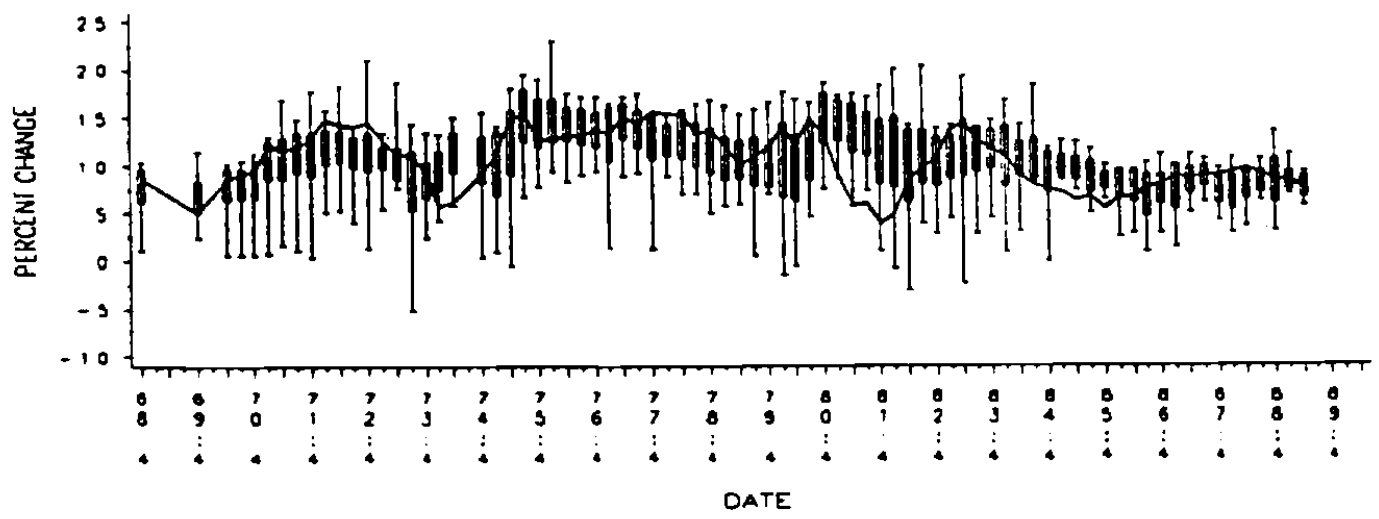


Table 1

L1st of Varlables Covered In the NBER-ASA Quarterly Economlc Outlook Surveys, 1968:4-1981:2 and 1981:3-1990:1

Line Varlable (Symbel)

Gross national product (GNP) CNP Impliclt price deflator (IPD) CNP In constant dollars (RGNP)

Industrlal production (IP)

Unemployment rate (UR)

Corporate profits after taxes (CP)

Plant and equipment expondicures (PE) \$bll. (N)

Privace nonfarm housing starts (HS) a.r..mll. (R)

Change in business Inventorles (CBI)\$bII.(N)

10 Consumer expenditures for durable

goods (CD)

11 Narlonal defense purchases (DEF)

12 Personal consumpion expenditures (PCE)

13 Nonresidential flxed Investment (NFI)

14 Residentlal flxed Investment (RFI)

15 Federal governent purchases (FGP)

16 State and local gove. purchases (SLGP)

17 Change in business Inventories (RCBI)

18 Net exports of goods and services (NX)

19 Consumer prlce Index (CPI)

20 Treasury blll race. 3-monch (TRB)

21 New high-grade corp. bond yleld (CBY)
Unit
(R. or N)

(2)

$\frac{\text { Seurceb }}{(3)} \frac{\text { Serles }}{\text { no c }}$

Sb11. (N)

b. y. $-100(\mathrm{~N})$

const.\$b11(R)

b.y. $-100(R)$

percent $(R)$

Sb11. (N)

Sb11. (N)

const.\$b11. (R) 1

const.\$b11. (R) 1

const. \$b11. (R)

const.\$b11. (R)

const. \$b11.

(R) 1

const.Sb11. (R)

const. Sb11. (R) 1255 perce

percent $(N) \quad 4 \quad 114$

percent(N) . $5 \quad 116$
Period Covered

$68: 4-81: 2$ 81:3-90:1 Eorm $^{4}$

(5) (6) (7)

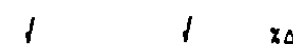

Abbreviatlons: b.y. - base year: a.r. - annual rate: const. $\$$ - In constant dollars.

$\iota_{R}$ - Real. N = nominal.

-Source 1 - U.S. Department of Commerce. Bureau of Economic Analysis (BEA). Source 2-U.S. Dept. of Commerce. Bureau of the Census. Source 3 - U.S. Department of Labor, Bureau of Labor Statlstics (BLS). Source 4 - Board of Governors of the Federal Reserve System (FRB). Source 5 - Clelbank and U.S. Department of Treasury.

'As IIsted in the Business Condtitions Digest (BCD) and the Survey of current Business (SBC).

¿As used In the computation of forecast arrors. 20-percentage change. 
Tabl. 2

NBER-ASA Quarterly Economic Outlook Surveys, All Forecasts and Sampled Forecasts. Selected Distributional Statistics, 1968-90 and Iwo Subperiods

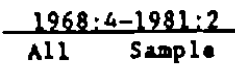
A11

$$
\longrightarrow
$$$$
\text { (3) }
$$

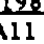

(3)

Sage:

ample

(4)

$\frac{1968: 4-1990: 1}{\text { A11 }}$

Number of survers

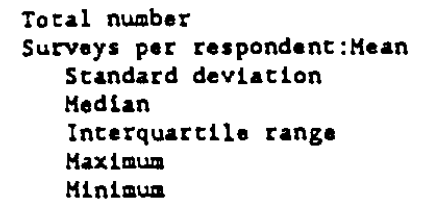

51
14.8
13.0
11
21
46
1

51
24.2
10.4
22
18
46
10

$\begin{array}{cc}35 & 35 \\ 10.3 & 20.8 \\ 9.9 & 7.5 \\ 6 & 20 \\ 14.8 & 9.5 \\ 35 & 35 \\ 1 & 10\end{array}$

$\begin{array}{ll}86 & 86 \\ 21.0 & 28.5 \\ 16.1 & 13.5 \\ 19 & 25 \\ 26 & 21 \\ 70 & 70 \\ 1 & 10\end{array}$

Number of Respondents

Total number
Respondents per survey:Mean
Standard deviacion
Median
Interquartile range
Maximum
Minimum

$\begin{array}{clcccc}136 & 86 & 74 & 29 & 159 & 111 \\ 45.8 & 40.8 & 21.7 & 17.2 & 39.0 & 36.8 \\ 14.5 & 11.3 & 5.9 & 3.3 & 15.9 & 14.1 \\ 44 & 42 & 21 & 18 & 37 & 34.5 \\ 24 & 16 & 10 & 6 & 26.2 & 22.5 \\ 86 & 61 & 33 & 22 & 78 & 67 \\ 22 & 20 & 10 & 9 & 12 & 12\end{array}$

Note: The counts refer to the forecasts one and two quarters ahead for the following varlables: 1968:4-1981:2 (51 surveys): Consumer expendicures for durable goods (CD): 1981:3-1990:1 (35 surveys): Nonresidential fixed Investment (NFI): 1968:4-1990:1 (86 surveys): Unemployent rate (UR). The sample includes the forecasters who participated in ac least 10 surveys in teras of these observations (see line 7). 


\section{Tablo 3}

Percentage Distributions of Respondents by Primary Afflliation.

Fout NBER-ASA Economlc Oitlook Surveys, 1968-80

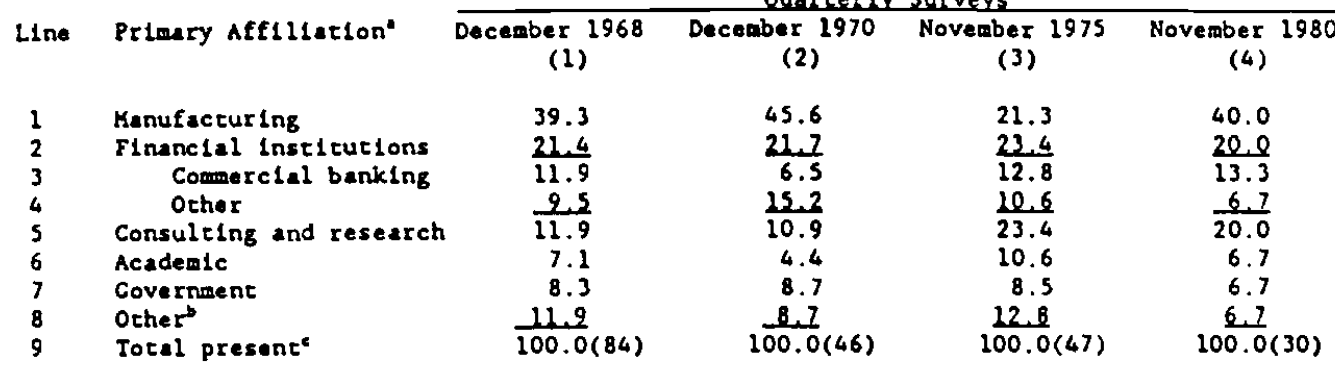

'As reported by the partlclpants in the given survey (those who did not respond to the question on primary afflilation are excluded).

Includes a very feu responses from labor unlon and trade associaclon economists, but malnly "not -lsewhere classifled." 1.e., not included in the caregorles listed above.

eTotal number of respondents is $11 s \mathrm{ted}$ In parentheses. The component percentages may not add up exactly to 100.0 because of rounding. 
Table 4

Average Ranks and Accuracy of Forecasting Mechods Used in the NBER-ASA Survays, 1968-81

\begin{tabular}{|c|c|c|c|c|c|c|c|}
\hline Line & Statistic & $\begin{array}{l}\text { Informal } \\
\text { GNP Model } \\
\text { (1) }\end{array}$ & $\begin{array}{l}\text { Eseno } \\
\text { Own } \\
(2)\end{array}$ & $\begin{array}{l}\text { re Models } \\
\text { Outside } \\
\text { (3) }\end{array}$ & $\begin{array}{l}\text { Leading } \\
\text { Indlcators } \\
\text { (4) }\end{array}$ & $\begin{array}{l}\text { Anticipations } \\
\text { Surveys } \\
\text { (5) }\end{array}$ & $\begin{array}{l}\text { Other } \\
\text { Mothods" } \\
\text { (6) }\end{array}$ \\
\hline $\begin{array}{l}1 \\
2 \\
3 \\
4\end{array}$ & $\begin{array}{l}\text { Percent Using } \\
\text { I Ranking First" } \\
\text { I Ranking Second } \\
\text { I Ranking Lover }\end{array}$ & $\begin{array}{r}75 \\
55 \\
13 \\
6\end{array}$ & $\begin{array}{r}24 \\
11 \\
7 \\
7\end{array}$ & $\begin{array}{r}48 \\
9 \\
15 \\
25\end{array}$ & $\begin{array}{l}62 \\
11 \\
29 \\
22\end{array}$ & $\begin{array}{r}57 \\
2 \\
21 \\
35\end{array}$ & $\begin{array}{r}16 \\
8 \\
4 \\
4\end{array}$ \\
\hline \multicolumn{8}{|c|}{ Average Boot Mean Souare Error" } \\
\hline $\begin{array}{l}5 \\
6 \\
7 \\
8\end{array}$ & $\begin{array}{l}\text { GNP. I changet } \\
\text { RGNP, I change } \\
\text { IPD. I change } \\
\text { UR, level }\end{array}$ & $\begin{array}{r}.96 \\
1.14 \\
.71 \\
.58\end{array}$ & $\begin{array}{r}1.09 \\
1.25 \\
.76 \\
.66\end{array}$ & $\begin{array}{r}.89 \\
1.05 \\
.72 \\
.52\end{array}$ & $\begin{array}{r}1.00 \\
1.24 \\
.79 \\
.62\end{array}$ & $\begin{array}{r}.99 \\
1.22 \\
.85 \\
.71\end{array}$ & $\begin{array}{r}1.15 \\
1.27 \\
.83 \\
.59\end{array}$ \\
\hline
\end{tabular}

"Write-in but often not specifled.

based on seven surveys 1968:4-1970:2 (496 repl1es), s1x surveys 1974:1-1975:2 (308 repl1es), and six surveys 1980:1-1981:2 (187 replles). The August 1969 survey uas held in connection ulth the ASA anrusl aeeting and stracted a very large number of raspondents (128. Including 46 regular panelists). Participation in the other surveys covered varled from 24 to 83 . The averages are valghted according to the numbers of the raplies.

"Most Important.

Ranks 3 to 6 (lease important).

-According to flrse-ranked aethod (tles for the flrst rank are not lncluded). Refers to 79 Individuals who partlcipated In at least 12 of the 46 quarterly surveys in the perlod $\mathrm{Erom} 1968: 4$ through 1980:1. Sae Zarnoulez 1983 for more detall.

'Symbols as defined in Table 1. 
Table 5

Mean Absolute Errors and Root Mean Square Errors of Forecasts of Nominal and Real GNP Growth and Inflation, Comparisons with Different Vintages of Target Data, 1968-90

\begin{tabular}{|c|c|c|c|c|c|c|c|c|c|c|c|}
\hline Line & $\begin{array}{l}\text { VIntage of } \\
\text { Actual Data" }\end{array}$ & $\begin{array}{c}\text { Gean } A \\
0-1 \\
(1)\end{array}$ & $0-2$ & $\begin{array}{c}\text { Errors } \\
0-3 \\
(3)\end{array}$ & $\begin{array}{l}\text { by Sp } \\
0-4 \\
(4)\end{array}$ & 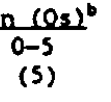 & $\begin{array}{c}\text { Boot Me } \\
0-1 \\
(6)\end{array}$ & $\begin{array}{l}0-2 \\
(7)\end{array}$ & $\begin{array}{l}0-3 \\
(8)\end{array}$ & $\begin{array}{l}\text { s. by } \\
0-4 \\
(9)\end{array}$ & $\begin{array}{l}\text { pancos } \\
0-5 \\
(10)\end{array}$ \\
\hline \multicolumn{12}{|c|}{ Gross Narlonal Product (CNP) } \\
\hline $\begin{array}{l}1 \\
2 \\
3 \\
4\end{array}$ & $\begin{array}{l}\text { 15-day } \\
45-d a y \\
\text { Early July } \\
\text { Late July }\end{array}$ & $\begin{array}{l}.59 \\
.62 \\
.65 \\
.69\end{array}$ & $\begin{array}{l}1.08 \\
1.12 \\
1.15 \\
1.17\end{array}$ & $\begin{array}{l}1.55 \\
1.60 \\
1.65 \\
1.66\end{array}$ & $\begin{array}{l}1.92 \\
1.99 \\
2.02 \\
2.03\end{array}$ & $\begin{array}{l}2.36 \\
2.48 \\
2.54 \\
2.52\end{array}$ & $\begin{array}{l}.77 \\
.86 \\
.85 \\
.89\end{array}$ & $\begin{array}{l}1.41 \\
1.45 \\
1.48 \\
1.50\end{array}$ & $\begin{array}{l}2.03 \\
2.07 \\
2.10 \\
2.10\end{array}$ & $\begin{array}{l}2.54 \\
2.58 \\
2.60 \\
2.60\end{array}$ & $\begin{array}{l}3.13 \\
3.20 \\
3.26 \\
3.23\end{array}$ \\
\hline $\begin{array}{l}5 \\
6 \\
7 \\
8\end{array}$ & $\begin{array}{l}\text { 15-day } \\
45-d a y \\
\text { Early July } \\
\text { Late July }\end{array}$ & $\begin{array}{l}.61 \\
.64 \\
.67 \\
.68\end{array}$ & $\begin{array}{l}1.06 \\
1.09 \\
1.09 \\
1.11\end{array}$ & $\begin{array}{l}1.51 \\
1.56 \\
1.57 \\
1.58\end{array}$ & $\begin{array}{l}1.96 \\
2.00 \\
1.99 \\
2.01\end{array}$ & $\begin{array}{l}2.44 \\
2.47 \\
2.46 \\
2.48\end{array}$ & $\begin{array}{l}.81 \\
.85 \\
.88 \\
.90\end{array}$ & $\begin{array}{l}1.40 \\
1.44 \\
1.44 \\
1.44\end{array}$ & $\begin{array}{l}2.04 \\
2.08 \\
2.07 \\
2.05\end{array}$ & $\begin{array}{l}2.70 \\
2.74 \\
2.69 \\
2.66\end{array}$ & $\begin{array}{l}3.35 \\
3.38 \\
3.33 \\
3.30\end{array}$ \\
\hline \multicolumn{12}{|c|}{ Implicit Price Deflater (IPD) } \\
\hline $\begin{array}{r}9 \\
10 \\
11 \\
12\end{array}$ & $\begin{array}{l}\text { 15-day } \\
45-d a y \\
\text { Early July } \\
\text { Late July }\end{array}$ & $\begin{array}{l}.40 \\
.42 \\
.42 \\
.41\end{array}$ & $\begin{array}{l}.71 \\
.77 \\
.77 \\
.79\end{array}$ & $\begin{array}{l}1.07 \\
1.16 \\
1.18 \\
1.21\end{array}$ & $\begin{array}{l}1.49 \\
1.63 \\
1.66 \\
1.70\end{array}$ & $\begin{array}{l}1.98 \\
2.14 \\
2.17 \\
2.21\end{array}$ & $\begin{array}{l}.50 \\
.54 \\
.53 \\
.53\end{array}$ & $\begin{array}{l}.92 \\
.99 \\
.99 \\
.99\end{array}$ & $\begin{array}{l}1.37 \\
1.50 \\
1.52 \\
1.53\end{array}$ & $\begin{array}{l}1.92 \\
2.10 \\
2.14 \\
2.16\end{array}$ & $\begin{array}{l}2.56 \\
2.79 \\
2.83 \\
2.84\end{array}$ \\
\hline
\end{tabular}

15-day: preliminary data released in the month following the target quarter of the forecast. 45-day: revised data released a month later. Early July: generally first July revislon: where this is not avallable, the preceding revision. Late July: generally second July revislon; where this is not available, the preceding revision.

Mean of the MaEs of the 1ndividual forecasts, where MEE $-1 / \Sigma\left|E_{t}\right| ; E_{t}-P_{t}-A_{t} ; P_{t}-$ predicted value; $A_{t}=$ actual value of the $g$ Iven vintage. The average errors refer to percent changes from quareer $t-1(0)$ to quarters $t, t+1, t+2, t+3$, and $t+4(1,2,3$, and 4$)$, respectively, where $t$ refers to the quarcerly date of che survey. Thus $0-1$ denotes the change frow quarter $t-1$ to quarter t; 0-2 denotes che change fron quarter $c-1$ co quarter $t+1$ : etc. All measures refer to percens change errors and are in percent.

Mean of the RMSEs of the Individual forecasts, where RMSE $-\left(1 / n \Sigma\left(P_{t}-A_{t}\right)\right.$. 
Tablo 6

Distrlbution of Mean Errors In Individual Forecests of Nominal and Real CNP Crowth and Inflation, 1968-90

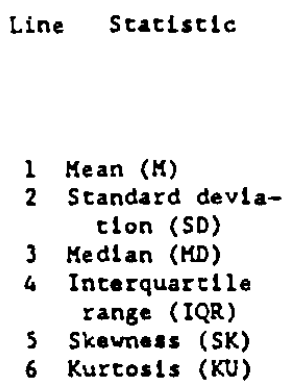

1 Mean ( $M$ )

Standard devlatIon (SD)

3 Medlan (HD)

4 Interquartlle range (IQR)

Skewness (SK)

6 Kurcosis (KU)

(3) (4)

(s)

(6)

(7)

(8)

(9)

Gross Naclonal Product (GNP)

$\begin{array}{rrrrrrrrr}-.09 & -.11 & -.11 & -.14 & -.30 & -.01 & .01 & .04 & .08 \\ .26 & .56 & .91 & 1.19 & 1.61 & .31 & .38 & .36 & .37 \\ -.05 & -.06 & .04 & .15 & .00 & .01 & .06 & .09 & .13 \\ .24 & .48 & .72 & .91 & 1.30 & .27 & .29 & .31 & .31 \\ -1.94 & -1.57 & -1.60 & -2.65 & -2.78 & -.55 & -1.41 & -1.64 & -1.92 \\ 12.14 & 12.42 & 11.90 & 12.81 & 13.80 & 10.89 & 8.49 & 8.50 & 8.66\end{array}$

\section{Gross Narlenal Product in Constanc Dollars (RGNP)}

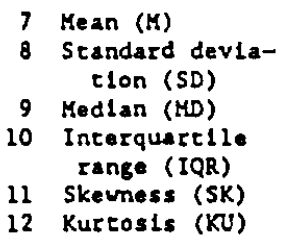

$\begin{array}{llllllll}-.01 & 09 & .25 & 45 & .48 & .10 & .16 & 22\end{array}$

$\begin{array}{lllllllll}.24 & .48 & .77 & 1.06 & 1.39 & .29 & .35 & .34 & .43\end{array}$

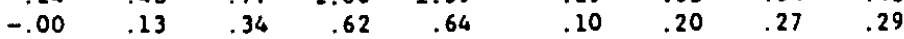

$\begin{array}{rrrrrrrrr}.27 & . .46 & .69 & .98 & 1.20 & .28 & .36 & .38 & .51 \\ -1.30 & -1.58 & -1.84 & -2.04 & -2.06 & -1.17 & -1.75 & -1.34 & -.89\end{array}$

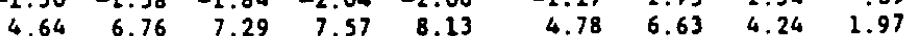

Imollate Price Deflacor (IPD)

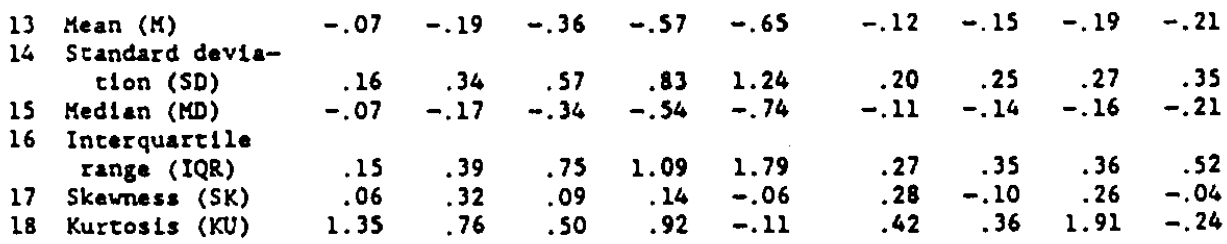

NOTE: Columns 1-5 refer to the errors In forecasts of average changes; columns 6-9 rofer to the errors in forecast of marglnal changes (for $0-1$, the average and marglnal changes are the same) $M E$, SD, $M D$, and $I Q R$ ( 11 nes $1-4,7-10$, and 13-16) are in percentage polnts; entrles for SK and KU (lines $5-6,11-12$, and 17-18) are dimenslonless ratlos. IQR - $Q_{3}-Q_{1}$ is the difference, thlrd quartlle minus flrst quartlle of the distrlbutlon (where $M D-Q_{2}$ ). SK $-\mu_{\mathrm{g}} / \sigma^{3}$ is the ratlo of the thlrd moment around the mean to the thlrd power of the sandard devlatlon SD - $O$. KU $\mu_{*} / 0^{\circ}$ is the ratlo of the fourth moment around the wean to the fourth power of SD. 
Table 7

Distribution of Mesn Absolute Errors In Individusl Forecasts of Nominal and Real GNP Growth and Inflacion, 1968-90

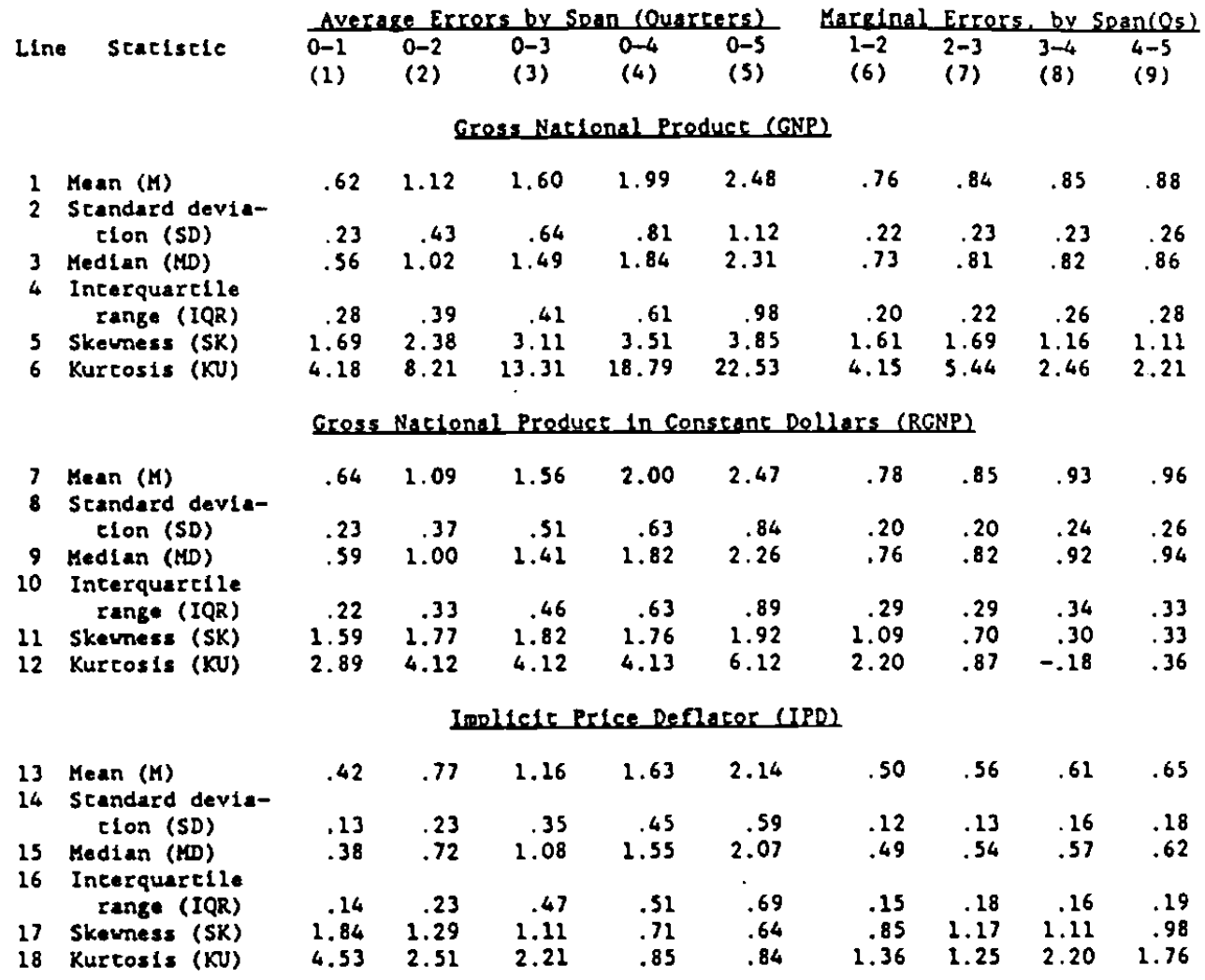

NOTE: See Table 6 . 
Table 8

Discribution of Root Mean Square Errors in Individual Forecass of Nominal and Real GNP Growth and Inflacion, 1968-90

Line Statistic

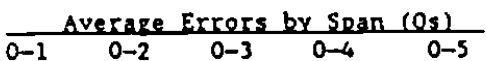

$\begin{array}{cccc}\text { Marginal Errors. by Spancos) } \\ 1-2 & 2-3 & 3-4 & 4-5\end{array}$

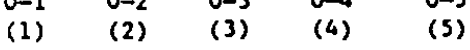

(6)

Gross National Produce (GNP)

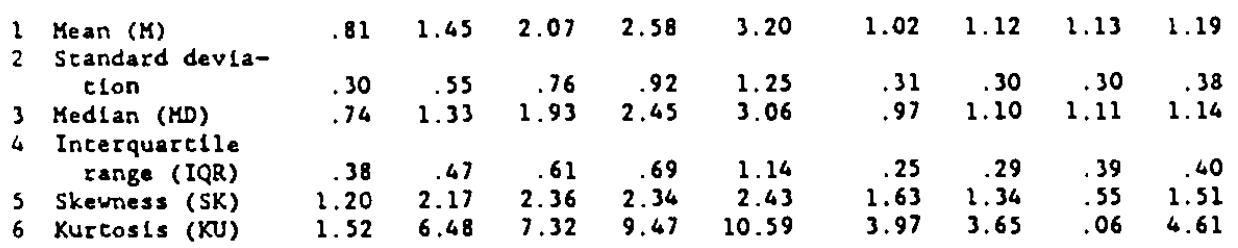

Gross Naclonal Produce in Constane Dollars (RGNP)

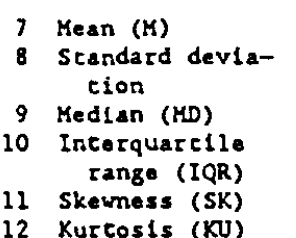

$\begin{array}{rrrrrrrrr}.85 & 1.44 & 2.08 & 2.74 & 3.38 & 1.05 & 1.16 & 1.27 & 1.32 \\ .35 & .49 & .67 & .82 & 1.04 & .31 & .28 & .33 & .38 \\ .77 & 1.32 & 1.90 & 2.57 & 3.12 & .98 & 1.15 & 1.26 & 1.31 \\ .34 & .54 & .80 & .83 & 1.18 & .38 & .39 & .50 & .51 \\ 1.78 & 1.54 & 1.54 & 1.30 & 1.22 & 1.37 & .47 & .18 & .46 \\ 4.02 & 3.42 & 3.29 & 2.04 & 1.90 & 3.08 & .20 & -.11 & .86\end{array}$

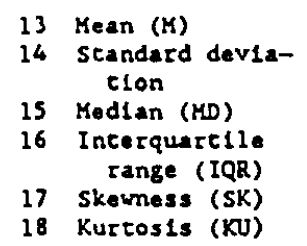

Inolicle Price Deflater (IPD)

NOTE: See Table 6 . 


\section{Table 9}

Individual and Group Mean Forecasts and Actual Values of Nowinal and Real GNP Growth and Inflation, Selected Statistics on Accuracy and Variability, 1968-90

Line $\operatorname{Span}(Q s)$
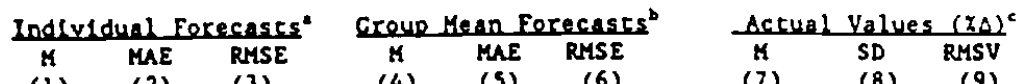

(1) (2) (3)

(4)

MAE

(6)

(7) (8) (9)

Gross National Product (GNP)

$\begin{array}{lrrrrrr}0-1 & -.09 & .62 & .81 & -.08 & .49 & .64 \\ 0-2 & -.11 & 1.12 & 1.45 & -.10 & .84 & 1.11 \\ 0-3 & -.11 & 1.60 & 2.07 & -.07 & 1.22 & 1.61 \\ 0-4 & -.14 & 1.99 & 2.58 & -.02 & 1.56 & 2.06\end{array}$

$1.98 \quad .96$

$4.00 \quad 1.00$

$6.07 \quad 2.14$

$8.20 \quad 2.63$

$\begin{array}{rrr}-.14 & 1.99 \quad 2.58\end{array}$

$-.09 \quad 1.91 \quad 2.51$

$10.38 \quad 3.12$

6.44

Gross Nactonal Product in Constane Dollars (RGNP)

$\begin{array}{rrr}-.01 & .64 & .85 \\ .09 & 1.09 & 1.44 \\ .25 & 1.56 & 2.08 \\ .45 & 2.00 & 2.74 \\ .48 & 2.47 & 3.38\end{array}$

$-.02 \quad .50 \quad .64$

$\begin{array}{lll}.61 & 1.03 & 1.20\end{array}$

$0-2$

.44

$.02 \quad .83 \quad 1.11$

1.23

$1.86 \quad 2.40 \quad 3.04$

$0-4$

$\begin{array}{lll}.16 & 1.17 & 1.61\end{array}$

$\begin{array}{lll}.33 & 1.42 & 2.05\end{array}$

$2.50 \quad 2.95 \quad 3.87$

Inplicle Price Deflater (IPD)

$\begin{array}{lllllllllll}11 & 0-1 & -.07 & .42 & .54 & -.04 & .28 & .35 & 1.36 & .65 & 1.51 \\ 12 & 0-2 & -.19 & .77 & .99 & -.12 & .55 & .70 & 2.74 & 1.25 & 3.01 \\ 13 & 0-3 & -.36 & 1.16 & 1.50 & -.22 & .84 & 1.13 & 4.16 & 1.84 & 4.55 \\ 14 & 0-4 & -.57 & 1.63 & 2.10 & -.34 & 1.21 & 1.64 & 5.60 & 2.43 & 6.10 \\ 15 & 0-5 & -.65 & 2.14 & 2.79 & -.37 & 1.63 & 2.23 & 7.08 & 3.03 & 7.70\end{array}$

"Means of the corresponding statistics for Individual forecasts (as shown In Table 6-8, 1ines 1.7, and 13, columns 1-5).

"Survey-by-survey "consensus" forecasts based on the sampled data, as explained in the text

45-day estimates, as used In tables 6-8. RHSV - root mean square value computed as $\sqrt{\left.\mid(M E)^{2}+(S D)^{2}\right]}$.

NOTE: On the symbols used, see previous tables and text. 
Table 10

Individual to Group Mean Ratios of Root Mean Square Errors.

Selected Distributional Statistics for Forecasts of Nominal and

Real GNP Growth and Inflation, 1968-90
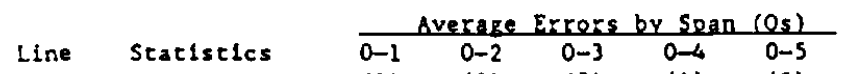

$\begin{array}{ccccc}\text { Margloal Errors, bv } \operatorname{Sran}(0 s) \\ 1-2 & 2-3 & 3-4 & 4-5\end{array}$

(1) (2)

(3)

(4)

(5)

(6) (7)

(8)

(9)

Gress National Product (GNP)

1 Lowest-error fore-

case (MIN)

2 First quartile $\left(0_{1}\right), .84$

3 Median (MD)

.72
1.07

1. 22

$1.23 \quad 1.19$

1.08
1.20

.78
1.03

.85

1.05

$\begin{array}{ll}.85 & 1.85 \\ 1.05 & 1.06\end{array}$

$1.15 \quad 1.11 \quad 1.13$

5 Highest-error

7.34

5.35

5.90

$5.78 \quad 5.57$

3.12

1.25

$1.28 \quad 1.32$

forecast (MAX)

Gross Natienal Produce in Constanc Dollars (RGNP)

6 Lowest-error fore-

7 First quartle $\left(Q_{1}\right) 1.11$

First quarel

Median (MD) $\quad 1.30$

Ihlrd quartile $\left(Q_{3}\right) 1.58$

HIghest-error

1.58

.63
1.09

1.09
1.20

.77

1.04

.82

$1.17 \quad 1.14$

.82

.76
1.06

1.06

1.06

$\begin{array}{lll}40 & 1.36 \quad 1.38 & 1.14\end{array}$

$1.31 \quad 1.30$

$1.14 \quad 1.13 \quad 1.11$

forecast (MAX)

4.84

3.87

6.45

$5.76 \quad 6.69$

3.29

$3.77 \quad 4.40$

Imolicit Prtce Deflater (IPD)

11 Lowest-error fore-

case (MIN)

$\begin{array}{ll}\text { case (MIN) } & .83 \\ \text { Flrst quarclle }\left(Q_{1}\right) & 1.13 \\ \text { Median (MD) } & 1.24\end{array}$

$.88 \quad .82$

Median (MD)

$\begin{array}{rr}.88 & .82 \\ 1.03 & 1.02\end{array}$

.55 .53

.53
1.00

.67

1.21

1.02
1.15

.99
1.12
1.27

1.03

1.17

$\begin{array}{lll}.88 & .81 \quad .71\end{array}$

HIghest-error

Q) $\begin{aligned} & 1.24 \\ & 1.56\end{aligned}$

$1.39 \quad 1.34$

$1.27 \quad 1.23$

1.39

$1.121 .11 \quad 1.11$

forecase (MAX)

3.55

$4.30 \quad 3.55$

$3.74 \quad 3.37$

3.27

$2.68 \quad 2.86$

3.71

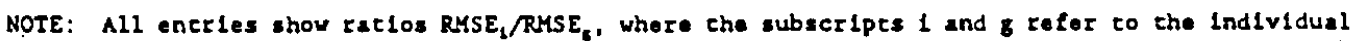
and group mean forecasts. respectively. MIN and MAX denote che lowese and hlghesc raclos in each distrbution. $Q_{1}$ and $Q_{j}$ denote the lower and upper quarclle ratlos, and MD denote the median raclos. 
Table 11

Ranking Forecesters According to Their Accurecy in Predicting Nominal and Real GNP and Inflation Rates, Selected Measures, 1968-1990
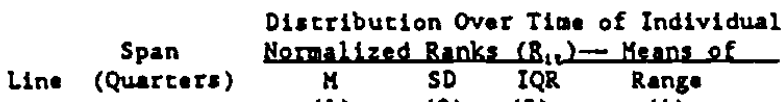

Distribution Across Individuals of Mean

\begin{tabular}{cccccc}
\multicolumn{7}{c}{ Nomald } & MEd Ranks & $\left(R_{1}\right)$ \\
\hline SD & MIN & $Q_{1}$ & MD & $Q_{3}$ & MAX \\
(5) & $(6)$ & (7) & (B) & (9) & (10)
\end{tabular}

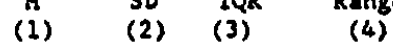

(5)

(6) (7) (B)

(10)

Gross Natienal Produce (CNP)

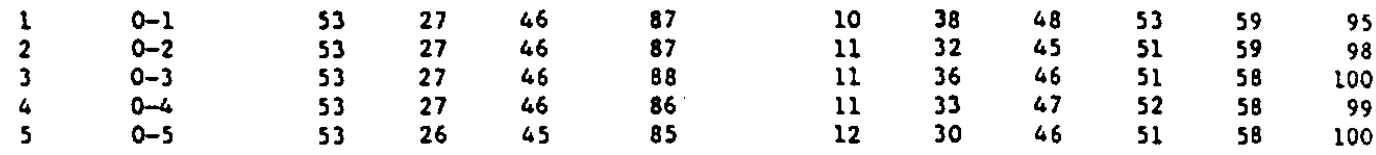

Gross Naclonal Produce in Constant Dellars (RGNP)

\begin{tabular}{|c|c|c|c|c|c|c|c|c|c|c|}
\hline $\begin{array}{r}6 \\
7 \\
8 \\
9 \\
10\end{array}$ & $\begin{array}{l}0-1 \\
0-2 \\
0-3 \\
0-4 \\
0-5\end{array}$ & $\begin{array}{l}52 \\
52 \\
52 \\
52 \\
52\end{array}$ & $\begin{array}{l}28 \\
28 \\
28 \\
28 \\
28\end{array}$ & $\begin{array}{l}50 \\
47 \\
47 \\
48 \\
48\end{array}$ & $\begin{array}{l}90 \\
89 \\
88 \\
88 \\
86\end{array}$ & $\begin{array}{r}9 \\
10 \\
9 \\
9 \\
10\end{array}$ & $\begin{array}{l}29 \\
30 \\
35 \\
34 \\
31\end{array}$ & $\begin{array}{l}47 \\
47 \\
46 \\
45 \\
45\end{array}$ & $\begin{array}{l}52 \\
51 \\
51 \\
51 \\
51\end{array}$ & $\begin{array}{l}56 \\
57 \\
57 \\
58 \\
57\end{array}$ \\
\hline \multicolumn{11}{|c|}{ Inolfeis Price Deflacer (IPD) } \\
\hline $\begin{array}{l}11 \\
12 \\
13 \\
14 \\
15\end{array}$ & $\begin{array}{l}0-1 \\
0-2 \\
0-3 \\
0-4 \\
0-5\end{array}$ & $\begin{array}{l}59 \\
56 \\
55 \\
54 \\
54\end{array}$ & $\begin{array}{l}28 \\
28 \\
28 \\
28 \\
27\end{array}$ & $\begin{array}{l}48 \\
48 \\
47 \\
46 \\
46\end{array}$ & $\begin{array}{l}89 \\
89 \\
88 \\
88 \\
86\end{array}$ & $\begin{array}{l}10 \\
10 \\
10 \\
10 \\
11\end{array}$ & $\begin{array}{l}40 \\
39 \\
33 \\
29 \\
29\end{array}$ & $\begin{array}{l}52 \\
49 \\
48 \\
48 \\
45\end{array}$ & $\begin{array}{l}57 \\
56 \\
54 \\
54 \\
54\end{array}$ & $\begin{array}{l}65 \\
62 \\
60 \\
60 \\
59\end{array}$ \\
\hline
\end{tabular}

NOTE: The basic unit of mesurement is the norwalized rank $R_{12}-100\left(r_{12} / r_{q}\right)$. where re $r_{2 t}$ rank of the 1-th forecaster in time $t$ set of predictions for given variable and span, and $n_{2}-$ number of forecasters in the same set. The ranks are. assigned according to the squared errors $(P-A)^{2}$, frod the sabllest to lergest. The entries in colums $1-4$ represent the means of the sumary besures for the distributions of the individuals' ranks over time (e.g.. M in column 1

refers to $\bar{R}-1 / n \sum_{1} R_{1}$. where $R_{1}-1 / m F_{t} R_{t}$; simflarly for the standard deviations in colums 2. etc.) The entries in colums 5-10 cheracterize the distributions across the individuals of $R_{1}$. All statistics are rounded off, with no decials shown. For symbols. see the preceding tables and text. 
Table 12

Respondonts to NBER-ASA Survoys Ranked According to the Accuracy of Their Forecasts of Noainal and Real GNP Groweh and IPD Inflation Rates: Cortelations Among the Ranks, Across Variables and Horizons.

$1968-1990$

\begin{tabular}{|c|c|c|c|c|c|c|}
\hline \multirow[t]{2}{*}{ Llne } & \multirow[t]{2}{*}{ Vartables } & \multicolumn{5}{|c|}{ Correlaced for Forecest Hortzons (In ouncers) } \\
\hline & & $0=1$ & $0=2$ & $0-3$ & $0-4$ & $0-5$ \\
\hline & & (1) & (2) & (3) & (4) & (5) \\
\hline \multirow{5}{*}{$\begin{array}{l}1 \\
2 \\
3\end{array}$} & GNP, RGNP & .73 & .74 & .68 & .64 & \\
\hline & GNP, IPD & .56 & .64 & .68 & .59 & .59 \\
\hline & RGNP. IPD & .47 & .52 & .54 & .51 & .42 \\
\hline & \multirow[t]{2}{*}{ Horizons } & \multicolumn{3}{|c|}{ correlaced for Vurlables } & & \\
\hline & & $\overline{G N P}$ & BGNP & IPD & & \\
\hline 4 & $0-1,0-2$ & .82 & .77 & .79 & & \\
\hline 5 & $0-1,0-3$ & .04 & .68 & .65 & & \\
\hline 6 & $0-1,0-4$ & .68 & .67 & .51 & & \\
\hline 7 & $0-1,0-5$ & .73 & .62 & .47 & & \\
\hline 8 & $0-2,0-3$ & .87 & .87 & .83 & & \\
\hline 9 & $0-2,0-4$ & .75 & .74 & .75 & & \\
\hline 10 & $0-2,0-5$ & .79 & .72 & .67 & & \\
\hline 11 & $0-3,0-4$ & .92 & .86 & .92 & & \\
\hline 12 & $0-3$, 0-5 & .87 & .80 & .86 & & \\
\hline 13 & $0-4,0-5$ & .92 & .86 & .92 & & \\
\hline
\end{tabular}

NOTE: The correlations are based on the nomalized ranks described in the toxt and Table 11 . On the symals used, see previous cables and cext. 
Table 13

BVAR Forecasts (Two Varlants) vs. Individual Forecasts from NBER-ASA Surveys. Summary Measures of Error and RMSE Rarlos for CNP. RCNP. and IPD.

1968-90

Line $\operatorname{Span(Qs)}$

\begin{tabular}{cccccccc}
\multicolumn{3}{c}{ BVAR Forecasts " } & \multicolumn{3}{c}{ RMSE Racios. Individual zo BVAR Ferecasts } \\
\hline M & MAE & RMSE & MIN & $Q_{1}$ & MD & $Q_{3}$ & MAX \\
(1) & (2) & (3) & (4) & (5) & (6) & (7) & (8)
\end{tabular}

Gross National Product (CNP)

Vartanes

$\begin{array}{ll}1 & 0-1 \\ 2 & 0-2 \\ 3 & 0-3 \\ 4 & 0-4 \\ 5 & 0-5\end{array}$

$\begin{array}{ll}0-1 & .07 \\ 0-2 & .28 \\ 0-3 & .26 \\ 0-4 & .33 \\ 0-5 & .38\end{array}$

$.84 \quad 1.11$

$1.47 \quad 1.92$

$2.08 \quad 2.73$

$.33 \quad 2.59 \quad 3.45$

$\begin{array}{ll}.32 & .54 \\ .34 & .57\end{array}$

$\begin{array}{llll}54 & .66 & .91 & 1.89\end{array}$

$\begin{array}{lllll}.24 & .59 & .68 & .85 & 2.6 \\ .25 & .54 & .67 & .82 & 2.41\end{array}$

yarlane B

$\begin{array}{rr}6 & 0-1 \\ 7 & 0-2 \\ 8 & 0-3 \\ 9 & 0-4 \\ 10 & 0-5\end{array}$

000

14

ก.a. ก.

.a. n.a. n.a. n.a. $\begin{array}{rrr}.07 & .87 & 1.14 \\ .17 & 1.49 & 1.96\end{array}$

$\begin{array}{lll}.26 & 2.12 & 2.80\end{array}$

$\begin{array}{lll}.33 & 2.63 & 3.53\end{array}$

$.43 \quad .75$

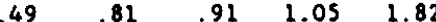

$.63 \quad .86$

$96 \quad 1.13-2.29$

Gross National Product in Constant Dollars (RGNP)

\section{Varlanes}

\begin{tabular}{llllllllll}
11 & $0-1$ & .08 & .78 & 1.00 & .29 & .59 & .75 & .99 & 3.65 \\
12 & $0-2$ & .20 & 1.09 & 1.51 & .36 & .73 & .89 & 1.07 & 2.25 \\
13 & $0-3$ & .28 & 1.53 & 2.03 & .43 & .79 & .93 & 1.13 & 2.36 \\
14 & $0-4$ & .35 & 1.76 & 2.34 & .52 & .96 & 1.08 & 1.29 & 2.74 \\
15 & $0-5$ & .39 & 2.05 & 2.64 & .41 & 1.00 & 1.13 & 1.40 & 2.90 \\
& \multicolumn{7}{c}{ Vorlanc 8}
\end{tabular}

$\begin{array}{ll}16 & 0-1 \\ 17 & 0-2 \\ 18 & 0-3 \\ 19 & 0-4 \\ 20 & 0-5\end{array}$

$\begin{array}{lll}0 & 0 & 0 \\ .09 & .78 & 1.01 \\ .20 & 1.11 & 1.53 \\ .29 & 1.56 & 2.06 \\ .36 & 1.79 & 2.38\end{array}$

$\begin{array}{rrrrr}\text { n.a. n.a. n.a. } & \text { n.a. } & \text { n.a. } \\ 48 & 83 & 96 & 1.16 & 3.87\end{array}$

$\begin{array}{lllllllll}0-2 & .09 & .78 & 1.01 & .48 & .83 & .96 & 1.16 & 3.87 \\ 0-3 & .20 & 1.11 & 1.53 & .46 & 1.00 & 1.15 & 1.33 & 2.85 \\ 0-4 & .29 & 1.56 & 2.06 & .63 & 1.06 & 1.19 & 1.37 & 3.68\end{array}$

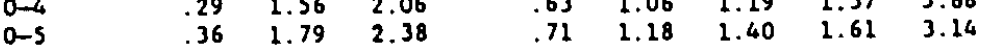

Imolleite Price Deflacer (IPD)

Varlanes

$\begin{array}{llllllllll}21 & 0-1 & .05 & .37 & .48 & .55 & .81 & .97 & 1.16 & 3.68 \\ 22 & 0-2 & .11 & .76 & .97 & .49 & .76 & .87 & 1.02 & 3.62 \\ 23 & 0-3 & .17 & 1.18 & 1.53 & .40 & .72 & .86 & 1.02 & 2.95 \\ 24 & 0-4 & .23 & 1.65 & 2.18 & .38 & .72 & .87 & 1.04 & 2.74 \\ 25 & 0-5 & .28 & 2.19 & 2.94 & .37 & .72 & .86 & 1.06 & 3.94\end{array}$


Line $\operatorname{Span}(Q s)$

\begin{tabular}{ccc}
\multicolumn{4}{c}{ BVAR Forecasts: } \\
\hline M MAE RHSE \\
(1) (2)
\end{tabular}

RMSE Raties. Individual to BVAR Ferecases'
$\begin{array}{lllll}\text { MIN } & Q_{1} & M D & Q_{3} & \operatorname{MaX} \\ \text { (4) } & \text { (5) } & \text { (6) } & \text { (7) } & \text { (8) }\end{array}$

Varianc B

$\begin{array}{rrrrrrrrrr}26 & 0-1 & 0 & 0 & 0 & \text { n. . } & \text { n.a. } & \text { n.a. } & \text { n.a. } & \text { n.a. } \\ 27 & 0-2 & .04 & .37 & .47 & .70 & 1.07 & 1.23 & 1.51 & 3.69 \\ 28 & 0-3 & .10 & .76 & .97 & .71 & .95 & 1.09 & 1.30 & 2.83 \\ 29 & 0-4 & .16 & 1.17 & 1.53 & .57 & .98 & 1.10 & 1.24 & 2.56 \\ 30 & 0-5 & .21 & 1.64 & 2.18 & .61 & .95 & 1.08 & 1.24 & 4.23\end{array}$

"Based on a model with five varlables (RCNP. IPD, M2, LI, and TBR) and six quarterly lags, estimated sequentially with presencly avallable data. Variant $A$ assumes that the last known values of the variables to be predicted refar to the quarter $t-1$ (denoted 0 ): varlant $B$ assumes that they refer to the current quartar $t$ (denoted 1).

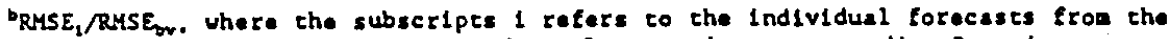
NBER/ASA surveys and the subscript bv refera to the corresponding Bayesian victor autoregrassive (BVAR) forecasts (varlant A In lines 1-5, 11-15, and 21-25: variant $B$ In lines 6-10, 16-20, and 26-30). MIN and MAX denote the lovest and highest

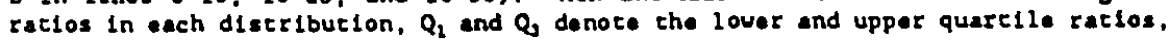
and $M$ denote the wedian ratios. 
Table 14

Individual, Group Mean, and BVAR Forecasts of Percent Changes in GNP, RCNP, and IPD, Selected Comparisons by Span and Subperiods. 1968-79 and 1979-90

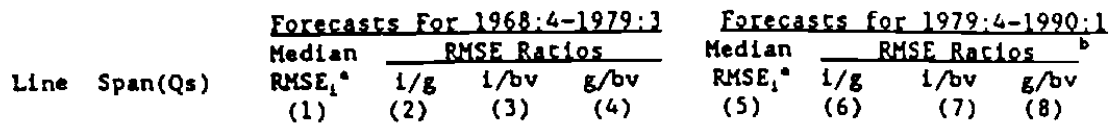

Gross National Product (CNP)

$\begin{array}{llllllllll}1 & 0-1 & .60 & 1.34 & .53 & .48 & .86 & 1.15 & .79 & .71 \\ 2 & 0-2 & 1.13 & 1.20 & .58 & .50 & 1.56 & 1.17 & .78 & .69 \\ 3 & 0-3 & 1.68 & 1.18 & .60 & .51 & 2.23 & 1.18 & .81 & .70 \\ 4 & 0-4 & 2.04 & 1.21 & .60 & .49 & 3.08 & 1.15 & .81 & .71 \\ 5 & 0-5 & 2.24 & 1.19 & .51 & .47 & 3.80 & 1.18 & .82 & .70\end{array}$

Gross National Produce in Constant Dollars (RGNP)

$\begin{array}{rrrrrrrrrr}6 & 0-1 & .69 & 1.29 & .62 & .57 & .80 & 1.20 & .88 & .76 \\ 7 & 0-2 & 1.25 & 1.18 & .78 & .69 & 1.34 & 1.15 & 1.01 & .82 \\ 8 & 0-3 & 1.87 & 1.17 & .85 & .76 & 1.80 & 1.15 & 1.03 & .86 \\ 9 & 0-4 & 2.59 & 1.14 & .99 & .84 & 2.30 & 1.16 & 1.16 & .94 \\ 10 & 0-5 & 3.13 & 1.13 & 1.04 & .92 & 2.84 & 1.15 & 1.24 & .99\end{array}$

Imolicis Price Deflater (IPD)

$\begin{array}{llllllllll}11 & 0-1 & .50 & 1.29 & .90 & .73 & .37 & 1.22 & .87 & .74 \\ 12 & 0-2 & 1.00 & 1.14 & .90 & .80 & .64 & 1.31 & .70 & .56 \\ 13 & 0-3 & 1.57 & 1.08 & .89 & .84 & .93 & 1.28 & .60 & .51 \\ 14 & 0-4 & 2.25 & 1.04 & .92 & .89 & 1.37 & 1.26 & .64 & .50 \\ 15 & 0-5 & 3.06 & 1.05 & .99 & .95 & 1.94 & 1.25 & .63 & .49\end{array}$

Median of the root mean squere errors of the individual forecasts from the quarerly NBER-ASA surveys.

bretio of the wedian RMSE of the Individusl forecasts (1) to the RMSE of the corresponding group mean forecast (g) in coluans 2 and 6 . Ratio of the wedian RMSE of the individual forecasts (1) to the RMSE of the corresponding BVAR model forecast (by) in columin 3 and 7. Ratio of the RMSE of the group dean forecast (g) to the RYSE of the corrtesponding BVAR model (bv) in columns 4 and 8. 
Table 15

Selected Measures of Forecast Accuracy and Accual Values, Percent Changes In Industrlal Production and Corporace Proflts, by Span, 1968-90

LIne Span(Qs) $\frac{\text { Mean Error }}{\mathrm{H}}$

\begin{tabular}{ccccc}
\multicolumn{5}{c}{ Roor Nean Souare Error } \\
\hline H & SD & MD & SK & KU \\
(4) & (5) & (6) & (7) & (B)
\end{tabular}

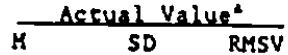

(1) (2) (3)

Index of Induscrial Preduacten (IP)

$\begin{array}{llll}0-1 & .04 & .58 & .02 \\ 0-2 & .83 & 1.07 & .30 \\ 0-3 & .67 & 1.58 & .6 \\ 0-4 & 1.04 & 1.90 & 1.09 \\ 0-5 & 1.06 & 2.27 & 1.3\end{array}$

$\begin{array}{lllll}1.66 & 1.08 & 1.54 & 7.89 & 73.16\end{array}$

$\begin{array}{lllll}3.13 & 1.80 & 2.93 & 7.66 & 69.68\end{array}$

$\begin{array}{lllll}4.52 & 2.10 & 4.26 & 6.28 & 52.71\end{array}$

$5.45 \quad 1.35 \quad 5.34 \quad 6.28050$

$6.19 \quad 1.37 \quad 6.02 \quad .36 \quad 1.05$

(9)

(10)

(11)

Cerporate Profles afcer Taxes (CP)

$\begin{array}{rrrrrrrrrrrrrr}6 & 0-1 & .26 & 2.49 & -.02 & 9.50 & 2.03 & 9.39 & .04 & 1.08 & 1.33 & 7.36 & 7.48 \\ 7 & 0-2 & 1.00 & 4.58 & .76 & 14.42 & 2.86 & 14.71 & -.39 & 1.95 & 2.78 & 11.13 & 11.47 \\ 8 & 0-3 & 2.58 & 6.54 & 2.64 & 18.58 & 3.32 & 18.75 & -.14 & 4.23 & 4.17 & 13.54 & 14.17 \\ 9 & 0-4 & 4.11 & 8.20 & 4.39 & 22.38 & 4.29 & 22.58 & .05 & 7.34 & 5.55 & 15.56 & 16.52 \\ 10 & 0-5 & 6.29 & 9.66 & 6.41 & 26.30 & 4.94 & 26.47 & .93 & 9.07 & 7.01 & 17.82 & 19.15\end{array}$

Refers to the perlod 1970:1-1989:4.

based on the second revision of the monthly data.

'Based on the first July revision of the quarterly data. 
Table 16

Individual, Group Mean, and BVAR Forecasts of Percent Changes in Industrial Production and Corporate Profics. Selected Comparisons. by Span. 1968-90

\begin{tabular}{|c|c|c|c|c|c|c|c|c|c|}
\hline \multirow[b]{2}{*}{ Line } & \multirow[b]{2}{*}{$\operatorname{Span}(Q s)$} & \multirow{2}{*}{$\begin{array}{l}\text { Group Mean } \\
\text { RMSE } \\
\text { (1) }\end{array}$} & \multicolumn{3}{|c|}{ RMSE RaCles N/R } & \multirow{2}{*}{$\begin{array}{l}\text { BVAR" } \\
\text { RMSE } \\
\text { (5) }\end{array}$} & \multicolumn{2}{|c|}{ RMSE Ratios } & Lov \\
\hline & & & $\begin{array}{l}Q_{1} \\
(2)\end{array}$ & $\begin{array}{l}M D \\
(3)\end{array}$ & $\begin{array}{l}Q_{3} \\
(4)\end{array}$ & & $\begin{array}{l}Q_{1} \\
(6)\end{array}$ & $\begin{array}{l}M D \\
(7)\end{array}$ & $\begin{array}{l}Q_{3} \\
(8)\end{array}$ \\
\hline \multicolumn{10}{|c|}{ Index of Industrial Production (IP) } \\
\hline $\begin{array}{l}1 \\
2 \\
3 \\
4 \\
5\end{array}$ & $\begin{array}{l}0-1 \\
0-2 \\
0-3 \\
0-4 \\
0-5\end{array}$ & $\begin{array}{l}1.17 \\
2.44 \\
3.50 \\
4.55 \\
6.16\end{array}$ & $\begin{array}{l}1.13 \\
1.06 \\
1.07 \\
1.06 \\
1.05\end{array}$ & $\begin{array}{l}1.26 \\
1.16 \\
1.16 \\
1.13 \\
1.13\end{array}$ & $\begin{array}{l}1.54 \\
1.30 \\
1.28 \\
1.24 \\
1.26\end{array}$ & $\begin{array}{l}1.56 \\
2.83 \\
3.66 \\
4.25 \\
4.78\end{array}$ & $\begin{array}{r}.85 \\
.90 \\
.99 \\
1.04 \\
1.04\end{array}$ & $\begin{array}{l}1.00 \\
1.04 \\
1.20 \\
1.25 \\
1.21\end{array}$ & $\begin{array}{l}1.32 \\
1.45 \\
1.58 \\
1.74 \\
1.66\end{array}$ \\
\hline \multicolumn{10}{|c|}{ Corporate Profits After Taxes $(C P)^{c}$} \\
\hline $\begin{array}{r}6 \\
7 \\
8 \\
9 \\
10\end{array}$ & $\begin{array}{l}0-1 \\
0-2 \\
0-3 \\
0-4 \\
0-5\end{array}$ & $\begin{array}{r}9.24 \\
13.68 \\
17.36 \\
20.98 \\
24.41\end{array}$ & $\begin{array}{l}1.00 \\
1.01 \\
1.00 \\
1.00 \\
.98\end{array}$ & $\begin{array}{l}1.08 \\
1.08 \\
1.06 \\
1.06 \\
1.05\end{array}$ & $\begin{array}{l}1.14 \\
1.16 \\
1.14 \\
1.14 \\
1.12\end{array}$ & $\begin{array}{r}7.22 \\
11.22 \\
14.35 \\
16.62 \\
19.16\end{array}$ & $\begin{array}{l}1.25 \\
1.15 \\
1.14 \\
1.18 \\
1.14\end{array}$ & $\begin{array}{l}1.41 \\
1.32 \\
1.29 \\
1.31 \\
1.33\end{array}$ & $\begin{array}{l}1.58 \\
1.49 \\
1.44 \\
1.48 \\
1.51\end{array}$ \\
\hline
\end{tabular}

-For IP: Based on a model with six varlables (RGNP. IPD, M2, LI, TBR, and IP) and six quarterly lags, esclosed sequentially with presently avallable daca. For CP: Based on a model with s $1 x$ varlables (RGNP, IPD, M2, LI, TBR, and CP) and six quarterly lags, estlmated sequentlally with presently avallable data. BVAR varlane $A$ is used throughout.

Based on the second revision of the monthly daca.

'Based on the first July revision of the quarterly daca. 
Tab1. 17

Individual. Croup Mean, and BVAR Forecasts of Percent Changes in Industrial Production and Corporite Proflts. Selected Comparisons. by Span and Subperlod, 1968-79 and 1979-90

Eerecasts For 1968:4-1979:3 Median

RMSE $1 / 8 \quad 1 / \mathrm{OV} \quad \mathrm{g} / \mathrm{BV}$

(1)

(3)

(4)

Eorecasts for 1979:4-1990:1 Medlan

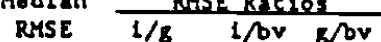

(5)

(6)

(7) (8)

\section{Index of Induscrial Produccion (IP)}

\begin{tabular}{rrrrrrrrrrr}
1 & $0-1$ & 1.65 & 1.23 & 1.00 & .91 & 1.49 & 1.30 & 1.22 & .83 \\
2 & $0-2$ & 2.95 & 1.16 & 1.01 & .92 & 3.13 & 1.09 & 1.42 & 1.07 \\
3 & $0-3$ & 4.17 & 1.17 & 1.09 & .95 & 4.54 & 1.11 & 1.65 & 1.21 \\
4 & $0-4$ & 4.96 & 1.14 & 1.14 & 1.00 & 5.84 & 1.10 & 1.70 & 1.29 \\
5 & $0-5$ & 5.37 & 1.18 & 1.03 & 1.28 & 6.98 & 1.08 & 1.64 & 1.35 \\
\multicolumn{8}{c}{ Corperate Profics Afrer Taxes (CP) } \\
6 & $0-1$ & 9.13 & 1.06 & 1.48 & 1.40 & 10.08 & 1.06 & 1.37 & 1.20 \\
7 & $0-2$ & 14.12 & 1.08 & 1.32 & 1.25 & 15.06 & 1.05 & 1.44 & 1.25 \\
8 & $0-3$ & 17.62 & 1.05 & 1.17 & 1.13 & 19.06 & 1.08 & 1.47 & 1.29 \\
9 & $0-4$ & 20.93 & 1.06 & 1.17 & 1.09 & 22.66 & 1.07 & 1.52 & 1.32 \\
10 & $0-5$ & 23.52 & 1.06 & 1.12 & 1.06 & 25.93 & 1.06 & 1.47 & 1.31
\end{tabular}

NOTE: Subscripts 1, 8 , and bv refer co the Individual, group wean, and BVAR forecasts, varianc $A$, respectively. RMSE, is che median of the RMSEs of che sampled forecasts (columns 1 and 5 ). The $1 / 8$ raclo is RMSE ${ }_{1} / R_{M S E}$ for serlecly macching observations, and the 1 bV ratio is RMSE, RMSE, with oedlans of the Individual forecasts used in each case (columns 2 and 6, and 3 and 7 , respecively). The g/bV raclo Is RMSE/RMSEv (colums 4 and 8 ). See slso noces co Tables 13 and 14 . 
Table 18

Selected Measures of Forecast Accuracy and Actual Values, Levels of the Unemployment Rate and Housing Starts, by Target Quarter, 1968-90
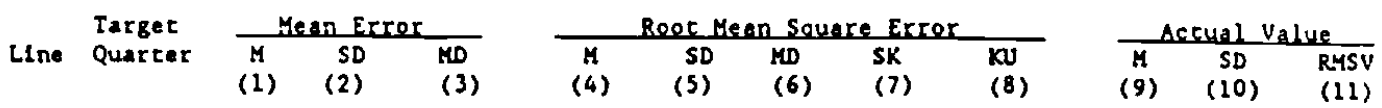

Unemoleyment Race (UR)*

$\begin{array}{lllll}1 & 1 & .02 & .08 & .03 \\ 2 & 2 & -.01 & .13 & .01 \\ 3 & 3 & -.08 & .20 & -.07 \\ 4 & 4 & -.20 & .28 & -.19 \\ 5 & 5 & -.22 & .34 & -.29\end{array}$

$\begin{array}{rrrrr}.26 & .21 & .21 & 4.93 & 27.12 \\ .52 & .20 & .49 & 3.83 & 19.92 \\ .77 & .23 & .73 & 2.31 & 11.73 \\ .98 & .26 & .97 & 1.22 & 5.93 \\ 1.15 & .25 & 1.13 & .53 & .65\end{array}$

$6.50 \quad 1.61 \quad 6.70$

Housing Starts (HS)

$\begin{array}{rrrrr}6 & 1 & -.04 & .06 & -.03 \\ 7 & 2 & -.03 & .09 & -.02 \\ 8 & 3 & -.00 & .12 & .01 \\ 9 & 4 & .03 & .15 & .03 \\ 10 & 5 & .06 & .18 & .08\end{array}$

$\begin{array}{rrrrr}.23 & .04 & .23 & -.01 & .08 \\ .29 & .05 & .29 & .18 & .67 \\ .34 & .07 & .34 & .61 & 2.23 \\ .38 & .09 & .38 & .72 & 3.32 \\ .42 & .10 & .41 & .69 & 2.45\end{array}$

Based on presently avallable data (no loportant revislons).

besed on the second revision of the monthly dete. 
Table 19

Individual. Group Mean, and BVAR Forecasts of Levels of the Unemployment Race and Housing Stares, Selected Comparisons, by Targec Quarcer,

1968-90

Targec Group Mean Line Quarcer RMSE
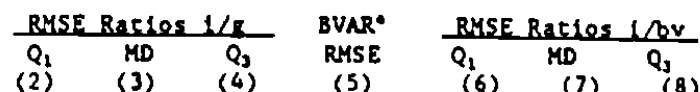

(1)

(2)

(3)

(4)

(5)

$Q_{1}$

(7)

(8)

Unempleyment Rate (UR)

$\begin{array}{lll}1 & 1 & .16 \\ 2 & 2 & .41 \\ 3 & 3 & .65 \\ 4 & 4 & .86 \\ 5 & 5 & 1.00\end{array}$

$\begin{array}{llll}1.19 & 1.42 & 1.73 & .28 \\ 1.05 & 1.17 & 1.32 & .50 \\ 1.01 & 1.10 & 1.23 & .66 \\ .98 & 1.09 & 1.20 & .78 \\ .99 & 1.10 & 1.20 & .85\end{array}$

$\begin{array}{lll}.72 \quad .84 & .96\end{array}$

$\begin{array}{lll}.89 & 1.02 & 1.23\end{array}$

$\begin{array}{lll}.96 & 1.16 & 1.38\end{array}$

$1.07 \quad 1.25 \quad 1.50$

$\begin{array}{lllllll}.99 & 1.10 & 1.20 & .85 & 1.14 & 1.30 & 1.71\end{array}$

Houstine starts (HS)"

$\begin{array}{rrrrrrrrrr}6 & 1 & .21 & .99 & 1.06 & 1.16 & .13 & 1.52 & 1.78 & 1.99 \\ 7 & 2 & .25 & 1.00 & 1.07 & 1.18 & .20 & 1.30 & 1.41 & 1.60 \\ 8 & 3 & .29 & 1.02 & 1.08 & 1.19 & .27 & 1.15 & 1.25 & 1.38 \\ 9 & 4 & .33 & .98 & 1.10 & 1.16 & .32 & .99 & 1.13 & 1.22 \\ 10 & 5 & .36 & .99 & 1.07 & 1.18 & .37 & .93 & 1.04 & 1.16\end{array}$

-For IP: Based on a modal with six varlables (RGNP, IPD, H2, LI. TBR, and UR) and ix quarcerly lags, escimaced sequenclally wich presencly avallable data. For HS: Based on a model with six variables (RCNP. IPD. H2, LI. IBR, and HS) and six quarterly lags, escimated sequenclally wich presencly avallable daca. See cexe and appendix. BVAR varlant $A$ is used throughour.

based on presenely avallable daca.

'Based on second revision of the wonthly deca. 
Tabl. 20

Individual. Group Mean, and BVAR Forecasts of the Unemployment Rate and Housing Stares, Selected Coaparlions, by Target Quarcer and Subperlod, $1968-79$ and $1979-90$
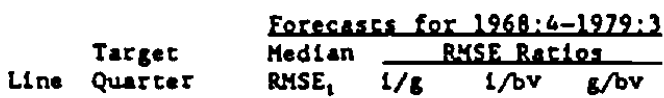

Median RMSF Ratior

Eorecasts for 1979:4-1990:1

RMSE $1 / 8$ 1/OV $8 / \mathrm{bV}$

Median

RMSE RMSE Ratios

(1) (2) (3)

(4)

(5)

(6) (7)

(8)

\section{Unemoloymenc Rate(UR)}

$\begin{array}{ll}1 & 1 \\ 2 & 2 \\ 3 & 3 \\ 4 & 4 \\ 5 & 5\end{array}$

.21
.45
.66
.84
.96

1.34
1.15
1.06
1.06
1.08

.84
.95
.98

.58

.5

$\begin{array}{lll}.21 & 1.39 & .82 \\ .52 & 1.19 & 1.16\end{array}$

.84

$.98 \quad .95$

1.03

.08

$\begin{array}{ll}1.09 & 1.04 \\ 1.11 & 1.02\end{array}$

Housine Stares (HS)

$\begin{array}{rr}6 & 1 \\ 7 & 2 \\ 8 & 3 \\ 9 & 4 \\ 10 & 5\end{array}$

$\begin{array}{llll}.23 & 1.07 & 1.58 & 1.39\end{array}$

$\begin{array}{lll}1.08 & 1.39 & 1.24\end{array}$

.23

1.03

1.10
1.09

$1.71 \quad 1.37$

$\begin{array}{llll}.30 & 1.08 & 1.39 & 1.24 \\ .37 & 1.10 & 1.27 & 1.14\end{array}$

$\begin{array}{llll}.42 & 1.08 & 1.11 & 1.07\end{array}$

.28

.31

$\begin{array}{lll}1.07 & 1.23 & 1.01\end{array}$

$\begin{array}{lll}1.05 \quad 1.14 \quad 98 & 98\end{array}$

$1.04 \quad 1.08 \quad .98$

NOTE: SEe tabl• 17. 
Table 21

MIchlgan (RSQE) Econonaerlc Forecases and NBER-ASA Survey Foracasts of Nosinal and Real GNP Groweh and IPO Inflacion Races by Span. 1970-90
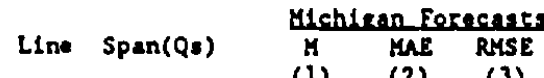

Groun Mean Forecases

M MAE RMSE

RMSE RaCKOSL, UM

$\begin{array}{lll}\text { M } & \text { MaE } & \text { RHSE } \\ \text { (1) } & \text { (2) } & \text { (3) }\end{array}$

(4)

(5)

(6)

(7) 180 Q

Gross Natlonal Product (GNP)

$\begin{array}{ll}1 & 0-1 \\ 2 & 0-2 \\ 3 & 0-3 \\ 4 & 0-4 \\ 5 & 0-5\end{array}$

$$
\begin{array}{r}
-.09 \\
.13 \\
.34 \\
.51 \\
.97
\end{array}
$$

$\begin{array}{rrr}.80 & 1.08 & -.09 \\ 1.24 & 1.60 & -.07\end{array}$

1.451 .91

$1.81 \quad 2.38$

$-.09$

.02

$\begin{array}{ll}.51 & .66 \\ .91 & 1.18\end{array}$

1.18
1.73

.56
.73

$.73 \quad .89$

2.152 .95

$-.02$

1.642 .15

n. $1.00 \quad 1.26$

Grost Nattonel Produce in Constane Dellare (RGNP)

$\begin{array}{rr}6 & 0-1 \\ 7 & 0-2 \\ 8 & 0-3 \\ 9 & 0-4 \\ 10 & 0-5\end{array}$

$\begin{array}{rrr}.01 & .77 & 1.02 \\ .25 & 1.09 & 1.49 \\ .46 & 1.34 & 1.77 \\ .77 & 1.38 & 2.18 \\ 1.20 & 1.96 & 2.88\end{array}$

-.05
.01

$.51 \quad .66$

$.88 \quad 1.16$

.56

$1.00 \quad 1.19$

\section{Imollate Prian Daflator (IPD)}

$\begin{array}{lllllllllll}11 & 0-1 & -.10 & .39 & .51 & -.03 & .27 & .34 & .71 & .88 & 1.17 \\ 12 & 0-2 & -.14 & .72 & .87 & -.08 & .52 & .68 & .81 & .97 & 1.17 \\ 13 & 0-4 & -.15 & 1.00 & 1.32 & -.12 & .76 & 1.05 & .78 & .90 & 1.05 \\ 14 & 0-4 & -.27 & 1.40 & 1.98 & -.14 & 1.12 & 1.56 & .78 & .89 & 1.02 \\ 15 & 0-5 & -.28 & 1.78 & 2.42 & -.18 & 1.57 & 2.20 & .87 & .98 & 1.12\end{array}$

NOTE: The Mchlign forecasts cover the perlod 1970:4-1990:1, except for the following quarters: 71:2,72:2,73:2,74:2,75:1,75:2,76:1,77:2, 78:2, and 79:2. We wach the MBER-ASA Lorecasts to the Mlchigan forecases perlod by perlod. The ratios in colums 7-9 aze RuSE,/PHSE. where the subsezipe 1 zefers to Individual forecasts from the HBER-ASA surveys and the subscrlpt $H$ refore to the Mlehigan Eozocases. 
Table 22

MIchigan (RSQE) Economecric Forecasts and NBER-ASA Survey Forecasts of Parcent Changes in Consumption. Investment, and Defense Expendi tures, by Span, 1981-90 and 1968-81

Line $\operatorname{span(Qs)}$

\begin{tabular}{|c|c|c|c|c|c|c|}
\hline $\mathrm{H} / \mathrm{ch}$ & E Fo & ecasts & Grous & $\operatorname{esc} f$ & ecasts & RMSE RAClOS 1/M \\
\hline $\begin{array}{c}M \\
\text { (1) }\end{array}$ & $\begin{array}{l}\text { MuE } \\
\text { (2) }\end{array}$ & $\begin{array}{l}\text { RMSE } \\
\text { (3) }\end{array}$ & $\begin{array}{c}M \\
(4)\end{array}$ & $\begin{array}{l}\text { MEE } \\
\text { (5) }\end{array}$ & $\begin{array}{l}\text { RYSE } \\
(6)\end{array}$ & $\begin{array}{ccc}Q_{1} & M D & Q_{3} \\
(7) & (8) & (9)\end{array}$ \\
\hline
\end{tabular}

Rersonal Consumpclon Expendteures (PCE)

$\begin{array}{llllllllll}0-1 & -.12 & .56 & .76 & -.14 & .47 & .59 & .82 & .89 & 1.56 \\ 0-2 & -.19 & .73 & .89 & -.24 & .64 & .77 & .78 & .97 & 1.25 \\ 0-3 & -.26 & .93 & 1.15 & -.39 & .84 & .99 & .98 & 1.15 & 1.41 \\ 0-4 & -.35 & 1.10 & 1.34 & -.51 & 1.04 & 1.25 & .94 & 1.21 & 1.52 \\ 0-5 & -.41 & 1.21 & 1.51 & -.66 & 1.28 & 1.56 & .92 & 1.30 & 1.51\end{array}$

Nonrestdenelal Fixed Investment (NFI)

$\begin{array}{rrrrrrrrrrr}6 & 0-1 & -.63 & 2.04 & 2.65 & -.49 & 1.68 & 2.10 & .71 & .93 & 1.18 \\ 7 & 0-2 & -1.04 & 3.25 & 4.26 & -.93 & 2.74 & 3.52 & .81 & 1.00 & 1.29 \\ 8 & 0-3 & -1.09 & 4.91 & 5.94 & -1.38 & 4.03 & 5.23 & .70 & .87 & 1.09 \\ 9 & 0-4 & -.95 & 6.47 & 7.48 & -1.71 & 5.57 & 7.09 & .76 & .93 & 1.16 \\ 10 & 0-5 & -.84 & 7.71 & 8.68 & -2.16 & 7.57 & 9.11 & .82 & 1.10 & 1.33\end{array}$

Besidencial Fixed lovestment (RFI)

$\begin{array}{rrrrrrrrrrrr}11 & 0-1 & -.34 & 2.53 & 3.54 & -.87 & 2.15 & 3.29 & .79 & 1.36 & 1.57 \\ 12 & 0-2 & -.30 & 3.89 & 5.93 & -1.99 & 4.34 & 7.55 & .92 & 1.20 & 1.79 \\ 13 & 0-4 & .31 & 5.26 & 7.57 & -3.72 & 6.51 & 11.43 & .92 & 1.11 & 1.37 \\ 14 & 0-4 & 1.36 & 6.59 & 9.02 & -5.43 & 8.43 & 14.32 & .94 & 1.16 & 1.29 \\ 15 & 0-5 & 2.32 & 8.19 & 10.56 & -7.51 & 10.55 & 17.46 & .93 & 1.14 & 1.26\end{array}$

Nationsl Defense Expendl tures (DEF)

$\begin{array}{rrrrrrrrrrr}16 & 0-1 & -.09 & 2.18 & 2.54 & -.07 & 1.44 & 2.00 & .85 & .98 & 1.20 \\ 17 & 0-2 & -.28 & 2.89 & 3.65 & .56 .20 & 2.28 & 3.08 & .84 & 1.04 & 1.19 \\ 18 & 0-3 & -.49 & 3.75 & 4.52 & -1.49 & 3.13 & 4.09 & .74 & .92 & 1.15 \\ 19 & 0-4 & -.65 & 4.03 & 4.76 & -2.14 & 4.34 & 5.23 & .79 & 1.01 & 1.25 \\ 20 & 0-5 & -.95 & 5.84 & 6.83 & -3.64 & 5.45 & 7.07 & .67 & .80 & .99\end{array}$

NOTE: SaE Table 21. 
Table 23

MIchigan (RSQE) Econometric Forecases and MBER-ASA Forecases of the Unemploymene Race. Treasury B1ll Rate, and Cotporace Bond Y1eld, by Target Quarter. 1968-90 and 1981-90

\begin{tabular}{|c|c|c|c|c|c|c|c|c|c|c|}
\hline \multirow[b]{2}{*}{ Line } & \multirow{2}{*}{$\begin{array}{l}\text { Target } \\
\text { Quarcer }\end{array}$} & \multicolumn{3}{|c|}{ Michlgan Forecasta } & \multicolumn{3}{|c|}{ Group Han Forecast } & \multicolumn{2}{|c|}{ RMSE_RACles } & \multirow{2}{*}{$\begin{array}{r}1 / 1 \\
Q_{1} \\
(9)\end{array}$} \\
\hline & & $\begin{array}{c}M \\
(1)\end{array}$ & $\begin{array}{l}\text { MAE } \\
(2)\end{array}$ & $\begin{array}{l}\text { RHSE } \\
\text { (3) }\end{array}$ & $\begin{array}{l}M \\
(4)\end{array}$ & $\begin{array}{l}\text { MAE } \\
(5)\end{array}$ & $\begin{array}{c}\text { RHSE } \\
(6)\end{array}$ & $\begin{array}{l}Q_{2} \\
(7)\end{array}$ & $\begin{array}{l}M D \\
(8)\end{array}$ & \\
\hline \multicolumn{11}{|c|}{ Unemoloyment Race, $1968-90$ (UR) } \\
\hline $\begin{array}{l}1 \\
2 \\
3 \\
4 \\
5\end{array}$ & $\begin{array}{l}1 \\
2 \\
3 \\
4 \\
5\end{array}$ & $\begin{array}{r}.05 \\
.08 \\
.05 \\
-.01 \\
-.11\end{array}$ & $\begin{array}{l}.14 \\
.33 \\
.49 \\
.58 \\
.69\end{array}$ & $\begin{array}{l}.17 \\
.44 \\
.67 \\
.78 \\
.93\end{array}$ & $\begin{array}{r}.02 \\
.05 \\
.03 \\
.00 \\
-.02\end{array}$ & $\begin{array}{l}.13 \\
.33 \\
.51 \\
.61 \\
.71\end{array}$ & $\begin{array}{l}.17 \\
.43 \\
.68 \\
.85 \\
.96\end{array}$ & $\begin{array}{l}1.07 \\
1.03 \\
1.01 \\
1.08 \\
1.01\end{array}$ & $\begin{array}{l}1.32 \\
1.15 \\
1.16 \\
1.21 \\
1.18\end{array}$ & $\begin{array}{l}1.72 \\
1.35 \\
1.32 \\
1.38 \\
1.33\end{array}$ \\
\hline \multicolumn{11}{|c|}{ Ireasury BHL Rare 198$)-90$ (TBR) } \\
\hline $\begin{array}{r}6 \\
7 \\
8 \\
9 \\
10\end{array}$ & $\begin{array}{l}1 \\
2 \\
3 \\
4 \\
5\end{array}$ & $\begin{array}{r}-.04 \\
-.05 \\
-.01 \\
.07 \\
.21\end{array}$ & $\begin{array}{r}.24 \\
.79 \\
1.13 \\
1.37 \\
1.67\end{array}$ & $\begin{array}{l}.31 \\
1.07 \\
1.39 \\
1.64 \\
1.90\end{array}$ & $\begin{array}{l}.01 \\
.15 \\
.38 \\
.62 \\
.87\end{array}$ & $\begin{array}{r}.15 \\
.69 \\
1.11 \\
1.45 \\
1.72\end{array}$ & $\begin{array}{r}.20 \\
.91 \\
1.40 \\
1.80 \\
2.16\end{array}$ & $\begin{array}{r}.96 \\
.85 \\
.97 \\
1.05 \\
1.06\end{array}$ & $\begin{array}{r}1.17 \\
.96 \\
1.11 \\
1.25 \\
1.25\end{array}$ & $\begin{array}{l}1.58 \\
1.19 \\
1.32 \\
1.39 \\
1.52\end{array}$ \\
\hline \multicolumn{11}{|c|}{ Corpornte Bond Yleld. $1981-90$ (CBY) } \\
\hline $\begin{array}{l}11 \\
12 \\
13 \\
14 \\
15\end{array}$ & $\begin{array}{l}1 \\
2 \\
3 \\
4 \\
5\end{array}$ & $\begin{array}{l}-.44 \\
-.31 \\
-.20 \\
-.12 \\
-.03\end{array}$ & $\begin{array}{r}.48 \\
.64 \\
.84 \\
1.17 \\
1.39\end{array}$ & $\begin{array}{r}.63 \\
.81 \\
1.08 \\
1.43 \\
1.68\end{array}$ & $\begin{array}{r}-.19 \\
-.07 \\
.16 \\
.37 \\
.57\end{array}$ & $\begin{array}{r}.31 \\
.66 \\
1.05 \\
1.32 \\
1.48\end{array}$ & $\begin{array}{r}.38 \\
.83 \\
1.25 \\
1.53 \\
1.74\end{array}$ & $\begin{array}{l}.73 \\
1.17 \\
1.23 \\
1.08 \\
1.02\end{array}$ & $\begin{array}{r}.97 \\
1.28 \\
1.36 \\
1.23 \\
1.12\end{array}$ & $\begin{array}{l}1.26 \\
1.55 \\
1.50 \\
1.39 \\
1.32\end{array}$ \\
\hline
\end{tabular}

NOTE: See Table 21 . 
Table 24

Sims Model Forecascs (Two Variants) and NBER-ASA Survey Forecasts of Nowinal and Real GNP Growth, and IPD Inflation, by Span. 1968-90 and 1981-90

Line Span(Qs)

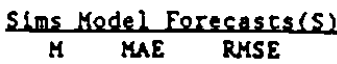

Group Mean Forecasts

(1) (2) (3)

(4)

MAE RMSE

$\begin{array}{lll}\text { RMSE Rajles } & \text { i } \\ Q_{2} & M D & Q_{3}\end{array}$

Gross Naffenal Product. 1968-90 (GNP)

\section{Varlant_A}

$\begin{array}{llllllllll}0-1 & .01 & .86 & 1.09 & -.08 & .49 & .64 & .51 & .66 & .89 \\ 0-2 & .01 & 1.31 & 1.68 & -.10 & .84 & 1.11 & .62 & .79 & .94 \\ 0-3 & -.05 & 1.87 & 2.34 & -.07 & 1.22 & 1.61 & .62 & .79 & .93 \\ 0-4 & -.11 & 2.32 & 2.93 & -.02 & 1.56 & 2.06 & .65 & .79 & .98 \\ 0-5 & -.20 & 2.74 & 3.48 & -.09 & 1.91 & 2.51 & .65 & .80 & 1.08\end{array}$

$\underline{\text { Varlanc B }}$

$\begin{array}{llll}0-1 & 0 & 0 & 0 \\ 0-2 & .00 & .85 & 1.08 \\ 0-3 & .02 & 1.29 & 1.66 \\ 0-4 & .08 & 1.85 & 2.33 \\ 0-5 & .15 & 2.29 & 2.90\end{array}$

$\begin{array}{lll}\text { n.a. } & \text { n.a. } & \text { n.a. } \\ .70 & .84 & .98 \\ .81 & .93 & 1.10 \\ .74 & .88 & 1.09 \\ .78 & .88 & 1.10\end{array}$

Gross National Product in Constanc Dollars. 1968-90 (RGNP)

Vartant A

$\begin{array}{lllllllllll}11 & 0-1 & .03 & .78 & .99 & -.02 & .50 & .64 & .63 & .77 & .98 \\ 12 & 0-2 & .05 & 1.18 & 1.50 & .02 & .83 & 1.11 & .73 & .86 & 1.06 \\ 13 & 0-3 & .04 & 1.68 & 2.12 & .16 & 1.17 & 1.61 & .75 & .89 & 1.05 \\ 14 & 0-4 & .02 & 2.10 & 2.66 & .33 & 1.42 & 2.05 & .79 & .93 & 1.08 \\ 15 & 0-5 & -.03 & 2.54 & 3.15 & .40 & 1.70 & 2.47 & .80 & .96 & 1.12\end{array}$

Varlane B

$\begin{array}{llllllll}16 & 0-1 & 0 & 0 & 0 & \text { n.a. } & \text { n.a. } & \text { n.a. } \\ 17 & 0-2 & -.02 & .79 & 1.00 & .81 & .96 & 1.11 \\ 18 & 0-3 & -.03 & 1.19 & 1.51 & .99 & 1.12 & 1.27 \\ 19 & 0-4 & -.03 & 1.70 & 2.14 & .97 & 1.12 & 1.30 \\ 20 & 0-5 & .00 & 2.11 & 2.68 & 1.01 & 1.13 & 1.36 \\ & & & & & \end{array}$

\section{Varlant A}

$\begin{array}{lllllllllll}21 & 0-1 & .01 & .30 & .38 & -.04 & .27 & .34 & .71 & .88 & 1.17 \\ 22 & 0-2 & .04 & .54 & .68 & -.12 & .55 & .70 & 1.81 & .97 & 1.17 \\ 23 & 0-4 & .08 & .75 & .95 & -.22 & .84 & 1.13 & 1.24 & 1.46 & 1.73 \\ 24 & 0-4 & .12 & 1.01 & 1.25 & -.34 & 1.21 & 1.64 & 1.35 & 1.58 & 1.85 \\ 25 & 0-5 & .16 & 1.29 & 1.59 & -.37 & 1.63 & 2.23 & 1.40 & 1.68 & 1.99\end{array}$




\begin{tabular}{|c|c|c|c|c|c|c|c|c|c|c|}
\hline \multirow[b]{2}{*}{ Line } & \multirow[b]{2}{*}{ Span(Qs) } & \multicolumn{3}{|c|}{ S1ms Model Forecasts (S) } & \multicolumn{3}{|c|}{ Group Mean Forecasca } & \multicolumn{3}{|c|}{ RMSE RACles I/S } \\
\hline & & $\begin{array}{c}M \\
\text { (1) }\end{array}$ & $\begin{array}{l}\operatorname{MAE} \\
(2)\end{array}$ & $\begin{array}{l}\text { RMSE } \\
\text { (3) }\end{array}$ & $\begin{array}{l}M \\
(4)\end{array}$ & $\begin{array}{l}\operatorname{maE} \\
(S)\end{array}$ & $\begin{array}{l}\text { RMSE } \\
(6)\end{array}$ & $(7)$ & $\begin{array}{l}M D \\
\text { (B) }\end{array}$ & $\begin{array}{l}Q_{3} \\
(9)\end{array}$ \\
\hline & & & & & Yartan & & & & & \\
\hline 26 & $0-1$ & 0 & 0 & 0 & & & & n.a. & n.e. & \\
\hline 27 & $0-2$ & -.02 & .31 & .39 & & & & 1.31 & 1.52 & 1.81 \\
\hline 28 & $0-3$ & -.05 & .55 & .69 & & & & 1.43 & 1.63 & 1.91 \\
\hline 29 & $0-4$ & -.09 & .76 & .96 & & & & 1.51 & 1.68 & 1.90 \\
\hline 30 & $0-5$ & -.14 & 1.02 & 1.26 & & & & 1.47 & 1.71 & 1.98 \\
\hline
\end{tabular}


Sims Model Forecasts (Varlant A) and NBER-ASA Survey Forecasts of the Unemploywent Rate, the Treasury B111 Rate, and Crowth in Real Nonresidentlal Investment, by Target Quarter.

or Span, 1968-90 and 1981-90

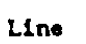

Target Quarter

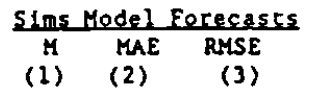

$\begin{array}{rrr}\text { Group Mean Forecasts } \\ \text { M NAE RMSE } \\ \text { (4) } & \text { (5) } & \text { (6) }\end{array}$

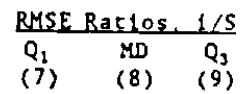

Unempleyment Rate, $1968-90$ (UR)

\begin{tabular}{rrrrrrrrrrr}
1 & 1 & .09 & .39 & .55 & .03 & .13 & .16 & .35 & .45 & .55 \\
2 & 2 & .14 & .56 & .79 & .04 & .32 & .41 & .54 & .65 & .81 \\
3 & 3 & .18 & .76 & 1.03 & -.00 & .49 & .65 & .59 & .71 & .93 \\
4 & 4 & .21 & .95 & 1.23 & -.08 & .63 & .86 & .64 & .78 & .94 \\
5 & 5 & .23 & 1.10 & 1.40 & -.10 & .73 & 1.00 & .66 & .79 & .98 \\
\multicolumn{7}{c}{ Tressury 8111 Rare, $1981-90(T B R)$} \\
6 & 1 & -.34 & 1.27 & 1.57 & .01 & .15 & .20 & .20 & .24 & .29 \\
7 & 2 & -.54 & 1.47 & 1.84 & .13 & .68 & .90 & .52 & .62 & .70 \\
8 & 3 & -.60 & 1.69 & 2.13 & .35 & 1.09 & 1.38 & .62 & .71 & .82 \\
9 & 4 & -.71 & 1.96 & 2.48 & .61 & 1.41 & 1.77 & .67 & .76 & .86 \\
10 & 5 & -.86 & 2.19 & 2.69 & 1.07 & 1.87 & 2.49 & .75 & .86 & .97
\end{tabular}

Nonrestdent dal Flxed Investment. $1981-90$ (NFI)

$\begin{array}{lllllllllll}11 & 0-1 & -.16 & 2.31 & 2.93 & -.45 & 1.61 & 2.01 & .72 & .85 & 1.01 \\ 12 & 0-2 & -.31 & 3.61 & 4.16 & -.88 & 2.67 & 3.43 & .63 & .72 & 1.01 \\ 13 & 0-3 & -.74 & 5.23 & 6.05 & -1.19 & 3.93 & 4.99 & .60 & .67 & .85 \\ 14 & 0-4 & -.90 & 4.50 & 6.69 & -1.74 & 5.51 & 6.89 & .60 & .65 & .93 \\ 15 & 0-5 & -1.63 & 4.95 & 7.31 & -2.31 & 7.29 & 8.69 & .54 & .65 & .75\end{array}$

NOTE to cables 24 and 25: Slas' is a nine-varlable, five-lag quartarly probabllistic wodel (see text for more decalld. The SIms forecasts contaln no gaps and refer to the same perlods as chose covered by che MBER-ASA survey forecasts (Individual and group means). The entrles in columns 7-9 represent raclos RMSE, RHSE, where the subscript 1 refers to Individual forecasts from the surveys and che subscript $S$ refers to che sims model forecasts. $Q_{1}$ and $Q_{3}$ denote che lower and upper quartle raclos, and MD denote the median ratios.

Varlant A assumes that the last known values of the varlables to be predicted refer to che quarter $t-1$ (denoted 0 ): varlant B assumes that they refer to the currenter quarter $t$ (denoted 1). 
Table 26

ARIMA Model Forecasts (Two Varlants) and NBER-ASA Survey Forecasts of Nowinal and Real GNP Growth, and IPD Inflation.

by Span, 1968-90

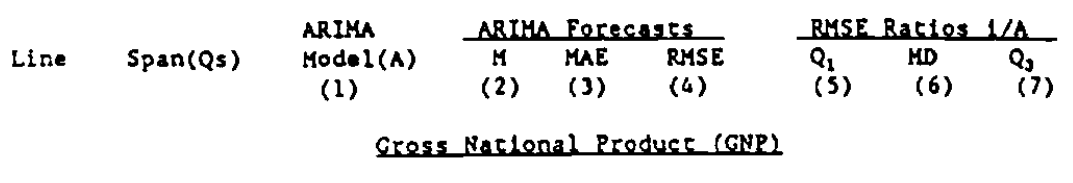

Varlanes

$\begin{array}{lllllllll}1 & 0-1 & \text { n.a. } & -.11 & .95 & 1.18 & .48 & .61 & .82 \\ 2 & 0-2 & & -.29 & 1.64 & 2.05 & .53 & .64 & .74 \\ 3 & 0-3 & & -.55 & 2.51 & 3.04 & .51 & .61 & .73 \\ 4 & 0-4 & & -.85 & 3.32 & 4.00 & .51 & .58 & .69 \\ 5 & 0-5 & & -1.19 & 4.11 & 4.96 & .49 & .61 & .74\end{array}$

Vartane 8

\begin{tabular}{|c|c|c|c|c|c|c|c|c|}
\hline 6 & $0-1$ & n.a. & 0 & 0 & 0 & n. & n.a. & n.a. \\
\hline 7 & $0-2$ & & .12 & .94 & 1.18 & .64 & .77 & .86 \\
\hline 8 & $0-3$ & & .32 & 1.62 & 2.02 & .71 & .81 & .95 \\
\hline 9 & $0-4$ & & .59 & 2.48 & 3.01 & .61 & .71 & .87 \\
\hline 10 & $0-5$ & & .91 & 3.28 & 3.96 & .59 & .74 & .94 \\
\hline
\end{tabular}

Vardanc $A$

\begin{tabular}{|c|c|c|c|c|c|c|c|c|}
\hline 11 & $0-1$ & $1,1,0$ & -.06 & .80 & 1.03 & .60 & .74 & .94 \\
\hline 12 & $0-2$ & & -.14 & 1.33 & 1.68 & .67 & .79 & .94 \\
\hline 13 & $0-3$ & & -.27 & 1.91 & 2.33 & .71 & .82 & 1.00 \\
\hline 14 & $0-4$ & e & -.40 & 2.37 & 2.88 & .77 & .86 & 1.05 \\
\hline 15 & $0-5$ & & -.54 & 2.82 & 3.39 & .76 & .93 & 1,11 \\
\hline
\end{tabular}

\section{Vurbans}

\begin{tabular}{|c|c|c|c|c|c|c|c|c|}
\hline $\begin{array}{l}16 \\
17 \\
18 \\
19 \\
20\end{array}$ & $\begin{array}{l}0-1 \\
0-2 \\
0-3 \\
0-4 \\
0-5\end{array}$ & 1.1 .0 & $\begin{array}{r}0 \\
.06 \\
.16 \\
.28 \\
.43\end{array}$ & $\begin{array}{l}0 \\
.81 \\
1.33 \\
1.93 \\
2.39\end{array}$ & $\begin{array}{l}0 \\
1.04 \\
1.68 \\
2.35 \\
2.91\end{array}$ & $\begin{array}{r}\text { n. } \\
.78 \\
.91 \\
.93 \\
.99\end{array}$ & $\begin{array}{r}\text { n.2. } \\
.93 \\
1.04 \\
1.07 \\
1.11\end{array}$ & $\begin{array}{l}n .2 . \\
1.08 \\
1.21 \\
1.29 \\
1.34\end{array}$ \\
\hline
\end{tabular}

Imollete Price Deflator (IPD)

\section{Vartanes}

$\begin{array}{lllllllll}21 & 0-1 & 1.1 .2 & .05 & .38 & .50 & .72 & .93 & 1.11 \\ 22 & 0-2 & & .15 & .80 & 1.00 & .71 & .87 & 1.10 \\ 23 & 0-4 & & .29 & 1.27 & 1.60 & .68 & .90 & 1.11 \\ 24 & 0-4 & & .49 & 1.84 & 2.29 & .65 & .93 & 1.16 \\ 25 & 0-5 & & .74 & 2.47 & 3.07 & .63 & 1.02 & 1.28\end{array}$




\begin{tabular}{|c|c|c|c|c|c|c|c|c|}
\hline \multirow[b]{2}{*}{ LIne } & \multirow[b]{2}{*}{ Span(Qs) } & \multirow{2}{*}{$\begin{array}{l}\text { ARIMA } \\
\text { Model (A) } \\
(1)\end{array}$} & \multicolumn{3}{|c|}{ ABIMA Eerecasts } & \multicolumn{3}{|c|}{ RMSE Ratios 1/A } \\
\hline & & & $\begin{array}{c}M \\
(2)\end{array}$ & $\begin{array}{l}\text { MAE } \\
(3)\end{array}$ & $\begin{array}{l}\text { RMSE } \\
\text { (4) }\end{array}$ & $\begin{array}{l}Q_{1} \\
(s)\end{array}$ & $\begin{array}{c}M D \\
(6)\end{array}$ & $\begin{array}{l}Q_{3} \\
(7)\end{array}$ \\
\hline & \multicolumn{8}{|c|}{ Vartane B } \\
\hline 26 & $0-1$ & $1,1,2$ & 0 & 0 & 0 & n.a. & n.e. & n.a. \\
\hline 27 & $0-2$ & & -.05 & .39 & .51 & .94 & 1.10 & 1.39 \\
\hline 28 & $0-3$ & & -.16 & .80 & 1.01 & .97 & 1.17 & 1.37 \\
\hline 29 & $0-4$ & & -.32 & 1.27 & 1.62 & .88 & 1.11 & 1.33 \\
\hline 30 & $0-5$ & & -.53 & 1.86 & 2.32 & .79 & 1.14 & 1.40 \\
\hline
\end{tabular}

n. Not available (forecasts obtained from those for RGNP and IPD). 
Table 27

ARIMA Model Forecasts (Varlant A) and NBER-ASA Survey

Forecasts of the Unemploywent Rate, the Ireasury Blll Rate, and Grouth In Real Nonresidentlal Investment, by Target Quarter. or Span. 1968-90 and 1981-90

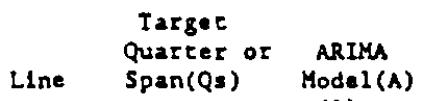

Span(Qs)

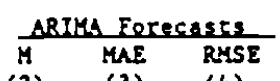

(2)
(3)

(3)
(4)

\begin{tabular}{ccc} 
RMSE RaEles & R/A \\
\hline$Q_{3}$ & $M D$ & $Q_{3}$ \\
$(5)$ & $(6)$ & $(7)$
\end{tabular}

Unemplevment Race (UR)

$\begin{array}{llll}1.1 .0 & -.25 & .45 & .65 \\ & -.44 & .67 & .96 \\ & -.63 & .87 & 1.26 \\ & -.80 & 1.07 & 1.50 \\ & -.94 & 1.21 & 1.67\end{array}$

$\begin{array}{lll}.30 & .36 & .44 \\ .44 & .52 & .60 \\ .50 & .58 & .68 \\ .56 & .63 & .74 \\ .58 & .66 & .76\end{array}$

Ireasury B 111 Rate (TBR)

$\begin{array}{rr}6 & 1 \\ 7 & 2 \\ 8 & 3 \\ 9 & 4 \\ 10 & 5\end{array}$

0.1 .1

$\begin{array}{lll}-.39 & 1.37 \quad 1.96\end{array}$

$\begin{array}{rrr}-.66 & 1.60 \quad 2.14\end{array}$

$\begin{array}{lll}-.80 & 1.88 \quad 2.59\end{array}$

$\begin{array}{lll}-.80 & 1.88 & 2.39 \\ -.96 & 2.26 & 3.19\end{array}$

$\begin{array}{lll}-1.19 & 2.51 \quad 3.49\end{array}$

$\begin{array}{lll}.15 & .19 & .26 \\ .42 & .49 & .61 \\ .53 & .60 & .72 \\ .57 & .65 & .72 \\ .59 & .69 & .78\end{array}$

Nencestdenclal Fixed Invescment (NFT)

$\begin{array}{llllllllr}11 & 0-1 & 1.1 .0 & -.07 & 1.63 & 2.37 & .58 & .84 & 1.21 \\ 12 & 0-2 & & -.16 & 3.32 & 4.27 & .65 & .78 & .98 \\ 13 & 0-3 & & -.22 & 5.10 & 6.26 & .58 & .64 & .81 \\ 15 & 0-4 & & -.22 & 6.76 & 8.11 & .50 & .59 & .65 \\ 16 & 0-5 & & -.16 & 8.19 & 9.69 & .40 & .48 & .56\end{array}$

NOTE to Tables 26 and 27: The speclflcations of the ARIMA models are as in SIms and Todd 1991, Table 1. For more detall, see 1b/d.. PP. 3-4. The ontries in columns 3-6 represent raclos RMSE, RMSE, where the subscrlpe 1 rafors to Individual forecssts fron the NBER-ASA survays and the subscrlpe A refers to the ARIMA model forecass. 
rable 28

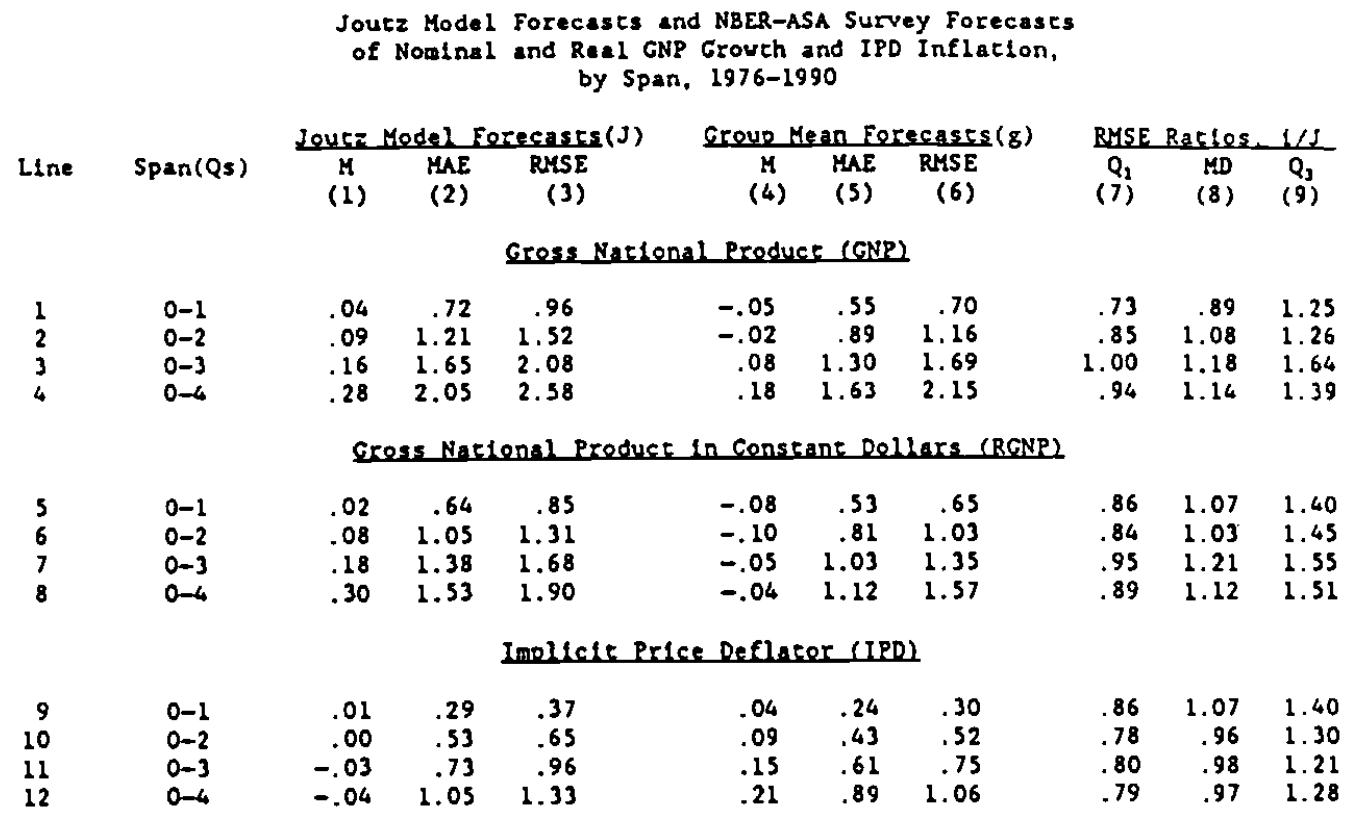


Table 29

Nine Secs of Forecasts Ranked According to Their Average RMSEs. Three Varlables. 1968:4-1990:1

\begin{tabular}{|c|c|c|c|c|c|c|c|}
\hline \multirow[b]{2}{*}{ Line } & \multirow[b]{2}{*}{ Forecast } & \multicolumn{2}{|c|}{$\begin{array}{l}\text { Gross National } \\
\text { Producr (GNP) }\end{array}$} & \multicolumn{2}{|c|}{$\begin{array}{l}\text { GNP In Constant } \\
\text { Dollars (RGNP) }\end{array}$} & \multicolumn{2}{|c|}{$\begin{array}{l}\text { Implicit Price } \\
\text { Deflacor (IPD) }\end{array}$} \\
\hline & & $\begin{array}{l}\text { ARMSE } \\
\text { (1) }\end{array}$ & $\begin{array}{l}\text { Rank } \\
\text { (2) }\end{array}$ & $\begin{array}{c}\text { ARMSE } \\
\text { (3) }\end{array}$ & $\begin{array}{l}\text { Rank } \\
\text { (4) }\end{array}$ & $\begin{array}{c}\text { ARHSE } \\
\text { (5) }\end{array}$ & $\begin{array}{r}\text { Rank } \\
\text { (6) }\end{array}$ \\
\hline 1 & NBER-ASA median & 1.90 & 4 & 1.94 & 7 & 1.53 & 7 \\
\hline 2 & NBER-ASA consensus & 1.586 & 1 & 1.58 & 3 & 1.21 & 5 \\
\hline 3 & MIchlgan (RSQE) & 1.98 & 5 & 1.87 & 5 & 1.42 & 6 \\
\hline 4 & $\operatorname{BVAR}(A)$ & 2.69 & 8 & 1.90 & 6 & 1.62 & 8 \\
\hline 5 & BVAR (B) & 1.89 & 3 & 1.40 & 1 & 1.03 & 3 \\
\hline 6 & Sims (A) & 2.30 & 7 & 2.08 & 8 & .97 & 2 \\
\hline 7 & Sims (B) & 1.594 & 2 & 1.47 & 2 & .66 & 1 \\
\hline 8 & SIms-Todd ARIMA(A) & 3.05 & 9 & 2.26 & 9 & 1.69 & 9 \\
\hline 9 & SIms-Todd ARIMA (B) & 2.03 & 6 & 1.60 & 4 & 1.09 & 4 \\
\hline
\end{tabular}

NOTE: ARMSE (average root wean square error) is computed by taking the mean of the RMSEs across the five spans $0-1, \ldots .0-5$. The swallest ARMSE is ranked 1 , the largest ARMSE is ranked 9. for each of the three variables.

SOURCE: Line 1 is based on entrles in table 10. Iine 3, columns 1-5: 1ine 2, on cable 9, column 6: IIne 3, on cable 21. column 3: lines 4 and 5 , on cable 13 . coluon 3: lines 6 and 7, on cable 24, column 3: and lines 8 and 7 . on cable 26. column 4 . 
Table 30

Six Sets of Forecast: Ranked According to their RMSEs Averaged Across Spans, 21 Variables. 1968:4-1990:1, 1968:4-1981:2 and 1981:3-1990:1

\begin{tabular}{|c|c|c|c|c|c|c|c|}
\hline \multirow[b]{2}{*}{ Line } & \multirow[b]{2}{*}{ Variable* } & \multicolumn{6}{|c|}{ sveraze Roor Mean Souare Frror (ARMSE) and the Corresponding Rank } \\
\hline & & $\begin{array}{l}\text { NBER-ASA Surveys } \\
\text { Median Individual } \\
\text { Forecast } \\
\text { (1) }\end{array}$ & $\begin{array}{c}\text { Group } \\
\text { (Consensus) } \\
\text { Forecast } \\
\text { (2) }\end{array}$ & $\begin{array}{c}\text { BVAR } \\
\text { Model } \\
\text { Forecast } \\
\text { (3) }\end{array}$ & $\begin{array}{l}\text { Michigan } \\
\text { (RSQE) } \\
\text { Forecast } \\
\text { (4) }\end{array}$ & $\begin{array}{c}\text { Sims } \\
\text { Probabilistic } \\
\text { Model } \\
\text { Forecast } \\
\text { (5) }\end{array}$ & $\begin{array}{l}\text { ARIMA } \\
\text { Model } \\
\text { Forecast } \\
\quad(6)\end{array}$ \\
\hline \multicolumn{8}{|c|}{$1968: 4-1990: 1$} \\
\hline $\begin{array}{l}1 \\
2 \\
3 \\
4 \\
5 \\
6 \\
7\end{array}$ & $\begin{array}{l}\text { GNP } \\
\text { RCNP } \\
\text { IPD } \\
\text { IP } \\
\text { CP } \\
\text { UR } \\
\text { HS }\end{array}$ & $\begin{array}{r}1.90(2) \\
1.94(4) \\
1.53(4) \\
4.02(3) \\
18.38(3) \\
.71(4) \\
.33(3)\end{array}$ & $\begin{array}{r}1.59(1) \\
1.58(1) \\
1.21(2) \\
3.56(2) \\
17.13(2) \\
.62(3) \\
.29(2)\end{array}$ & $\begin{array}{r}2.69(5) \\
1.90(3) \\
1.62(5) \\
3.42(1) \\
13.71(1) \\
.61(2) \\
.26(1)\end{array}$ & $\begin{array}{l}1.98(3) \\
1.87(2) \\
1.42(3) \\
n .2 . \\
\text { n.a. } \\
.60(1) \\
\text { n.a. }\end{array}$ & $\begin{array}{l}2.30(4) \\
2.08(5) \\
.97(1) \\
\text { n.a. } \\
\text { n.a. } \\
1.00(5) \\
\text { n.a. }\end{array}$ & $\begin{array}{l}3.05(6) \\
2.26(6) \\
1.69(6) \\
\text { n.a. } \\
\text { n.a. } \\
1.21(6) \\
\text { n.a. }\end{array}$ \\
\hline \multicolumn{8}{|c|}{$1968: 4-1981: 2$} \\
\hline $\begin{array}{r}8 \\
9 \\
10 \\
11\end{array}$ & $\begin{array}{l}C D \\
P E \\
D E F \\
C B I\end{array}$ & $\begin{array}{r}5.65(2) \\
11.49(3) \\
3.92(2) \\
11.38(1)\end{array}$ & $\begin{array}{r}5.05(1) \\
11.08(2) \\
3.34(1) \\
12.38(2)\end{array}$ & $\begin{array}{r}5.93(3) \\
4.35(1) \\
8.19(4) \\
13.94(3)\end{array}$ & $\begin{array}{l}\text { n.a. } \\
\text { n.a. } \\
4.46(3) \\
\text { n.a. }\end{array}$ & $\begin{array}{l}\text { n.a. } \\
\text { n.a. } \\
\text { n.a. } \\
\text { n.a. }\end{array}$ & $\begin{array}{l}\text { n.a. } \\
\text { n.a. } \\
\text { n.a. } \\
\text { n.a. }\end{array}$ \\
\hline \multicolumn{8}{|c|}{$2981: 3-1990: 1$} \\
\hline $\begin{array}{l}12 \\
13 \\
14 \\
15 \\
16 \\
17 \\
18 \\
19 \\
20 \\
21\end{array}$ & $\begin{array}{l}\text { RCBI } \\
\text { NX } \\
\text { PCE } \\
\text { NFI } \\
R F I \\
\text { FCP } \\
\text { SLCP } \\
\text { CPI } \\
\text { TBR } \\
\text { CBY }\end{array}$ & $\begin{array}{r}19.69(2) \\
47.29(3) \\
1.30(3) \\
6.06(5) \\
9.59(3) \\
4.96(2) \\
1.47(3) \\
1.19(3) \\
1.71(3) \\
1.64(3)\end{array}$ & $\begin{array}{r}18.96(1) \\
44.19(2) \\
1.24(2) \\
1.11(1) \\
1.22(1) \\
1.38(1) \\
.94(1) \\
.52(1) \\
1.35(2) \\
1.28(2)\end{array}$ & $\begin{array}{r}26.69(3) \\
21.02(1) \\
5.69(4) \\
5.25(2) \\
8.70(2) \\
8.54(3) \\
1.27(2) \\
.76(2) \\
2.03(4) \\
1.72(4)\end{array}$ & $\begin{array}{c}\text { n.a. } \\
\text { n.a. } \\
1.13(1) \\
5.80(4) \\
10.81(4) \\
\text { n.a. } \\
\text { n.a. } \\
\text { n.a. } \\
1.26(1) \\
1.13(1)\end{array}$ & $\begin{array}{l}\text { n.a. } \\
\text { n.a. } \\
\text { n.a. } \\
5.43(3) \\
\text { n.a. } \\
\text { n.a. } \\
\text { n.a. } \\
\text { n.a. } \\
2.14(5) \\
\text { n.a. }\end{array}$ & $\begin{array}{l}\text { n.a. } \\
\text { n.a. } \\
\text { n.a. } \\
\text { 6.14(6) } \\
\text { n.a. } \\
\text { n.a. } \\
\text { n.a. } \\
\text { n.a. } \\
\text { 2.67(6) } \\
\text { n.a. }\end{array}$ \\
\hline
\end{tabular}

n.a. - not avallable.

On the symbols used, see previous tables and cext.

bARMSE - average of the RMSEs across the five horizons $(0-1, \ldots 0-5$ or $1, \ldots 5)$. Entries in parentheses represent ranks according to ARMSE (smallest to largest). 
Table 31

Six Secs of Forecasts Ranked According to Their Overall Accuracy Across Varlables by Perlod, 1968:4-1990:1. 1968:4-1981:2, and 1981:2-1990:1

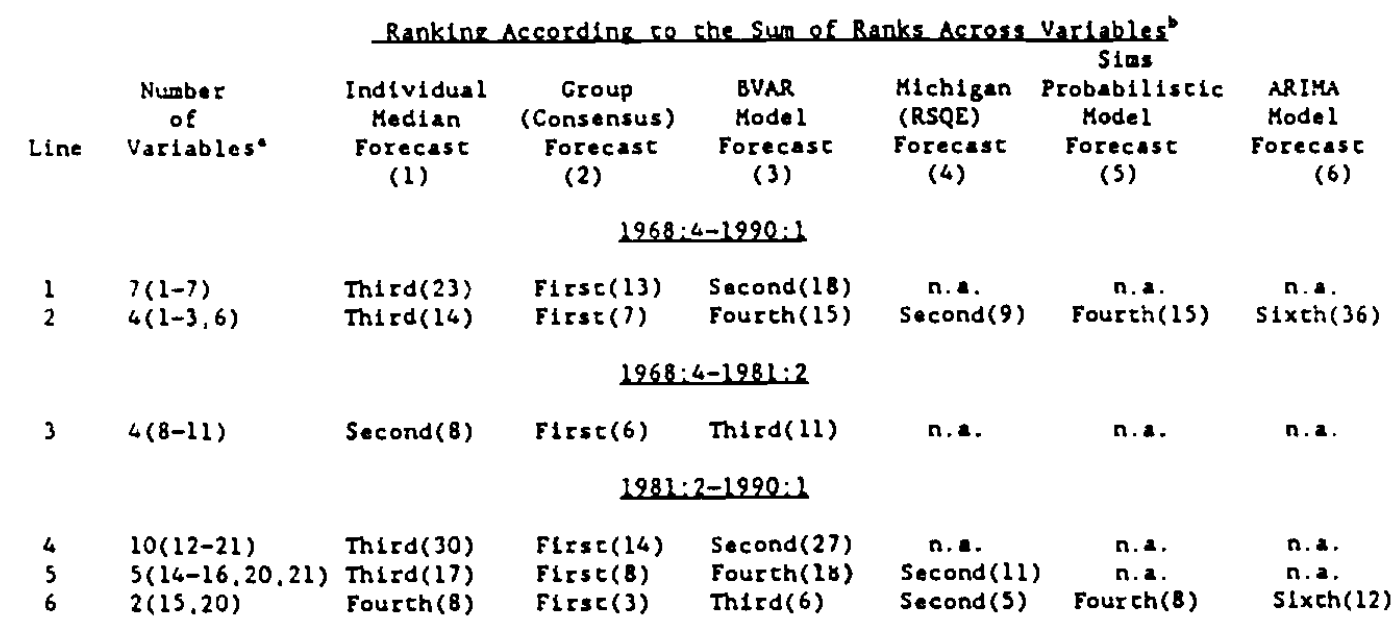

n.a. - not avallable.

'Idencified by lines in Table 30 in parentheses.

bsum of the ranks frow Table 30 is given in parentheses. 
Braun, P.A. and I. Yaniv, 1991. "A Case Study of Expert Judgment: Economists Probabilistic Forecasts," mimeo, Universicy of Chicago.

Burns, A.F. and W.C. Micchell. 1946. Measuring Business Cycles. New York: NBER.

Butler, W.F. and R.A. Kavesh. 1974. "Judgmental Forecasting of the Gross National Product" in W.F. Butler, R.A. Kavesh, and R.B. Plact, eds., Methods and Techniques of Business Forecasting. Englewood Cliffs, N.J.: Prentice-Hall. Inc., Pp. 207-221.

Carlson, J.A. 1977. "Study of Price Forecasts." Annals of Economic and Social Measurement, vol. 6, no. 1 (Winter), pp. 27-56.

Clemen, R.T. 1989. "Combining Forecasts: A Review and Annotated Bibliography." International Journal of Forecasting, vol. 5, no. 4, pp. 559-583.

Cole, R. 1969. Errors in Provisional Estimates of Gross National Product. New York: NBER.

Cox, G.V. 1929. An Appraisal of American Business Forecasts. Chicago: University of Chicago Press.

Dominguez, K.M. R.C. Falr, and M.D. Shapiro, 1988. "Forecasting the Depression: Harvard versus Yale,"American Economic Review, vol. 78, no. 4 (September). pp. 595-612.

Evans, M.K., Y. Haltovsky, and C.I, Treyz, assisted by V. Su. 1972. "An Analysis of the Forecasting Properties of U.S. Econometric Models." In G. Hickman. ed. Econometric Models of Cyclical Behavior. New York: Columbia University Press for NBER, vol. 2. PP. 949-1158.

Fels, R. and C.E. Hinshaw. 1968. Forecasting and Recognizing Business Cvcle Turning Poincs. New York: NBER.

Grunberg. E. and F. Modigliani. 1954. "The Predictability of Social Events," Joumal of Polftical Economy, vol. 62, no. 6 (December), pp. $465-478$.

Haitovsky, Y., G.I. Treyz, and V. Su. 1974. Forecascs with Quarterly Macroeconometrle Models. New York: NBER.

Hicks, J.R. 1979. Causality in Economics. New York: Basic Books.

Keynes, J.M. 1936. The General Theory of Enoloyment. Interest and Money. London: Macmllian.

Knight, F.M 1921. Risk. Uncertalnty and Proflc. Boston: Houghton-Mifflin. 
Litterman, R.B. 1986. "Forecasting with Bayesian Vector Autoregressions - Five Years of Experience," Journal of Business Economics Statistics, vol. 4. no. I (January), pp. 25-38.

McCloskey, D.N. 1988. "The Limlts of Expertise: If You' re So Smart, Why Ain't You Rich?, "The American Scholar. Summer, Pp. 393-406.

McNees, S.K. 1979. "The Forecasting Record of the 1970s, "New England Economic Review, Sepcember/October: 1-21.

Mincer, J. 1969. Economic Forecasts and Expectations: Analyses of Forecasting Behavior and Performance. New York: Columbia University Press for NBER.

Moore, G.H. 1969. "Forecasting Short-Term Economic Change," Journal of the Amerfcan Statistical Association, 64(March): 1-22.

Morgenstern, 0 . 1928. Wirtschaftspregnose: Eine Untersuchung threr Vorausserzungen and Moglichkeften. Wien: Springer.

Niemira, M. and P.A. Klein. 1991. "Forecasting the Great Depression Using Cyclical Indicators: Another Look," mimeo. New York: Mitsubishi Bank.

Okun, A.M. 1959. "A Review of Some Economic Forecasts for 1955-57." Journal of Business, vol. 32 (July): 199-21l.

Sims, C.A. 1989. NA Nine-Variable Probabilist1c Macroeconomic Forecasting Model, Discussion Paper 14. Institute for Empirical Macroeconomics. Federal Reserve Bank of Minnesota. (May) mimeo.

Sims, C.A. and R.M. Todd. 1991. "Evaluating Bayesian Vector Autoregressive Forecasting Procedures for Macroeconomlc Data: Part 2, presented at NSFNBER Seminar on Bayesian Inference in Econometrics and Statistics, St. Paul, Minnesota (April).

Solow, R.M. 1985. "Economic History and Economics, "American Economic Review, vol. 75, no. 2, (May), pp. 328-331.

Stekler, H.O. 1968. "Forecasting with Econometric Models: An Evaluation," Econometrica, vol. 36, Pp. 437-463.

Su, V. and J. Su. 1975. "An Evaluation of the ASA/NBER Business Outlook Survey Forecasts, "Explorations in Economic Research, vol. 2, pp. 588-618.

Suits, D. B. 1962. "Forecasting and Analysis with an Econometrlc Model." American Economic Review, vol. 52, pp. 104-132.

Thorp. W.L. 1926. Buslness Annals. New York: NBER.

The 11. H. 1961. Economic Forecasts and Pollcy. 2nd rev. ed., Amsterdam: North-Holland. 
Theil, H. 1966. Apolied Economic Forecasting. Amsterdam: North-Holland. Chicago: Rand McNally.

Theil, H. 1967. Economics and Information Theory. Amsterdam: North Holland. Chicago: Rand McNally.

Zarnowitz, V. 1967. An Appraisal of Short-Term Economic Forecast. New York: NBER.

Zarnowitz, V. 1968. "The New ASA-NBER Survey of Forecasts by Economic Statisticians" A Supplement to Nactonal Bureau Report 4 (December). Also in The American Statistician, vol. 23, no. 1, Pp. 12-16.

Zarnowitz, V. 1971. "New Plans and Results of Research in Economic Forecasting." Fifty-first Annual Report. New York: NBER.

Zarnowitz, V. 1972. Forecasting Economic Conditions: The Record and the Prospect," in V. Zarnowitz, ed. , The Business Cycle Today, Columbia University Press for NBER, pp. 183-239.

Zarnowitz, v. 1979. "An Analysis of Annual and Multiperiod Quarterly Forecasts of Aggregate Income, Output, and the Price Level." Journal of Business, vol. 52, no. 1, pp. 1-33.

Zarnowitz, V. 1982. "Improvements and New Studies of the Economic Outlook Survey, NBER Reporter, Summer 1982, pp. 11-13.

Zarnowitz, v. 1983. "Some Lessons from Research in Macroeconomic Forecasting." Economic Outiook USA, vol. 10 , no. 4 (Autumn), pp. 83-86.

Zarnowitz, V. 1984. The Accuracy of Individual and Group Forecasts from Business Outlook Surveys." Journal of Forecasting, vol. 3, no. I (JanuaryMarch), pp.11-26.

Zarnowitz, V. 1985. "Rational Expectations and Macroeconomic Forecasts." Journal of Business \& Economic Statistics, vol. 3, no. 4 (October). pp. 293-311.

Zarnowitz, v. 1991a. Business Cycles: Theories. History. Indicators and Forecasting. University of Chicago Press for NBER. In print.

Zarnowitz, V. 1991b. "Has Macro-Forecasting Failed?, Money Macroeconomics. and Forecasting. Cato Institute' s Ninth Annual Monetary Conference (February).

Zarnowitz, V. and P. Braun, 1990. Major Macroeconomic Variables and Leading Indexes: Some Estimates of Their Interrelations," In P.A. Klein, ed., Analyzine Modern Business Cycles: Essays Honoring Geoffrey $H$. Moore. Arwonk, N.Y.: M.E. Sharpe, Inc., PP. 177-205.

Zarnowitz, V. and L.A. Lambros. 1987. "Consensus and Uncertainty in Economic Prediction." Journal of Political Economy, vol. 95, no. 3 (June), pp. 591.621 . 
Appendix

Appendix: Forecasts of Diverse Macroeconomic Series, 1968-81 and 1981-90

\section{A. 1 Selected Nominal Aggregates, 1968-81}

Current-dollar expenditures on durable consumer goods, business plant and equipment, and national defense (CD, $P E$, and $D E F$, respectively) all contribute strongly to the cyclicality and volatility of quarterly changes in GNP. DEF is generally treated as an important exogenous varlable.

The statistics for wean errors suggest that underestimates prevailed in the forecasts of $C D$ and $P E$, overestimates in those of $D E F$, but there is much dispersion across the Individual respondents here, which increases strongly with the forecast hortzon (Table A.1, columns 1-3). The RMSE measures show much the same kind of progression (columns 4-6). The forecast errors generally are at least smaller than the actual percent changes in CD. PE, and DEF, but often not by much, as can be seen by comparing the corresponding entries in columns 4-6 and 9-11. Most of the SK and $K U$ values are small, and only a few for CD and DEF may be significant (columns 7 and 8 ).

The gains from averaging across the Individual forecasts are modest for CD and DEF and, perhaps surprisingly, hardly existent for PE (Table A.2, columns 14). The RMSE ratios for PE are closely clustered, Indicating lack of differentiation among the forecasts for this varlable. One possible reason may be the avallability and influence of the quarterly anticipation series for plant and equipment outlays.

The RMSEs of our BVAR forecasts are larger than those of the group mean forecasts for $C D$, and much larger for DEF. In contrast, BVAR is found to be wuch more accurate than the survey averages for PE. Indeed, the RMSE ratios 1/bv are relatively very low for $C D$ and $D E F$, very high for PE throughout. (Compare the 
corresponding measures in columns $1-4$ and 5-8).

Finally, the NBER-ASA survey questionnalre used through 1981:2 asked for forecasts of the levels of inventory investment in current dollars (CBI), anocher important but highly volatile and hard-to-predict variable. Table A.3 shows that the mean errors and root mean square errors for CBI increased markedly with the span, while the corresponding standard deviation did not ( 1 ines $1-5$ ). The $M$ and MD statistics for mean errors are all positive here, the RMSE for target quarter $5(1 . e . t+4)$ is about equal to the actual RMSV.

Apparently. CBI is another of those rare cases in which combining the individual survey forecasts is of litele help. The group mean's RMSE is relatively large, and even the lower quartile $i / g$ ratios are close to one (see Table A.4, Iines 1-5). However, our BVAR model performs somewhat worse still here (cf. columns $1-4$ and 5-8).

\section{A. 2 Components of Real GNP $1981-90$}

After mid-1981, the survey collected forecasts of the main GNP expenditure categories in constant dollars. We start with real inventory investment (RCBI). to follow up on the preceding. It turns out that the RCBI forecasts for 1981-90, like the CBI forecasts for 1981-90, have RMSEs that are large relative to the average actual levels and their variability, especially for the more distant target quarters (Table A.3, Iines 6-10). The average MEs are negative but very small, the SDs are large and stable. Again. little is gained by averaging the individual forecasts, but the group mean forecasts do have a distinct advantage over the BVAR forecasts (Table A.4, lines 6-10).

Similarly, real net exports $(N X)$ were on the whole poorly predicted in the 1980s, as seen from the large relative size of the summary error measures in 
Table A.3, lines 11-15. For $N X$, too, the group mean forecasts do not help much. but in this case the BVAR forecasts are found to be much more accurate (Table A.4, lines 11-15).

One would expect total consumption (PCE), the largest and smoothest component of real GNP, to be the easiest to predict and in fact best predicted. A relatively small but smooth and presumably also well predictable series should be that of state and local government purchases (SLGP). Federal government purchases (FCP) are more autonomous and volatile, hence more difficult to forecast. Residential fixed investment (RFI) is another hard problem for the forecasters, though for different reasons: it is highly cyclical and an early leading series (construction lags behind housing permits and starts are short). Nonresidential fixed investment (NFI) has more persistence, more of an upward trend, and lags at cyclical turning points, which should make it more predictable than RFI. Also, NFI is anticipated with long leads by new capital appropriations and contracts and orders for plant and equipment- but these monthly series on business investment commitments are themselves very volatile.

The evidence on the forecasts of percent changes in PCE, NFI, RFI, FCP, and SLGP is generally consistent with these priors. Thus, forecasts of growth in PCE four quarters ahead have errors averaging about half the actual percent change (Table A.S, lines 1-S). This is not great but fair, and in sharp contrast to the apparent failure of forecasts of inventory investment (the least predictable of the components of aggregate demand). The RMSEs of the NFI forecasts are much smaller than their counterparts for RFI (but the actual percent changes are also smaller for NFI; cf. the corresponding entries in lines 6-10 an 11-15). The SLGP forecasts are definitely much more accurate than the FGP forecasts (cf. lines 1620 and $21-25$ ). 
The forecasts share some characteristics across all the varlables. All the $M$ and $M D$ statistics for mean errors are negative. suggesting a prevalence of underprediction errors (columns 1 and 3 ). The absolute values of these statistics increase with the span in each case. Indeed, all the summary error measures, except SK and KU, show such increases, as do the statistics for actual values. ${ }^{16}$ The means of the RMSEs are generally larger than the medians, and SK $>0$. The KU statistics are large in some cases, particularly for NFI (shore forecasts) and SLGP.

Combining the individual forecasts into group means reduces the RMSEs for each variable and span, as can be seen by comparing column 1 in Table A.6 with column 6 (and fertiori with colum 4) in Table A.5. At the lower quartile $Q_{1}$, the RMSE ratios $1 / 8$ are close to one throughout; the range of the median ratios is about 1.1-1.3, that of the $Q_{3}$ ratios is 1.2-1.7. The group mean forecasts perform best (the ratios are highest) for PCE and SLCP. (See Table A.6, columns 2-4).

Our BVAR forecasts have larger RMSEs than the NBER-ASA group mean forecasts 80 percent of the time, according to the paired entries in columns 1 and 5 of Table A.6. They are very poor for PCE and definitely inferior for FGP, whereas elsewhere the differences are much smaller (cf. columns 1-4 and 5-8).

\section{A. 3 Consumer Price Inflation and Interest Rates. 1981-90}

Forecasters underpredicted the CPI inflation fust as they did the IPD inflation (see the negative signs of the mean errors in Table A.7, Iines 1-5. columns 1 and 3 ). The RMSEs of these forecasts are discouragingly large compared to the descriptive statistics for the actual values (cf. columns 4 and 6 with 11 . in particular). Note that the NBER-ASA survey questionnaire asked directly for 
forecasts of the level of CPI inflacion at annual race in the current quarter and the following four quarters (not for forecasts of the CPI itself).

In contrast, the forecasts of the 3-month Treasury bill race (TBR) had relatively small errors according to these comparisons (1ines 6-10). The forecasts of the (new high-grade) corporace bond yield (CBY) were even more accurace (1ines 11-15).

Despite the already noted weakness of wost of the individual CPI forecasts. the corresponding group mean forecasts perform relatively well. Their RMSEs are considerably smaller than those of the BVAR model, and less than half those of che average individual forecasts (cf. Table A.8, lines 1-5, and Table A.7, lines 1-5. columns 4 and 6 ). The $i / g$ ratios cluster close to one between $Q_{1}$ and $Q_{2}$. which indicates that the forecasts concerned are remarkably alike.

For the interest rates $T B R$ and $C B Y$, combining the individual forecasts greatly reduces errors, but with notable exceptions at the most distant target quarter (5). Here the RMSEs are much larger for the BVAR than the group mean forecasts, and correspondingly the 1 /ov ratios are much lower than the $1 / g$ ratios (cf. Table A.8, lines $6-15$, columns $1-4$ and 5-8). 
Table A.1

Selected Measures of Forecast Accuracy and Actual Values. Percent Changes In Expenditures for Consumer Durable Coods, Plant and Equipment, and National Defense. by Span. 1968-81

Line

Span (Qs)
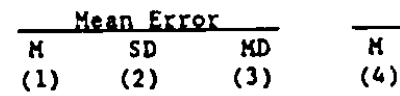

Roor

(4)

Consumer Expenditures for Durable Goods (CD)

$\begin{array}{lrrr}0-1 & -.79 & .73 & -.87 \\ 0-2 & -1.10 & 1.26 & -1.18 \\ 0-3 & -1.30 & 1.59 & -1.26 \\ 0-4 & -.97 & 2.07 & -.87 \\ 0-5 & -1.23 & 2.61 & -.74\end{array}$

$3.60 \quad 1.06$

$5.35 \quad 1.80$

$6.30 \quad 1.52$

$6.94 \quad 1.83$

8,39

Plant and Eoutpment Expenditures (PE)

3.42

4.95
5.96

$\begin{array}{llll}0-1 & -.71 & 1.02 & -.51 \\ 0-2 & -1.24 & 1.89 & -1.24 \\ 0-3 & -1.69 & 2.55 & -1.95 \\ 0-4 & -1.83 & 3.12 & -1.95 \\ 0-5 & -2.77 & 4.18 & -2.46\end{array}$

$5.49 \quad 1.75$

8.492 .52

$11.51 \quad 2.84$

$13.78 \quad 3.26$

$16.46 \quad 3.68$
$6.45-1.73 \quad 4.03$

23.83

5.69

9.00

11.82

$-.07$

$14.17-.32$

$16.79-.60$

\section{National Defense Expenditures (DEF)}

$\begin{array}{rrrr}11 & 0-1 & .16 & .55 \\ 12 & 0-2 & .21 & .97 \\ 13 & 0-3 & .17 & 1.52 \\ 14 & 0-4 & .04 & 2.06 \\ 15 & 0-5 & -.23 & 2.62\end{array}$

$\begin{array}{llll}2.33 & .56 & 2.25 & .54\end{array}$

$\begin{array}{llll}3.48 & .97 & 3.41 & .72\end{array}$

$\begin{array}{llll}4.19 & 1.21 & 4.05 & 1.02\end{array}$

$\begin{array}{llll}4.80 & 1.57 & 4.51 & 1.80\end{array}$

$\begin{array}{llll}5.79 & 1.94 & 5.38 & 2.21\end{array}$

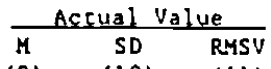

$\begin{array}{ll}M & \text { SD } \\ \text { (9) } & (10)\end{array}$

NotE: On the symbols used, see previous tables and text. 
Table A. 2

Individual, Group Mean, and BVAR Forecasts of Percent Changes in Expenditures for Consumer Durable Coods, Plant and Equipment, and National Defense, Selected Comparisons, by Span, 1968-81

\begin{tabular}{|c|c|c|c|c|c|c|c|c|c|}
\hline & & Group Mean & RMSE & Racto & $1 / 2$ & BVAR & RM & lacto & Lov \\
\hline Line & $\operatorname{Span}(Q s)$ & $\begin{array}{l}\text { RMSE } \\
\text { (1) }\end{array}$ & $\begin{array}{l}Q_{1} \\
(2)\end{array}$ & $\begin{array}{l}M D \\
(3)\end{array}$ & $\begin{array}{l}Q_{3} \\
(4)\end{array}$ & $\begin{array}{l}\text { RMSE } \\
\text { (5) }\end{array}$ & $\begin{array}{l}Q_{1} \\
(6)\end{array}$ & $\begin{array}{l}M D \\
(7)\end{array}$ & $\begin{array}{l}Q_{3} \\
(8)\end{array}$ \\
\hline
\end{tabular}

Consumer Expenditures for Durable Goods (CD)

$\begin{array}{rrrrrrrrrrr}1 & 0-1 & 3.23 & .95 & 1.12 & 1.34 & 3.98 & .72 & .93 & 1.05 \\ 2 & 0-2 & 4.70 & 1.01 & 1.11 & 1.23 & 5.23 & .88 & 1.02 & 1.15 \\ 3 & 0-3 & 5.38 & 1.02 & 1.13 & 1.31 & 6.27 & .88 & .98 & 1.19 \\ 4 & 0-4 & 5.50 & 1.06 & 1.16 & 1.36 & 6.74 & .84 & .96 & 1.13 \\ 5 & 0-5 & 6.42 & 1.04 & 1.17 & 1.43 & 7.45 & .83 & .99 & 1.18\end{array}$

\section{Plant and Equipment Expendifures (PE)}

$\begin{array}{rrrrrrrrrr}6 & 0-1 & 5.82 & 1.01 & 1.05 & 1.09 & 2.19 & 1.87 & 2.72 & 3.04 \\ 7 & 0-2 & 8.96 & 1.01 & 1.07 & 1.10 & 3.16 & 2.19 & 2.83 & 3.33 \\ 8 & 0-3 & 11.54 & 1.00 & 1.06 & 1.10 & 4.47 & 2.36 & 2.79 & 3.20 \\ 9 & 0-4 & 13.76 & 1.00 & 1.05 & 1.12 & 5.51 & 2.39 & 2.70 & 3.30 \\ 10 & 0-5 & 15.69 & .98 & 1.05 & 1.13 & 6.41 & 2.50 & 2.89 & 3.55\end{array}$

Nacional Defense Expenditures (DEF)

$\begin{array}{llllllllll}11 & 0-1 & 1.78 & 1.07 & 1.19 & 1.38 & 2.85 & .66 & .75 & .87 \\ 12 & 0-2 & 2.73 & 1.05 & 1.16 & 1.34 & 5.78 & .47 & .54 & .63 \\ 13 & 0-4 & 3.31 & 1.02 & 1.17 & 1.38 & 8.53 & .38 & .45 & .54 \\ 14 & 0-4 & 3.91 & 1.03 & 1.20 & 1.44 & 10.55 & .35 & .43 & .50 \\ 15 & 0-5 & 4.96 & 1.05 & 1.22 & 1.44 & 13.25 & .32 & .38 & .48\end{array}$

NOTE: On the symbols used, see previous tables and text. 
Table A.3

Selected Measures of Forecasc Accuracy and Actual Values. Nominal and Real Inventory Investaenc and Real Net Exports, by Span. 1968-81 and 1981-90

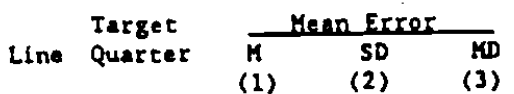

M

Roer Mean Souare Error

M SD KD SK KU

$\frac{\text { Actual Value }}{\text { AT SOSV }}$

(1) (2) (3)

(4)

(5)

(6)

(8)

(9) (10) (11)

Chanke in Business Inventertes $1968-8)(C B I)$

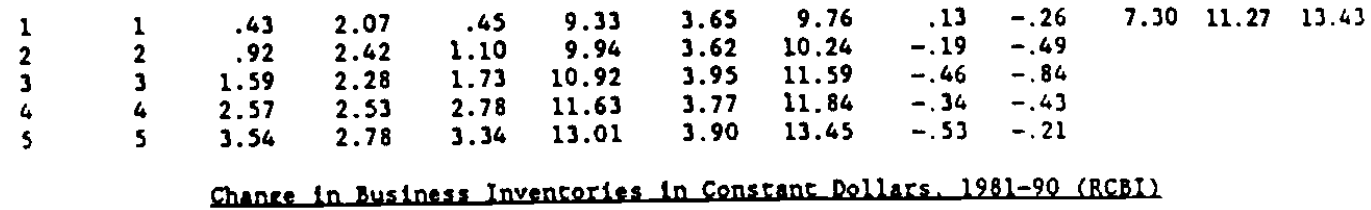

$\begin{array}{rrrrrrrrrrrrr}6 & 1 & -.20 & 2.94 & -.18 & 18.27 & 4.64 & 18.58 & .58 & 1.35 & 14.58 & 20.37 & 25.05 \\ 7 & 2 & -.47 & 3.57 & .27 & 18.90 & 3.72 & 19.26 & -.02 & -.07 & & & \\ 8 & 3 & -1.09 & 3.26 & -.83 & 19.70 & 3.78 & 19.35 & .47 & .35 & & & \\ 9 & 4 & -.08 & 3.73 & -.64 & 20.46 & 4.10 & 20.25 & .41 & -.22 & & & \\ 10 & 5 & -.69 & 4.41 & -.58 & 21.06 & 4.47 & 21.03 & .70 & .75 & & & \end{array}$

Nec Exports of Goods and services in Constant Dollars. 1981-90 (NX)

\begin{tabular}{|c|c|c|c|c|c|c|c|c|c|c|}
\hline $\begin{array}{l}11 \\
12 \\
13 \\
14 \\
15\end{array}$ & $\begin{array}{l}1 \\
2 \\
3 \\
4 \\
5\end{array}$ & $\begin{array}{r}9.33 \\
14.52 \\
21.36 \\
27.04 \\
31.53\end{array}$ & $\begin{array}{r}6.02 \\
8.81 \\
10.72 \\
12.72 \\
15.13\end{array}$ & $\begin{array}{r}7.48 \\
12.99 \\
18.35 \\
27.36 \\
28.56\end{array}$ & $\begin{array}{l}28.83 \\
37.89 \\
47.60 \\
54.15 \\
60.21\end{array}$ & $\begin{array}{r}9.87 \\
12.21 \\
12.79 \\
12.06 \\
12.31\end{array}$ & $\begin{array}{l}31.32 \\
40.35 \\
48.36 \\
55.81 \\
60.63\end{array}$ & $\begin{array}{l}-.90 \\
-1.15 \\
-1.02 \\
-1.09 \\
-1.38\end{array}$ & $\begin{array}{r}.35 \\
.94 \\
1.21 \\
1.68 \\
2.89\end{array}$ & -53.1966 .09 \\
\hline
\end{tabular}

NOTE: On the symbols used, see previous tables and cexc. 
Table A.4

Individual. Group Mean, and BVAR Forecasts of Nominal and Real Inventory Investment and Real Net Exports, Selected Comparisons. by Span, 1968-81 and 1981-90

\begin{tabular}{|c|c|c|c|c|c|c|}
\hline & Target & Group Mean & RMSE Ratios & $1 s$ & BVAR. * & RMSE Ratlos i/bv \\
\hline & Quarter & $\begin{array}{l}\text { RMSE } \\
\text { (1) }\end{array}$ & $\begin{array}{cc}Q_{2} & M D \\
(2) & (3)\end{array}$ & $\begin{array}{l}Q_{3} \\
(4)\end{array}$ & $\begin{array}{l}\text { RMSE } \\
(5)\end{array}$ & $\begin{array}{l}\text { MD } \\
\text { (7) }\end{array}$ \\
\hline
\end{tabular}

Change in Bustness Inventerles. 1968-81 (CBI)

$\begin{array}{rrrrrrrrrr}1 & 1 & 10.57 & .98 & 1.07 & 1.15 & 10.70 & .83 & 1.03 & 1.15 \\ 2 & 2 & 10.75 & .97 & 1.07 & 1.18 & 13.32 & .72 & .89 & 1.02 \\ 3 & 3 & 12.69 & .99 & 1.07 & 1.16 & 14.17 & .76 & .95 & 1.07 \\ 4 & 4 & 13.41 & 1.00 & 1.06 & 1.12 & 16.24 & .78 & .91 & 1.09 \\ 5 & 5 & 14.50 & 1.00 & 1.05 & 1.12 & 15.28 & .81 & .99 & 1.12\end{array}$

Change in Business Inventories in Constanc Dollars, 1981-90 (RCBI)

$\begin{array}{rrrrrrrrrr}6 & 1 & 17.87 & .96 & 1.03 & 1.14 & 19.78 & .76 & .91 & 1.08 \\ 7 & 2 & 18.35 & .99 & 1.06 & 1.12 & 25.95 & .52 & .72 & .82 \\ 8 & 3 & 19.19 & 1.00 & 1.05 & 1.13 & 28.45 & .50 & .66 & .80 \\ 9 & 4 & 19.40 & .97 & 1.06 & 1.20 & 29.38 & .52 & .68 & .95 \\ 10 & 5 & 20.01 & .98 & 1.02 & 1.11 & 29.89 & .55 & .68 & .84\end{array}$

Net Exports of Goods and Services in Constant Dollars. 1981-90 (NX)

$\begin{array}{llllllllll}11 & 1 & 28.04 & 1.00 & 1.03 & 1.07 & 13.28 & 2.06 & 2.30 & 2.60 \\ 12 & 2 & 36.45 & 1.00 & 1.04 & 1.14 & 17.71 & 2.00 & 2.21 & 2.65 \\ 13 & 3 & 44.91 & .98 & 1.03 & 1.11 & 19.66 & 2.17 & 2.45 & 2.78 \\ 14 & 4 & 52.11 & .98 & 1.03 & 1.10 & 23.08 & 2.16 & 2.36 & 2.51 \\ 15 & 5 & 59.44 & .97 & 1.02 & 1.08 & 31.39 & 1.79 & 1.94 & 2.13\end{array}$

NOTE: On the symbols used, see previous tables and text. 
Table A.5

Selected Measures of Forecast Accuracy and Actual Values, Percent Changes in Consumption, Investment, and Government Components of Real CNP.

by Span. 1981-90
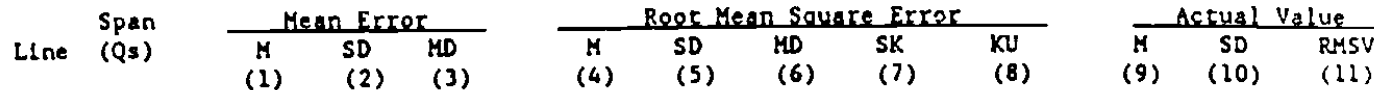

Personal Consumpeton Expendicures (PCE)

$\begin{array}{llllllllllll}0-1 & -.14 & .20 & -.14 & .83 & .30 & .68 & 1.61 & 2.17 & .78 & .69 & 1.04 \\ 0-2 & -.26 & .29 & -.29 & 1.10 & .42 & .94 & 1.81 & 2.67 & 1.58 & .99 & 1.86 \\ 0-3 & -.47 & .46 & -.44 & 1.45 & .51 & 1.27 & 1.96 & 3.74 & 2.44 & 1.22 & 2.73 \\ 0-4 & -.63 & .65 & -.59 & 1.80 & .64 & 1.60 & 1.96 & 4.33 & 3.33 & 1.41 & 3.62 \\ 0-5 & -.85 & .85 & -.74 & 2.23 & .86 & 2.00 & 2.03 & 4.02 & 4.22 & 1.69 & 4.55\end{array}$

Nencestdenelal Elxed Investment (NFI)

6
7
8
10

$\begin{array}{llll}0-1 & -.59 & .91 & -.71 \\ 0-2 & -1.22 & 1.42 & -1.26 \\ 0-3 & -1.47 & 1.88 & -1.51 \\ 0-4 & -2.31 & 2.38 & -2.36 \\ 0-5 & -2.76 & 3.14 & -2.97\end{array}$

$\begin{array}{rrrrr}2.85 & 2.10 & 2.43 & 5.07 & 26.62 \\ 4.53 & 1.91 & 4.07 & 3.99 & 18.39 \\ 6.76 & 2.51 & 5.86 & 2.32 & 5.35 \\ 8.47 & 2.14 & 7.97 & 1.43 & 1.69 \\ 10.33 & 2.55 & 9.99 & 1.35 & 1.81\end{array}$

$\begin{array}{lll}1.05 & 2.00 \quad 2.80\end{array}$

$\begin{array}{lll}2.21 & 4.40 \quad 4.92\end{array}$

$3.46 \quad 6.18 \quad 7.08$

$\begin{array}{lll}4.87 & 7.85 \quad 9.24\end{array}$

$\begin{array}{lll}6.46 & 9.26 \quad 11.29\end{array}$

\section{Besidential Fixed Investment (RFI)}

$\begin{array}{rrrrrrrrrrrrr}11 & 0-1 & -.85 & 1.08 & -.67 & 4.16 & 1.52 & 3.83 & 1.89 & 4.70 & 1.18 & 4.84 & 4.98 \\ 12 & 0-2 & -1.87 & 2.27 & -1.42 & 7.56 & 2.48 & 7.18 & .67 & -.24 & 2.95 & 9.01 & 4.27 \\ 13 & 0-3 & -2.93 & 3.19 & -2.32 & 10.23 & 3.28 & 10.14 & .36 & -.21 & 5.06 & 12.59 & 13.57 \\ 14 & 0-4 & -4.12 & 3.93 & -3.56 & 12.68 & 4.26 & 12.42 & .28 & -.67 & 7.39 & 15.78 & 17.42 \\ 15 & 0-5 & -5.58 & 5.23 & -4.94 & 14.95 & 5.07 & 14.40 & .21 & -.95 & 9.90 & 18.71 & 21.17\end{array}$

\section{Eederel Governmenc Purchases (FGP)}

$\begin{array}{rrrrrrrrrrrrr}16 & 0-1 & -.60 & 1.33 & -.51 & 3.99 & .81 & 3.77 & .60 & -.37 & 1.16 & 4.15 & 4.31 \\ 17 & 0-2 & -.79 & 1.50 & -.90 & 5.25 & 1.32 & 5.03 & 1.49 & 3.63 & 2.22 & 5.24 & 5.69 \\ 18 & 0-3 & -.94 & 1.75 & -1.21 & 5.35 & 1.43 & 5.01 & 1.78 & 4.47 & 3.09 & 5.28 & 6.12 \\ 19 & 0-4 & -.74 & 2.36 & -1.35 & 5.91 & 3.06 & 5.27 & 3.75 & 17.22 & 4.00 & 4.85 & 6.29 \\ 10 & 0-5 & -1.55 & 2.70 & -1.81 & 6.16 & 1.71 & 5.74 & 1.14 & 1.48 & 5.27 & 6.05 & 8.02\end{array}$

state ind Lecal Government Purchases (SICP)

$\begin{array}{rrrrrrrrrrrrr}21 & 0-1 & -.13 & .28 & -.17 & .90 & .33 & .85 & 1.87 & 4.40 & .52 & .70 & .87 \\ 22 & 0-2 & -.24 & .52 & -.26 & 1.24 & .56 & 1.15 & 2.77 & 9.44 & 1.12 & 1.07 & 1.55 \\ 23 & 0-3 & -.38 & .72 & -.40 & 1.57 & .77 & 1.52 & 2.61 & 9.42 & 1.72 & 1.32 & 2.17 \\ 24 & 0-4 & -.62 & .88 & -.58 & 1.89 & .92 & 1.79 & 2.98 & 12.01 & 2.34 & 1.54 & 2.80 \\ 25 & 0-5 & -.92 & 1.09 & -1.13 & 2.35 & 1.11 & 2.03 & 2.82 & 11.02 & 2.99 & 1.85 & 3.52\end{array}$

NOTE: On the symbols used, see provious tables and text. 
Table A.6

Individual, Group Mean, and BVAR Forecasts of Percent Changes in Consumption, Investment, and Government Components of Real GNP. Selected Comparisons, by Span, 1981-90

\begin{tabular}{|c|c|c|c|c|c|c|c|}
\hline & Group Mean & RMSE Ratis & $i / g$ & BVAR & RMSE & acios & ov \\
\hline Span (Qs) & $\begin{array}{l}\text { RMSE } \\
\text { (1) }\end{array}$ & $\begin{array}{ll}Q_{1} & M D \\
(2) & \text { (3) }\end{array}$ & $\begin{array}{l}Q_{3} \\
(4)\end{array}$ & $\begin{array}{c}\text { RMSE } \\
\text { (5) }\end{array}$ & $\begin{array}{l}Q_{1} \\
(6)\end{array}$ & $\begin{array}{l}M D \\
(7)\end{array}$ & $\begin{array}{l}Q_{3} \\
(8)\end{array}$ \\
\hline
\end{tabular}

Personal Consumocton Expenditures (PCE)

$\begin{array}{llllllllll}1 & 0-1 & .58 & 1.08 & 1.23 & 1.73 & 1.97 & .31 & .36 & .48 \\ 2 & 0-2 & .79 & 1.12 & 1.22 & 1.41 & 3.78 & .22 & .24 & .28 \\ 3 & 0-3 & .98 & 1.11 & 1.25 & 1.51 & 5.65 & .20 & .22 & .27 \\ 4 & 0-4 & 1.18 & 1.15 & 1.24 & 1.71 & 7.66 & .18 & .20 & .25 \\ 5 & 0-5 & 1.47 & 1.10 & 1.27 & 1.66 & 9.37 & .18 & .21 & .24\end{array}$

\section{Nonresidential Fixed Investment (NFI)}

$\begin{array}{rrrrrrrrrr}6 & 0-1 & 2.01 & 1.10 & 1.19 & 1.34 & 2.23 & .90 & 1.02 & 1.19 \\ 7 & 0-2 & 3.43 & 1.03 & 1.11 & 1.26 & 3.64 & .95 & 1.04 & 1.17 \\ 8 & 0-3 & 4.99 & 1.04 & 1.12 & 1.26 & 5.31 & .96 & 1.04 & 1.19 \\ 9 & 0-4 & 6.89 & 1.00 & 1.06 & 1.22 & 6.83 & .99 & 1.09 & 1.23 \\ 10 & 0-5 & 8.69 & .99 & 1.05 & 1.18 & 8.25 & 1.02 & 1.09 & 1.26\end{array}$

Besidential Fixed Investment (RFI)

$\begin{array}{rrrrrrrrrr}11 & 0-1 & 3.01 & 1.05 & 1.26 & 1.45 & 3.97 & .79 & .97 & 1.21 \\ 12 & 0-2 & 5.83 & .96 & 1.25 & 1.43 & 5.24 & 1.10 & 1.30 & 1.80 \\ 13 & 0-4 & 8.42 & .94 & 1.21 & 1.41 & 8.33 & .90 & 1.15 & 1.51 \\ 14 & 0-4 & 10.63 & .93 & 1.24 & 1.42 & 11.30 & .80 & 1.02 & 1.35\end{array}$

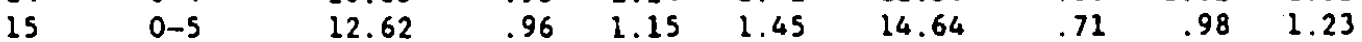

Federal Government Purchases (FGP)

$\begin{array}{rrrrrrrrrr}16 & 0-1 & 3.31 & 1.00 & 1.14 & 1.27 & 4.61 & .72 & .80 & .95 \\ 17 & 0-2 & 4.22 & 1.02 & 1.10 & 1.29 & 7.26 & .59 & .65 & .82 \\ 18 & 0-3 & 4.11 & 1.04 & 1.18 & 1.37 & 9.02 & .50 & .54 & .66 \\ 19 & 0-4 & 3.79 & 1.13 & 1.31 & 1.48 & 10.39 & .39 & .52 & .63 \\ 20 & 0-5 & 4.55 & 1.07 & 1.30 & 1.48 & 11.44 & .44 & .53 & .65\end{array}$

\section{State and Local Government Purchases (SLGP)}

$\begin{array}{llllllllll}21 & 0-1 & .61 & 1.14 & 1.23 & 1.51 & .49 & 1.40 & 1.64 & 2.07 \\ 22 & 0-2 & .75 & 1.02 & 1.19 & 1.39 & .82 & 1.09 & 1.44 & 1.62 \\ 23 & 0-3 & .91 & 1.00 & 1.17 & 1.27 & 1.20 & 1.11 & 1.41 & 1.60 \\ 24 & 0-4 & 1.07 & 1.13 & 1.19 & 1.40 & 1.68 & 1.13 & 1.29 & 1.54 \\ 25 & 0-5 & 1.35 & 1.01 & 1.13 & 1.30 & 2.18 & 1.04 & 1.28 & 1.53\end{array}$

NOTE: On the sumbols used, see previous tables and text. 
Table A.7

Selected Measures of Forecast Accuracy and Actual Values, Consumer Price Inflation, Tressury Bill Rate, and Corporace Bond Yleld, 1981-90
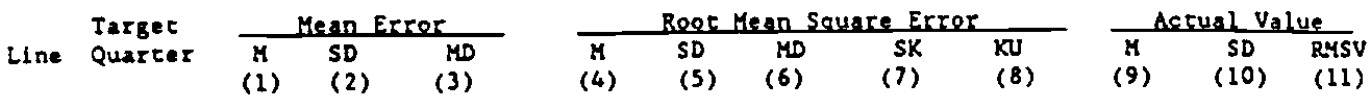

Consumar Prtes Index. Percent Change (CPI)

$\begin{array}{lllllllllll}1 & 1 & -.61 & .47 & -.50 & 1.20 & .39 & 1.08 & .34 & -1.37 \\ 2 & 2 & -.58 & .48 & -.46 & 1.18 & .43 & 1.15 & .11 & -1.41 \\ 3 & 3 & -.57 & .50 & -.46 & 1.20 & .42 & 1.20 & .19 & -1.36 \\ 4 & 4 & -.53 & .50 & -.51 & 1.21 & .38 & 1.26 & .10 & -1.50 \\ 5 & 5 & -.51 & .53 & -.50 & 1.23 & .39 & 1.24 & .00 & -1.41 \\ & & & & & & & & & & \end{array}$

Ireasury BU11 Race. 3-Monch. Percent (TBR)

\begin{tabular}{|c|c|c|c|c|c|c|c|c|c|c|c|c|}
\hline $\begin{array}{r}6 \\
7 \\
8 \\
9 \\
10\end{array}$ & $\begin{array}{l}1 \\
2 \\
3 \\
4 \\
5\end{array}$ & $\begin{array}{r}.03 \\
.19 \\
.39 \\
.65 \\
1.05\end{array}$ & $\begin{array}{l}.24 \\
.49 \\
.68 \\
.59 \\
.68\end{array}$ & $\begin{array}{r}-.03 \\
.24 \\
.61 \\
.83 \\
1.03\end{array}$ & $\begin{array}{l}.49 \\
1.51 \\
1.85 \\
2.03 \\
2.48\end{array}$ & $\begin{array}{l}.36 \\
.51 \\
.50 \\
.56 \\
.71\end{array}$ & $\begin{array}{l}.40 \\
1.52 \\
1.80 \\
2.23 \\
2.62\end{array}$ & $\begin{array}{r}2.50 \\
.06 \\
.11 \\
-1.55 \\
-.42\end{array}$ & $\begin{array}{r}8.01 \\
2.75 \\
.85 \\
2.14 \\
1.09\end{array}$ & 8.38 & 2.48 & 8.74 \\
\hline \multicolumn{13}{|c|}{ Cotporate Band Yleld. Percenc (CBY) } \\
\hline $\begin{array}{l}11 \\
12 \\
13 \\
14 \\
15\end{array}$ & $\begin{array}{l}1 \\
2 \\
3 \\
4 \\
5\end{array}$ & $\begin{array}{r}-.26 \\
-.00 \\
.21 \\
.39 \\
.60\end{array}$ & $\begin{array}{l}.30 \\
.48 \\
.61 \\
.72 \\
.74\end{array}$ & $\begin{array}{r}-.24 \\
.12 \\
.31 \\
.58 \\
.69\end{array}$ & $\begin{array}{l}.72 \\
1.59 \\
1.86 \\
2.05 \\
2.25\end{array}$ & $\begin{array}{l}.35 \\
.59 \\
.49 \\
.43 \\
.66\end{array}$ & $\begin{array}{l}.63 \\
1.37 \\
1.81 \\
2.02 \\
2.36\end{array}$ & $\begin{array}{r}2.01 \\
.66 \\
.78 \\
.39 \\
.88\end{array}$ & $\begin{array}{r}5.65 \\
-.26 \\
.51 \\
-.28 \\
1.58\end{array}$ & 11.64 & 2.34 & 11.87 \\
\hline
\end{tabular}

NOTE: On the symbols used, see previous tables and text. 
Table A.8

Individual, Group Mean, and BVAR Forecasts of Consumer Price Inflation, Treasury Bill Rate, and Corporate Bond Yleld, Selected Comparisons, by Span, 1981-90

\section{Target Group Mean Line Quarter RMSE}

(1)

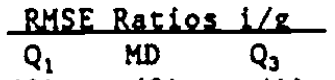

(2)

(3)

(4)

BVAR, * RMSE Q

(5)

(6)

(7)

(8)

Consumer Price Index. Percent Change (CPU)

$\begin{array}{ll}1 & 1 \\ 2 & 2 \\ 3 & 3 \\ 4 & 4 \\ 5 & 5\end{array}$

.53
.46
.48
.54
.58

$$
1.01
$$

1.03

1.12

1.12

.54

1.63

2.63

1.02

1.05

1.01

1.03

1.18

1.02

1.02

1.09

.78

1.01

1.02

1.08

95

1.07

1.63
1.80

1.63

.921 .36

3. 22

Ireasury Bill Race, 3-mench. Percent (TBR)

$\begin{array}{llllllll}.20 & 1.45 & 1.83 & 2.46 & .96 & .29 & .38 & .56 \\ .90 & 1.09 & 1.26 & 2.11 & 1.62 & .59 & .81 & 1.17 \\ 1.38 & 1.02 & 1.31 & 1.54 & 2.03 & .65 & .80 & 1.08 \\ 1.77 & 1.00 & 1.14 & 1.29 & 2.51 & .68 & .77 & .94 \\ 2.49 & 1.01 & 1.08 & 1.18 & 3.03 & .67 & .78 & .95\end{array}$

Comorate Bond Yleld. Percent (CBY)

$\begin{array}{llrrrrrrrr}11 & 1 & .38 & 1.17 & 1.57 & 1.81 & .77 & .56 & .77 & .98 \\ 12 & 2 & .83 & 1.15 & 1.48 & 2.52 & 1.26 & .72 & .95 & 1.75 \\ 13 & 3 & 1.24 & 1.09 & 1.25 & 1.74 & 1.74 & .77 & .92 & 1.25 \\ 14 & 4 & 1.51 & 1.03 & 1.19 & 1.46 & 2.19 & .69 & .88 & 1.03 \\ 15 & 5 & 2.42 & .98 & 1.11 & 1.20 & 2.65 & .60 & .83 & 1.02\end{array}$

NOTE: On the symbols used, see previous tables and text. 